University of Louisville

ThinkIR: The University of Louisville's Institutional Repository

Electronic Theses and Dissertations

$12-2020$

\title{
On the straight and narrow: how cultural beliefs about sex/gender manifest in college biology learning environments.
}

Katherine Ray Kng

University of Louisville

Follow this and additional works at: https://ir.library.louisville.edu/etd

Part of the Biology Commons, and the Science and Mathematics Education Commons

\section{Recommended Citation}

Ray Kng, Katherine, "On the straight and narrow: how cultural beliefs about sex/gender manifest in college biology learning environments." (2020). Electronic Theses and Dissertations. Paper 3554.

https://doi.org/10.18297/etd/3554

This Doctoral Dissertation is brought to you for free and open access by ThinkIR: The University of Louisville's Institutional Repository. It has been accepted for inclusion in Electronic Theses and Dissertations by an authorized administrator of ThinkIR: The University of Louisville's Institutional Repository. This title appears here courtesy of the author, who has retained all other copyrights. For more information, please contact thinkir@louisville.edu. 


\title{
ON THE STRAIGHT AND NARROW: HOW CULTURAL BELIEFS ABOUT SEX/GENDER MANIFEST IN COLLEGE BIOLOGY LEARNING ENVIRONMENTS
}

\author{
By \\ Katherine Ray King \\ B.S., University of Louisville, 2015 \\ M.S., University of Louisville, 2018

\begin{abstract}
A Dissertation
Submitted to the Faculty of the

College of Arts and Science of the University of Louisville

in Partial Fulfillment of the Requirements

for the Degree of
\end{abstract}

Doctor of Philosophy

in Biology

Department of Biology

University of Louisville

Louisville, Kentucky

December 2020 

ON THE STRAIGHT AND NARROW: HOW CULTURAL BELIEFS ABOUT SEX/GENDER AND SEXUALITY MANIFEST IN COLLEGE BIOLOGY LEARNING ENVIRONMENTS

\author{
By \\ Katherine Ray King \\ B.S., University of Louisville, 2015 \\ M.S., University of Louisville, 2018 \\ A Dissertation Approved on
}

October 30, 2020

By the following Dissertation Committee:

Linda Fuselier

Paul Ewald

Holly Swain Ewald

Jennifer Mansfield-Jones

Sheron Mark 


\section{DEDICATION}

This dissertation is dedicated to my parents

Charles Ray and Michelle Ray Cox,

who made sure I knew the value of all people, including myself;

to my partners

Michael King, Jamison Huebsch, and Landon Cain

for their unwavering support while I pursue my dreams;

and to the giants on whose shoulders I stand

Marsha P. Johnson,

Breonna Taylor,

David McAtee,

Tyler Gerth,

Brayla Stone,

Tony McDade,

and too many more to name.

Because when there is no justice, there can be no peace. 


\section{ACKNOWLEDGMENTS}

First, I would like to thank my major advisors. Without Dr. Linda Fuselier's endless guidance and patience, I would probably never have made it to the finish line. And I am eternally grateful to Dr. Paul Ewald for agreeing to take me on as a graduate student five years ago and for supporting my decision to throw out two years of work and start a biology education project instead. I would also like to thank my other committee members, Dr. Holly Swain Ewald, Dr. Jennifer Mansfield-Jones, and Dr. Sheron Mark, for their comments and assistance during this endeavor. I am grateful for the undergraduate researchers that contributed to chapters one and two, Mal Martin and Harshini Sirvisetty. Last, I am thankful to my family and friends for your support (emotional, physical, and financial) over the last five years. 


\section{ABSTRACT \\ ON THE STRAIGHT AND NARROW: HOW CULTURAL BELIEFS ABOUT SEX/GENDER AND SEXUALITY MANIFEST IN COLLEGE BIOLOGY LEARNING ENVIRONMENTS

\author{
Katherine E. Ray King
}

October 16, 2020

This dissertation focused on the ways that social beliefs about sex/gender and sexuality manifest in biology classrooms. Especially for health science students, classes include topics like sex, sexuality, sexual behaviors, or sex determination that forms the foundation of their understanding of human forms and behaviors. If the information they receive does not include the LGBTQIA+ community, their education will fail to adequately prepare them for the reality of healthcare practice where they will be expected to treat all patients with dignity and respect.

There are three chapters in this dissertation. In chapter one, I asked what beliefs about and conceptions of sex/gender are present in undergraduate students. I found that students with more academic experience view sex/gender characteristics as occurring along a continuum rather than discrete traits and that health science students were more likely to conflate sex and gender along dichotomous male/female lines, with innate and essential characteristics defining these groups. This led me to analyze the ways that college-level nursing anatomy/physiology textbooks represent sex/gender and 
LGBTQIA+ populations. For chapter two, I conducted a qualitative content analysis of four common nursing textbooks and found that the books either excluded LGBTQIA+ healthcare needs and history or only mentioned LGBTQIA+ people in the context of disease or pathology, and they promoted social norms as scientifically validated. In an effort to counter these representations, I challenged the binary 'two sex' model using intersex case studies. Chapter three also assessed the phobias, attitudes, and cultural competence (ability to treat patients in a culturally sensitive manner) of biology students. I found that students still hold binary views of the sexes even after reading an intersex case study, and that case study had minimal impact on phobia, attitudes, or competence. However, there was evidence of a paradigm shift toward a sex model that sees the similarities between humans rather than the differences. Future directions should consider common misconceptions related to the 'two sex' model and how best to address these in biology curricula. 


\section{TABLE OF CONTENTS}

DEDICATION ACKNOWLEDGMENTS

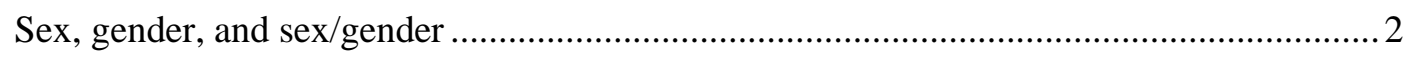

Theoretical framework ........................................................................................ 3

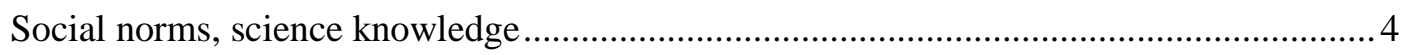

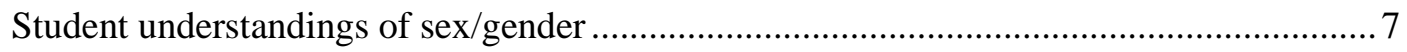

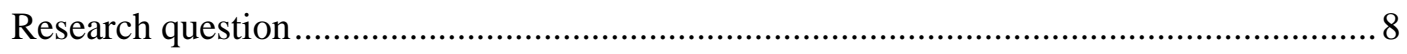

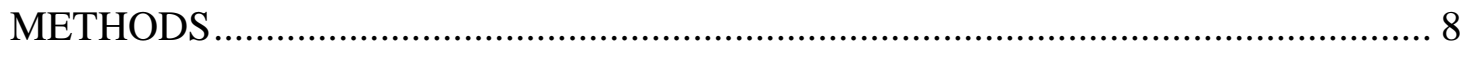

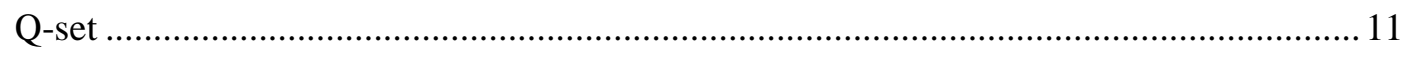

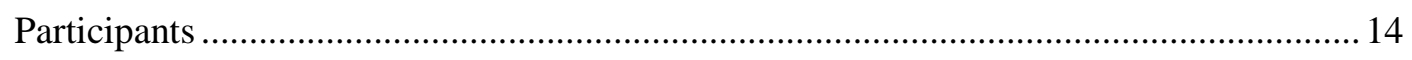

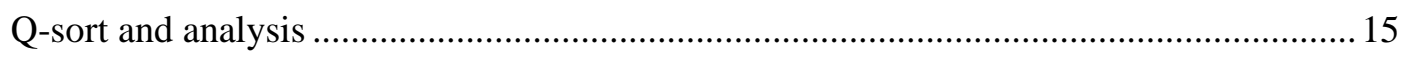

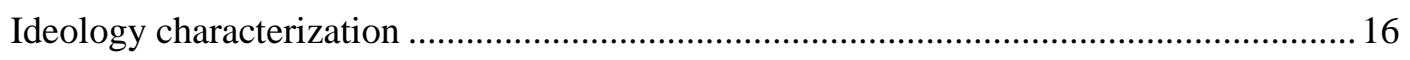

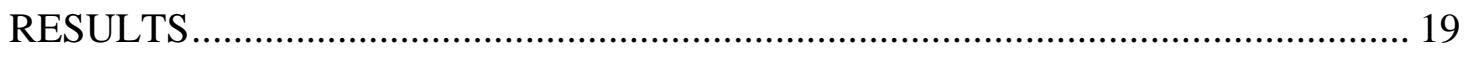

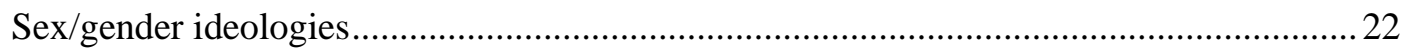

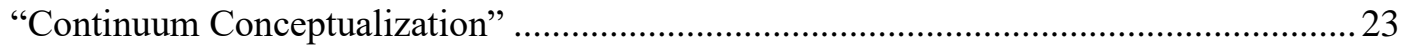

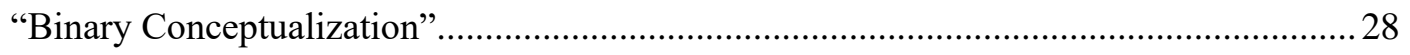

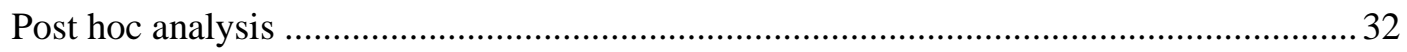


DISCUSSION

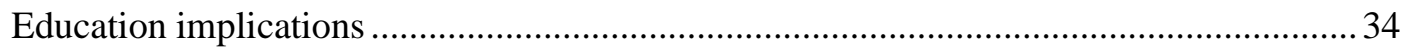

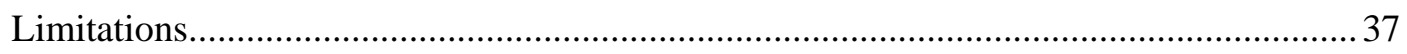

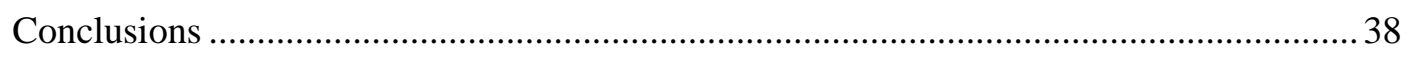

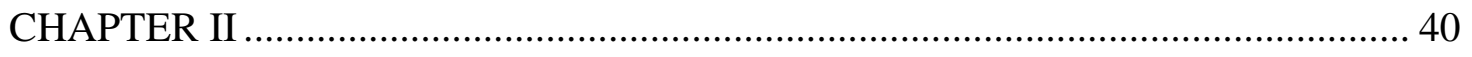

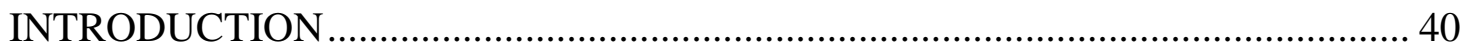

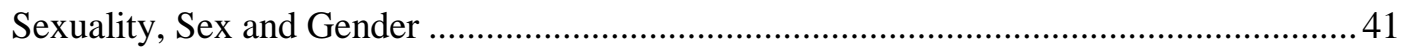

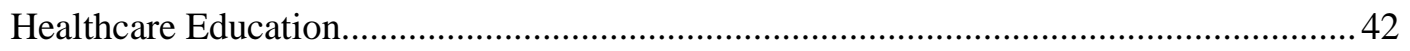

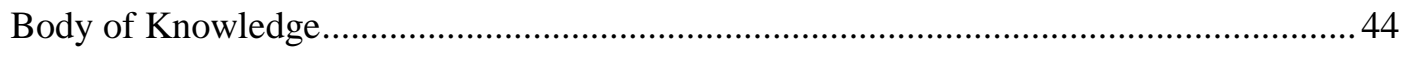

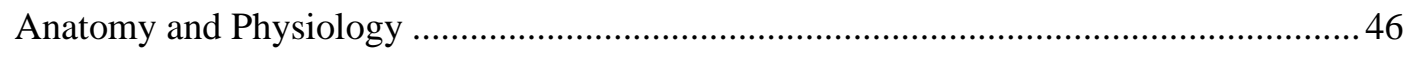

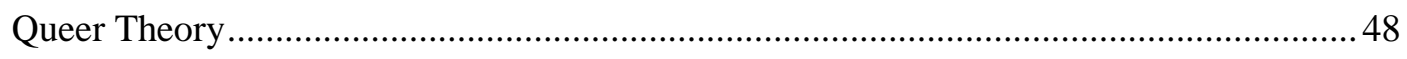

Research Questions and Predictions...........................................................................52

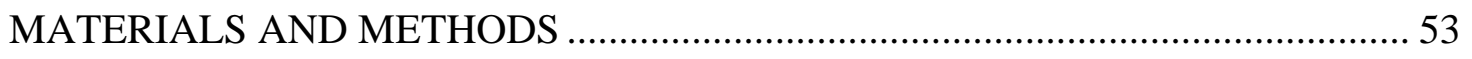

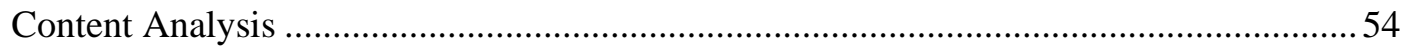

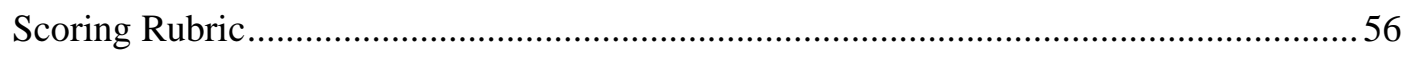

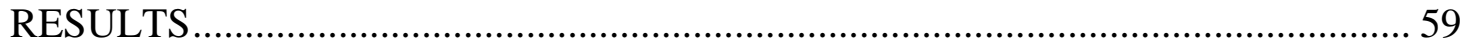

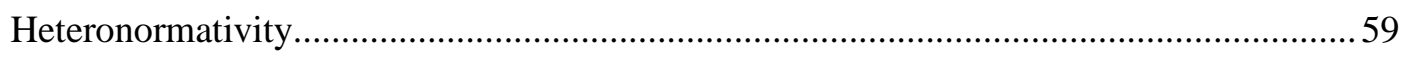

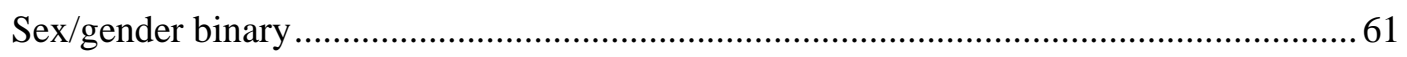

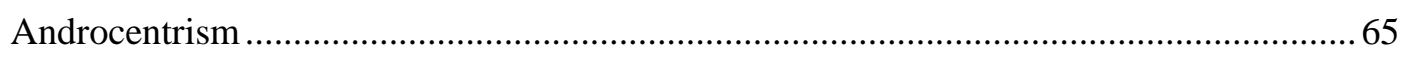

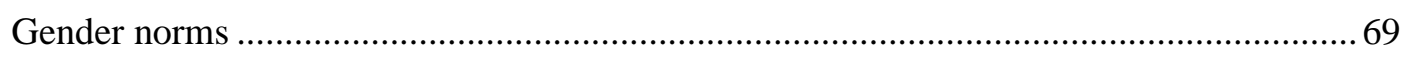

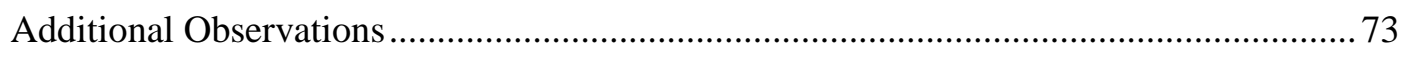

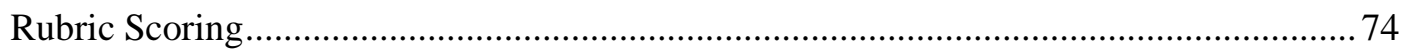

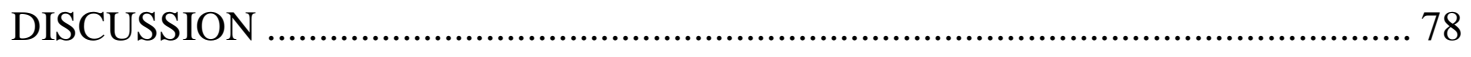

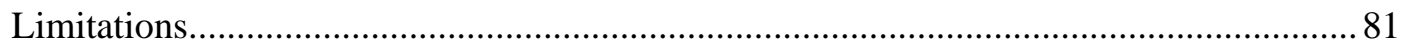

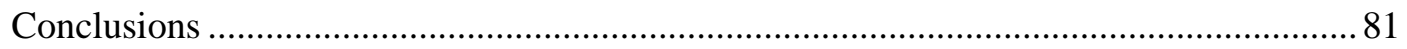




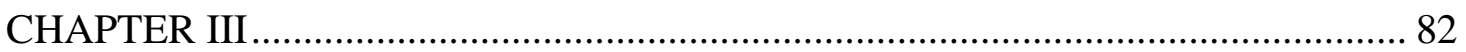

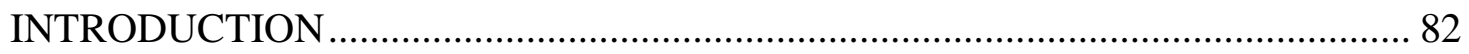

Background and Significance ................................................................................ 83

Research Questions and Predictions............................................................................ 86

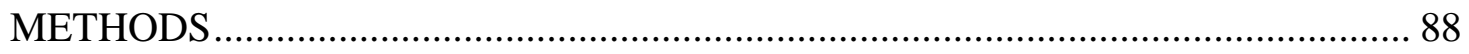

Study Context and Population ................................................................................ 88

Educational Intervention ...................................................................................... 90

Survey

Data management and statistical analysis ...................................................................... 96

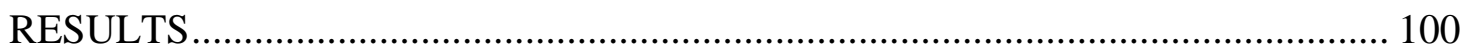

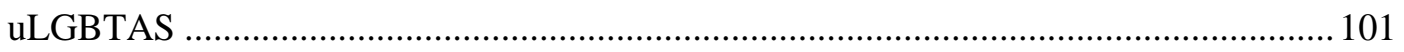

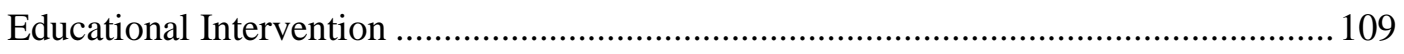

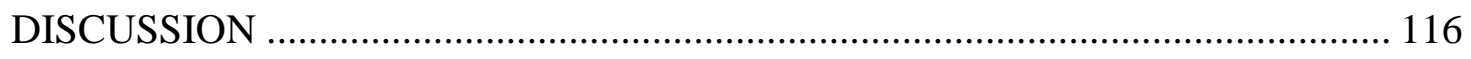

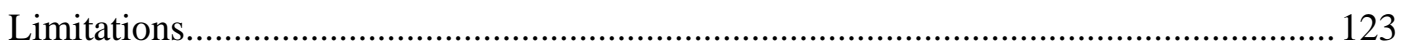

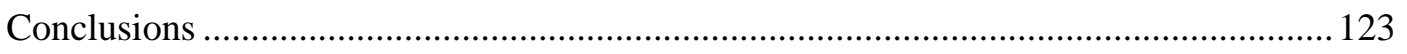

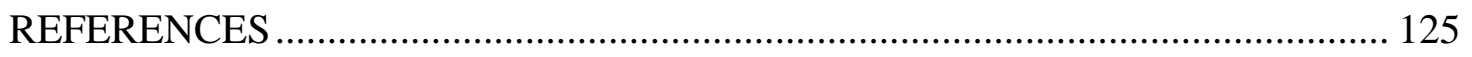

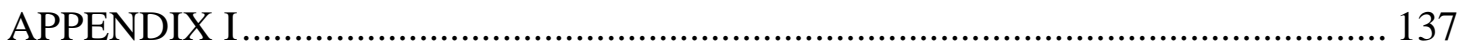

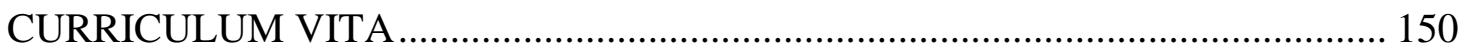




\section{LIST OF TABLES}

TABLE $\quad$ PAGE

1. Q-Set Topics and Statements and Q-factor Sort Positions and Z-score ....................... 12

2. Concepts Used to Rationalize Beliefs Within the Two Ideologies ............................... 22

3. Statements Defining the Understanding of Biological Sex and Social Gender for the

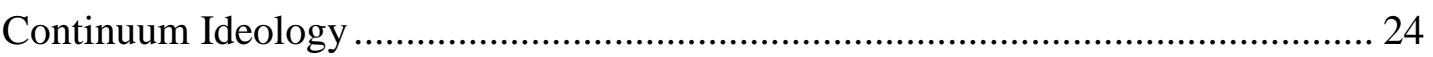

4. Statements Supporting the Continuum Ideology's Non-Binary View of Sex .............. 25

5. Statements Exemplifying Uncertainty About Scientific Claims in the Continuum

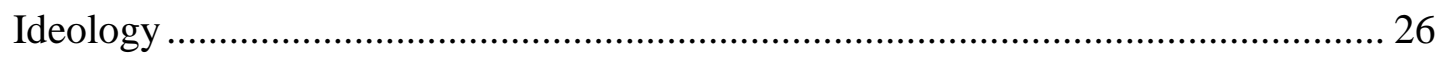

6. Students in the Continuum Ideology Rejected Gender Stereotypes ............................. 27

7. Statements Supporting the Binary Ideology's View of Sex as Binary ......................... 28

8. Statements Exemplifying Student Struggles with Scientific Claims in the Binary

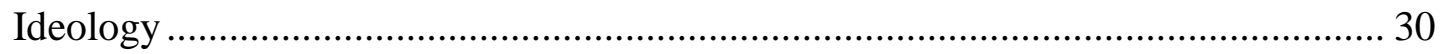

9. Students in the Binary Ideology Rejected Gender Stereotypes ..................................... 32

10. Undergraduate Nursing Anatomy/Physiology Textbooks Analyzed .......................... 53

11. Themes, Subthemes, and Examples of Anatomy/Physiology Textbook Content ...... 55

12. Gendered Language Rubric ................................................................................... 57

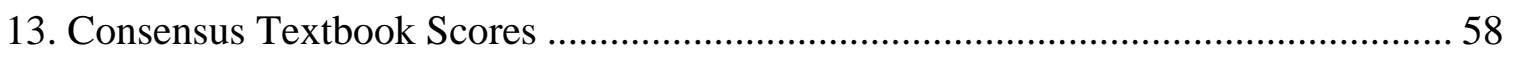

14. Count of Excerpts Informing Rubric Scores............................................................ 75

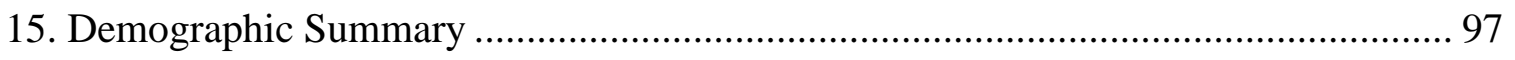

16. Cronbach's Alpha Values for Scales and Subscales................................................ 102 
17. Mean, SD, and SEM for Scales and Subscales .................................................... 102

18. Correlation of Students' LGBTQ+ Phobia and Attitudes....................................... 103

19. General Linear Models and Fit Criteria ................................................................. 105

20. Main Effects of Ethnicity and Scores ……………………................................ 106

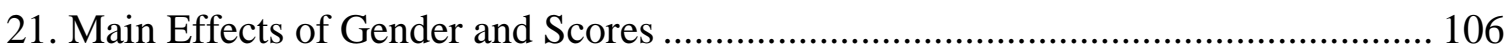

22. Main Effects of LGBTQIA+ Identity and Scores................................................. 107

23. Main Effect of Course and Cultural Competence ................................................... 108

24. Cumulative, Control, and Treatment Coding Counts for 'Similar', 'Dissimilar', or

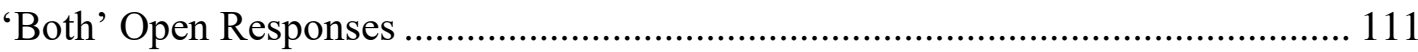

25. Cumulative, Control, and Treatment Coding Counts for 'Female First', 'Male First',

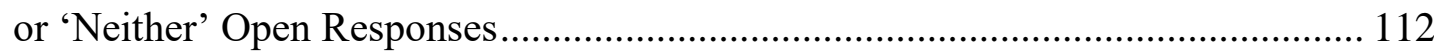

26. Concept Counts and Frequencies of Similarities and Differences Cited in Open

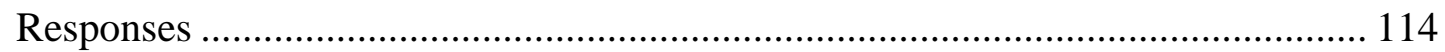




\section{LIST OF FIGURES}

$\begin{array}{ll}\text { FIGURE } & \text { PAGE }\end{array}$

1. Example of a Q-sort forced-choice distribution...................................................... 10

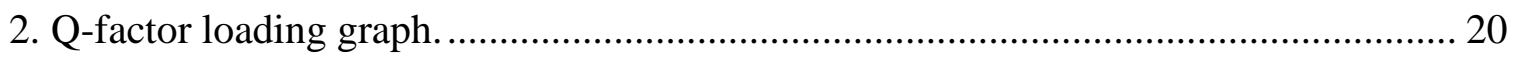

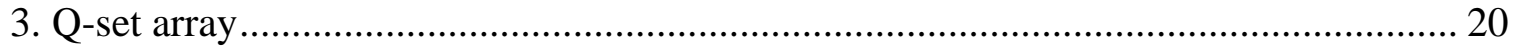

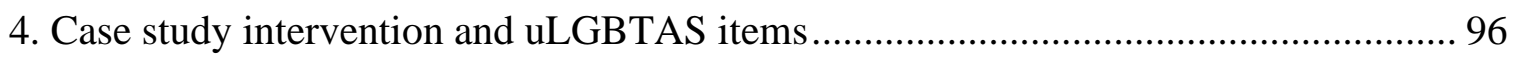

5. Frequency distributions of individual item responses ...................................... 108

6. Proportion of open response answers by group ............................................. 111

7. Proportion of open responses listing females first, males first, or neither................. 113 


\section{CHAPTER I}

\section{USING A Q-METHODOLOGICAL APPROACH TO CHARACTERIZE SEX/GENDER BELIEFS IN U.S. UNDERGRADUATES}

\section{INTRODUCTION}

Popular conceptions of sex, gender, and sexuality have changed relative to the last century. We live in the era of legislation dictating appropriate hormone levels for female athletes (Kato et al., 2018) and papal outrage over gender ideology (Reilly, 2016) juxtaposed against international pronoun day and Lesbian, Gay, Bisexual, Transgender, Queer, Intersex, Asexual (LGBTQIA+) pride celebrations across the globe. Given the shifting landscape of sex and gender, current college students could hold complex or essentialist beliefs about sex/gender. Because learning involves building upon existing knowledge (N. R. Council, 1999), it is necessary to document what students already know or believe about sex/gender to develop curricula that address misconceptions (de Bruin, 2020; Versteeg, van Loon, Wijnen-Meijer, \& Steendijk, 2020) and provide comprehensive coverage of these topics. This is especially important for teaching students who will be future healthcare providers because some sex/gender beliefs are associated with negative attitudes towards LGBTQIA+ people (Makwana et al., 2018; Stefurak, Taylor, \& Mehta, 2010; Whitley \& Ægisdóttir, 2000), which in turn contribute to hostile healthcare environments (Nadal, Whitman, Davis, Erazo, \& Davidoff, 2016). 


\section{Sex, gender, and sex/gender}

Although, the terms sex and gender are often used synonymously (Hammarstrom \& Annandale, 2012), conventionally sex refers to the material and biological whereas gender is a social construct (Makadon, Mayer, Potter, Goldhammer, \& American College of Physicians, 2015). In many biology textbooks, sex is described a set of static, innate characteristics that enables most individuals to be designated as (reproductive) female or male based on the appearance of their genitalia at birth or their chromosomes (Bazzul \& Sykes, 2011). Historically, medical providers recommended that children with “ambiguous sex development” undergo genital surgeries, often accompanied by forced sterilization, in efforts to align their bodies with the binary sex category selected for them (K. A. Karkazis, 2008; Kessler, 1990; Knight, 2017).

If sex is the coatrack, gender is the clothing placed on its frame; thus gender is a social identity constructed with input from biological characteristics (i.e., sex traits) and external culture, upbringing, and environmental factors (Nicholson, 1994). Someone's gender identity need not align with their sex or along a female/male binary and can encompass behaviors, feelings, and appearance (Mayer, 2016). However, some scholars find difficulties with this sex $=$ biological and gender $=$ social divide and instead view both sex and gender as intrinsically intertwined concepts. Hence, they adopted the term sex/gender to highlight this entanglement.

Instead of forcing a separation along sex or gender differences, sex/gender more accurately describes the dynamic processes of body, mind, and environment across an individual's life (Pitts-Taylor, 2016). Notably, sex/gender recognizes that environmental factors related to culture can modify genetic pathways in ways that have long-term 
effects (Weasel, 2016). For example, differences in bone density between Middle Eastern men and women are characterized medically as sex-based, but the differences can be attributed to a lack of vitamin D among women who, due to a gender-based ideology, are expected to wear extensive head and body coverings that reduce their exposure to sunlight relative to uncovered men (Fausto-Sterling, 2005). In this way, culture (gender) becomes written on the body (sex) because they intra-act in the manifestation of this sex/gender difference. Thus, throughout this study I adopt the term sex/gender to acknowledge this entanglement and as a recognition of my theoretical grounding in new materialist feminism. Before delving further into contemporary conceptualizations of sex/gender, I will first describe my theoretical framework.

\section{Theoretical framework}

I adopted new materialist feminism (NMF) as my theoretical perspective because this approach highlights how culture and environment are written on the physical bodies just as that physical form is imbued with social meaning (Fausto-Sterling, 2012). In the context of sex, gender, and sex/gender, NMF wants social seen as part of, instead of distinct from, nature; rather than accepting sex and gender as distinct constructs relegated to separate domains of science and social, it views sex/gender as a biocultural entity (Pitts-Taylor, 2016). As a critical theory, NMF challenges the historical separation of the intangible, thinking self and material, inert body by calling attention to the ways that environment and body co-create sex/gender (Birke, 2000; Fausto-Sterling, 2012).

Challenging the separation of science/sex and social/gender is important because relegating nature to science reinforces a dichotomy that enables the power of science to be leveraged in perpetuating social norms as scientific fact (Lemke, 2011) by framing 
some topics as 'unnatural' and thus outside the purview of science (Gunckel, 2019; Reiss, 2019). Embedded in these binary pairs are dichotomies that frames one half of the dyad as lesser or subservient to the other (Santavicca, Bazzul, \& Witzig, 2019). NMF pushes back against the privileging of science over social by encouraging new perspectives for engaging with science research and the generation of science knowledge (Roy \& Subramaniam, 2016).

Notably, conflating or simply interchanging the terms sex and gender is not indicative of an NMF perspective and is problematic because it relies on binary delineations, presenting a view of human bodies as "straight and naturally sexed" (Bazzul \& Sykes, 2011). This conflation, called biological gender theory (Coleman \& Hong, 2008), ignores environmental and social influences on sex and, critically, interchanging sex and gender does not leave room for LGBTQIA+ students whose identities when fall outside of the biological sex/gender binary (Knaier, 2019).

\section{Social norms, science knowledge}

Biological gender theory is rooted in claims that all humans are born with immutable, biologically determined traits based on their sex at birth that align with social gender roles (Coleman \& Hong, 2008). At the foundation of these assertions is the notion that these essential, female/male gendered characteristics are biological, fixed, and natural (Bohan, 1993). These beliefs are problematic because adherents of gender essentialism tend to hold stronger gender stereotypes (Heyman \& Giles, 2006) and are more likely to self-stereotype (Coleman \& Hong, 2008). Endorsement of gender essentialism is also linked to firm in-group boundaries that promote unfavorable biases (Keller, 2005). For example, gender essentialism is related to a greater difficulty in 
accepting LGBTQ+ peers (Broussard \& Warner, 2019) and is frequently leveraged to justify the exclusion of gender nonconforming and transgender people, particularly transwomen, from gendered spaces like public bathrooms or competitive sports (K. Karkazis \& Jordan-Young, 2018).

However, the 'two sex' model that underlies gender essentialistic beliefs is not representative of recent scientific studies or understandings of human sex traits (Carlson, 2013; Fausto-Sterling, 2018; Stévant, Papaioannou, \& Nef, 2018). It relies on the (over)simplification of human characteristics into discrete categories of "female" or "male" while simultaneously excluding intersex bodies whose sex characteristics do not match binary assumptions (K. A. Karkazis, 2008; McCredie, 2011; Pitts-Taylor, 2016; Rippon, 2019). The simplification of sex into binary groups based on chromosomes or genitals ignores other features (like fetal gonadal, fetal hormonal, or pubertal hormonal sex) that contribute to the characteristics collectively described as sex (Donovan, Stuhlsatz, Edelson, \& Buck Bracey, 2019; Fausto-Sterling, 2012). Furthermore, very few individuals possess all 'male' or all 'female' traits across these categories, rather sex traits occur along a continuum (Johnson, Greaves, \& Repta, 2009) and visible intersex traits occur in approximately 1 in 2000 live births (Fausto-Sterling, 2000). However, reports suggest that cryptic intersex characteristics are more common than estimated (Lee et al., 2013), in part because some intersex people can reproduce without technological assistance (Dumic et al., 2008). Rather than representing a group of disorders of sex development, intersex bodies are natural expressions of the diversity of human sex characteristics (Knight, 2017). 
In the context of contemporary scientific research into human sex/gender, technological advances have allowed researchers to visualize structures and processes in novel ways that indicate that the physical traits used to define sex as a fixed biological category (e.g., chromosomes, gonads, and hormones) are not fixed, they're plastic (Stévant et al., 2018). For example, despite being called "sex chromosomes," allosomes ${ }^{1}$ are not the sole contributor to sex development nor do they contain only genes for sex development (McCredie, 2011; Richardson, 2013). In fact, the genetic pathways for sex development are complex, involving more than just $\mathrm{X}$ and $\mathrm{Y}$ chromosomes (Stévant et al., 2018) and, further complicating efforts to define sex based on allosomes, genes involved in development can jump from one chromosome to another, including from allosome to autosome (Chien et al., 2009). The products of sex development, like gonads, must maintain their state throughout an individual's life, e.g., the post-natal deletion of ${ }^{1}$ the Dmrtl gene leads to the transformation of testicular cells into ovarian ones (Minkina et al., 2014) while deletion of the Foxl2 gene in ovarian follicles leads to the 'reprograming' of these cells into a testicular phenotype (Uhlenhaut et al., 2009).

When considering sexually dimorphic organs, advances in scanning and imaging support the idea that the brain is a mosaic of traits rather than an essentially (binary) sexed organ (Hyde, Bigler, Joel, Tate, \& van Anders, 2018; Rippon, 2019). However, some scientists continue to look for brain-based differences between females and males (Choleris, Galea, Sohrabji, \& Frick, 2018), and explanations for LGBTQ+ identity (Nguyen et al., 2019) or attractions (Manzouri \& Savic, 2018). They are also criticized for suggesting that "sex hormones" (i.e., androgens or estrogens) cause different brain

\footnotetext{
${ }^{1}$ Early term used to describe non-autosomal chromosomes like the human $\mathrm{X}$ and $\mathrm{Y}$ chromosomes (Schaffner, 1927).
} 
structures and behaviors along the female/male binary (Hyde, 2016; Hyde et al., 2018). This both misrepresents individual brain scans as stable over time and suggests that different levels of sex hormones are the cause of any observed differences (Hyde et al., 2018).

In regard to hormone levels, although people categorized as 'males' typically have higher testosterone levels, there is significant overlap in levels among the sexes (Liening, Stanton, Saini, \& Schultheiss, 2010; van Anders, 2010). And, despite characterizations of estrogens and progesterone as "female hormones" (R. Glaser \& Dimitrakakis, 2013), levels of these hormones do not significantly differ among nonpregnant people (i.e., whether classified as male or female) (Tulchinsky, Hobel, Yeager, \& Marshall, 1972). Indeed, a more accurate hormonal dichotomy (if such a dyad was vital to understanding these concepts) would be "pregnant" and "non-pregnant" people (Hyde et al., 2018).

\section{Student understandings of sex/gender}

This conceptual muddle of gender essentialism and contemporary research into sex/gender make for an interesting learning environment for this generation of college students to navigate. How a student perceives a subject through the lens of their personal experiences and how the instructor presents that concept is informed by belief and experience (both student's and teacher's); this then forms the context in which knowledge is constructed (Bendixen \& Feucht, 2010). In this way, beliefs, knowledge, and personal experiences intra-act. While other researchers have evaluated students' belief about the validity of gender roles and stereotypes (Broussard \& Warner, 2019; Nagoshi et al., 2008;

Stefurak et al., 2010; Whitley \& Ægisdóttir, 2000), they did not consider beliefs about 
sex (e.g., are sex traits fixed, do sex hormones control how people look and feel, where do intersex bodies fit within a sex binary?).

\section{Research question}

To investigate current understandings and beliefs associated with college student notions of sex/gender, I used Q-methodology and posed the following question: What common knowledge beliefs about sex/gender are present among college early undergraduate students? I predicted that, if students held a contemporary view of sex/gender in alignment with new materialist feminism, they would acknowledge there is no clear line between sex/gender because bodies cannot be separated from the physical and social environment in which they exist, that sex (as a biological concept) can be subdivided into multiple smaller categories such as chromosomal, gonadal, or hormonal with great variation therein and that there is no basis for gender-stereotypes (because these are grounded in essentialist beliefs). In complete contrast, students may still hold essentialistic beliefs about sex/gender, equate sex and gender, and endorse claims that perpetuate gender stereotypes.

\section{METHODS}

Q-sort methods are used to identify commonalities in viewpoints and have been used in a variety of fields relevant to this study, including nursing (Akhtar-Danesh, Baumann, \& Cordingley, 2008; Dennis, 1986) and nursing education (Barker, 2008), science education (Fuselier, McFadden, \& Ray King, 2019), and as a feminist

methodology (Kitzinger, 1986; Senn, 1996). Q-methods focus on characterizing perceptions rather than quantitatively depicting the frequency that certain beliefs occur among participants (McKeown \& Thomas, 1988). 
Q-methodology functions as an inverse of R methodologies (such as factor analysis and principle components analysis); thus, "reliability and validity, as understood in R methodology, are not applicable to Q methodology.”(Watts \& Stenner, 2012, p. 66) Because Q-methodology is not a test of difference, it does not require large sample sizes to draw valid conclusions (Watts \& Stenner, 2012, pp. 72-73). Indeed, for this type of study, the participants themselves are the variables, while the statements evaluated by the participants are the sample (Watts \& Stenner, 2012, p. 70). Therefore, smaller numbers of participants are standard. Post-hoc comparisons of Q-sort participants permits researchers to evaluate differences between the ideologies detected but, typically this is not the focus of Q studies (Watts \& Stenner, 2012, p. 54).

There are three parts to a typical Q-sort: first researchers generate a collection of statements to be evaluated by participants (the Q-set), next, participants sort the Q-set (the Q-sort) by agreement/disagreement in the context of a guiding question, and last, participants are interviewed about their choices. The Q-sort and interview are a sequential mixed-method tool that enables researchers to identify and describe shared ideologies, called Q-factors (Neff, 2011; Watts \& Stenner, 2012). Quantitatively, these ideologies are represented as linear combinations of Q-set statements similar to but different from axes produced from exploratory factor analysis or principle components analysis (Watts \& Stenner, 2012). To emphasize the distinction, I refer to the multivariate combinations embodied by the Q-factors as ideologies.

The Q-sort also differs from a traditional Likert-scale surveys in that the participant is forced to evaluate the relative strength of their agreement or disagreement with statements in the Q-set. In effect, the participants create a dialog between 
themselves and the statements (which represent a body of literature); this interaction with and evaluation of the Q-set permits the researchers to characterize the participant's subjective point of view (Watts \& Stenner, 2012, p. 44). During the sort all statements are placed on a pyramid-shaped distribution (for an example of this, see Figure 1) such that only a limited number of statements can be the 'most agreed' or 'most disagreed' statements respectively. The middle of the distribution can be thought of as uncertain, neutral, not understood, and/or no reaction depending on the participant's feelings about those Q-set statements and the participant dictates the boundaries among these categories of agreement.

\begin{tabular}{|c|c|c|c|c|c|c|c|c|}
\hline & & & & 18 & & & & \\
\hline & & & 22 & 14 & 24 & & & \\
\hline & & 10 & 21 & 12 & 17 & 25 & & \\
\hline & 6 & 5 & 13 & 9 & 7 & 16 & 20 & \\
\hline 19 & 4 & 1 & 2 & 8 & 3 & 11 & 15 & 23 \\
\hline-4 & -3 & -2 & -1 & 0 & 1 & 2 & 3 & 4 \\
\hline
\end{tabular}

Figure 1. Example of a Q-sort forced-choice distribution My Q-set contains 25 items, so the distribution contains 25 spaces for ranking the statements. All 25 statements must be placed on the distribution; statements are indicated by the numbers in the boxes. The scale at the bottom of the distribution ranges from -4 , most disagree to +4 , most agree. 


\section{Q-set}

I constructed my Q-set from scholarly sources identified during a literature review of common "myths" about sex/gender that are grounded in scientific/biological contexts: e.g., the existence of essential differences between two sexes, gender-based behavioral stereotypes, the roles of genes, hormones, and environment in sex/gender determination, and the evolution of human sex/gender characteristics (Ah-King, 2013a). Sources included secondary sources, books targeting general and academic audiences, and peerreviewed journal articles that presented a range of viewpoints. My decision to use popular press sources was appropriate because my population of interest was undergraduate students from a variety of academic majors. I did not include statements about human sexuality.

The goal in creating a Q-set is a "balance" (Watts \& Stenner, 2012, p. 58) of statements that sufficiently cover the topic and that can be sorted in a reasonable time. From my initial literature review, 230 statements were identified from 10 sources. To facilitate choosing statements for the card sort, two researchers independently reviewed the statements and divided them into categories. The researchers then compared and refined category designations. Four categories that emerged were: fundamental differences, evolution of sex characteristics, genes/hormones/environment, and sex/gender-based behavior stereotypes. From this, a structured sample of 36 statements was extracted such that these four categories were represented equally. In choosing from among statements within categories, wording appropriate for college students and more recent sources were prioritized. I chose 36 statements to represent a range of viewpoints with the aim of the sort lasting only 30 minutes. 
I piloted the 36-statement set with 10 volunteers with varying levels of science education (ranging from non-science major undergraduate to biology professor) to determine the comprehensibility and check validity of the statements and time to complete the sort. Based on participant feedback in the pilot, some statements were excluded, and others adjusted for readability. Participants took up to 50 minutes to complete the sort, too long according to volunteers. In response, I reduced my final Q-set to 25 statements from eight sources (still representing the four categories) to reduce the total time required for the sort. Again, two researchers independently categorized the statements to ensure adequate representation of the categories. Comparison of proportions categorized similarly gave an inter-rater reliability of $92 \%$. We initially agreed on the categorization of 23 (out of 25) statements and returned to examples described by Ah-King (2013b) to resolve the categorization of the final two statements. The resulting Q-set statements, shown in Table 1, were designated with numbers 1-25 for tracking purposes.

\section{Table 1}

Q-Set Topics and Statements and Q-factor Sort Positions and Z-score (in parentheses)

\begin{tabular}{llccl}
\hline Topic & Statement & $\begin{array}{l}\text { Q-factor 1 } \\
\text { Sort Position } \\
\text { and Z-score }\end{array}$ & $\begin{array}{l}\text { Q-factor 2 } \\
\text { Sort Position } \\
\text { and Z-score }\end{array}$ & Source \\
\hline $\begin{array}{l}\text { Sex/gender- } \\
\text { based behavior } \\
\text { stereotype }\end{array}$ & $\begin{array}{l}\text { (1) In romantic relationships, the man is } \\
\text { more likely than the woman to "cheat" by } \\
\text { seeking sex outside the relationship. }\end{array}$ & $-2(-1.01)$ & $-4(-2.04)$ & Saini (2017) \\
\hline $\begin{array}{l}\text { Fundamental } \\
\text { differences }\end{array}$ & $\begin{array}{l}\text { (2) Conceptualizing sex relies on the } \\
\text { male/female binary. }\end{array}$ & $-1(-0.60)$ & $0(-0.11)$ & $\begin{array}{l}\text { Johnson, } \\
\text { Greaves, } \\
\text { and Repta } \\
\text { (2009) }\end{array}$ \\
\hline $\begin{array}{l}\text { Genes/ } \\
\text { hormones/ } \\
\text { environment }\end{array}$ & $\begin{array}{l}\text { (3) Sex hormones control how our bodies } \\
\text { look and how we perceive ourselves. * }\end{array}$ & $1(0.34)$ & $1(0.51)$ & $\begin{array}{l}\text { Fausto- } \\
\text { Sterling } \\
\text { (2012) }\end{array}$ \\
\hline
\end{tabular}




\begin{tabular}{|c|c|c|c|c|}
\hline $\begin{array}{l}\text { Sex/gender- } \\
\text { based behavior } \\
\text { stereotype }\end{array}$ & $\begin{array}{l}\text { (4) Women experience more variation in } \\
\text { their erotic and affectional feelings than } \\
\text { men. }\end{array}$ & $-3(-1.22)$ & $0(0.16)$ & $\begin{array}{l}\text { Health } \\
(2011)\end{array}$ \\
\hline $\begin{array}{l}\text { Sex/gender- } \\
\text { based behavior } \\
\text { stereotype }\end{array}$ & $\begin{array}{l}\text { (5) Boys and girls manifest depression } \\
\text { differently: boys have more angry } \\
\text { outbursts and girls become more } \\
\text { withdrawn. }\end{array}$ & $-2(-0.67)$ & $-3(-1.85)$ & $\begin{array}{l}\text { McCredie } \\
(2011)\end{array}$ \\
\hline $\begin{array}{l}\text { Fundamental } \\
\text { differences }\end{array}$ & $\begin{array}{l}\text { (6) There are two sexes, so we classify } \\
\text { individuals as belonging to one or the } \\
\text { other. }\end{array}$ & $-3(-1.39)$ & $3(1.61)$ & $\begin{array}{l}\text { Risberg, } \\
\text { Johansson, } \\
\text { and } \\
\text { Hamberg } \\
(2009) \\
\end{array}$ \\
\hline $\begin{array}{l}\text { Fundamental } \\
\text { differences }\end{array}$ & $\begin{array}{l}\text { (7) Intersex individuals should be seen as } \\
\text { occupying a biological middle point } \\
\text { between males and females. }\end{array}$ & $1(0.23)$ & $0(-0.15)$ & Saini (2017) \\
\hline $\begin{array}{l}\text { Evolution of sex } \\
\text { characteristics }\end{array}$ & $\begin{array}{l}\text { (8) Males produce more offspring when } \\
\text { they have sex with multiple mates and } \\
\text { females do not. }\end{array}$ & $0(0.05)$ & $-1(-0.52)$ & Saini (2017) \\
\hline $\begin{array}{l}\text { Fundamental } \\
\text { differences }\end{array}$ & $\begin{array}{l}\text { (9) Differences in brain structure between } \\
\text { men and women - and between gay and } \\
\text { straight people - explains a range of } \\
\text { behavioral, emotional and cognitive } \\
\text { differences. * }\end{array}$ & $0(-0.24)$ & $-1(-0.16)$ & $\begin{array}{l}\text { McCredie } \\
\text { (2011) }\end{array}$ \\
\hline $\begin{array}{l}\text { Genes/ } \\
\text { hormones/ } \\
\text { environment }\end{array}$ & $\begin{array}{l}\text { (10) Sex hormone effects on the genitals } \\
\text { are fixed: always the same. * }\end{array}$ & $-2(-0.72)$ & $-2(-0.77)$ & $\begin{array}{l}\text { Fausto- } \\
\text { Sterling } \\
\text { (2012) }\end{array}$ \\
\hline $\begin{array}{l}\text { Genes/ } \\
\text { hormones/ } \\
\text { environment }\end{array}$ & $\begin{array}{l}\text { (11) The human Y chromosome contains } \\
\text { the gene that determines sex during fetal } \\
\text { development. }\end{array}$ & $2(0.91)$ & $2(1.31)$ & $\begin{array}{l}\text { Richardson } \\
\text { (2013) }\end{array}$ \\
\hline $\begin{array}{l}\text { Genes/ } \\
\text { hormones/ } \\
\text { environment }\end{array}$ & $\begin{array}{l}\text { (12) Males and females are different } \\
\text { because they have different levels of sex- } \\
\text { biasing factors that affect cells in differing } \\
\text { amounts at different times. }\end{array}$ & $0(-0.37)$ & $1(0.48)$ & Saini (2017) \\
\hline $\begin{array}{l}\text { Sex/gender- } \\
\text { based behavior } \\
\text { stereotype }\end{array}$ & $\begin{array}{l}\text { (13) When it comes to the average number } \\
\text { of heterosexual partners men and women } \\
\text { have, women have significantly fewer } \\
\text { sexual partners than men do. }\end{array}$ & $-1(-0.46)$ & $-2(-1.31)$ & $\begin{array}{l}\text { McCredie } \\
(2011)\end{array}$ \\
\hline $\begin{array}{l}\text { Fundamental } \\
\text { differences }\end{array}$ & $\begin{array}{l}\text { (14) Boys and girls are born different; } \\
\text { displaying characteristics that are not just } \\
\text { due to the way their parents raised them } \\
\text { and how society treated them. }\end{array}$ & $0(-0.09)$ & $4(1.69)$ & Saini (2017) \\
\hline $\begin{array}{l}\text { Evolution of sex } \\
\text { characteristics }\end{array}$ & $\begin{array}{l}\text { (15) Both same- and opposite-sex sexual } \\
\text { encounters occur in human and animal } \\
\text { populations. }\end{array}$ & $3(1.54)$ & $2(0.55)$ & $\begin{array}{l}\text { Ah-King } \\
(2013)\end{array}$ \\
\hline $\begin{array}{l}\text { Genes/ } \\
\text { hormones/ } \\
\text { environment }\end{array}$ & $\begin{array}{l}\text { (16) Particularly for sex and gender diverse } \\
\text { individuals, society and the environment } \\
\text { can sometimes influence illness more than } \\
\text { a person's underlying biology. }\end{array}$ & $2(0.95)$ & $0(0.23)$ & $\begin{array}{l}\text { Health } \\
(2011)\end{array}$ \\
\hline
\end{tabular}




\begin{tabular}{|c|c|c|c|c|}
\hline $\begin{array}{l}\text { Fundamental } \\
\text { differences }\end{array}$ & $\begin{array}{l}\text { (17) The most reliable definition of an } \\
\text { individual's sex is based on whether they } \\
\text { have ovaries or testes. }\end{array}$ & $1(0.27)$ & $3(1.32)$ & $\begin{array}{l}\text { Richardson } \\
\text { (2013) }\end{array}$ \\
\hline $\begin{array}{l}\text { Fundamental } \\
\text { differences }\end{array}$ & $\begin{array}{l}\text { (18) Maleness and femaleness are not } \\
\text { arbitrary constructs but objective ways of } \\
\text { being human. }\end{array}$ & $0(-0.16)$ & $1(0.55)$ & $\begin{array}{l}\text { Johnson, } \\
\text { Greaves, } \\
\text { and Repta } \\
(2009) \\
\end{array}$ \\
\hline $\begin{array}{l}\text { Fundamental } \\
\text { differences }\end{array}$ & $\begin{array}{l}\text { (19) Gender differences' and 'sex } \\
\text { differences' are the same with respect to } \\
\text { medical research. }\end{array}$ & $-4(-1.74)$ & $-2(-0.63)$ & $\begin{array}{l}\text { Risberg, } \\
\text { Johansson, } \\
\text { and } \\
\text { Hamberg } \\
(2009)\end{array}$ \\
\hline $\begin{array}{l}\text { Fundamental } \\
\text { differences }\end{array}$ & $\begin{array}{l}\text { (20) An individuals' sex characteristics } \\
\text { exist on a continuum, with traits considered } \\
\text { male or female occurring in different } \\
\text { combinations depending on the person. }\end{array}$ & $3(1.51)$ & $2(0.73)$ & $\begin{array}{l}\text { Johnson, } \\
\text { Greaves, } \\
\text { and Repta } \\
(2009)\end{array}$ \\
\hline $\begin{array}{l}\text { Sex/gender- } \\
\text { based behavior } \\
\text { stereotype }\end{array}$ & $\begin{array}{l}\text { (21) A mate's physical attractiveness is far } \\
\text { more important to men than it is to women. }\end{array}$ & $-1(-0.64)$ & $-3(-1.57)$ & Saini (2017) \\
\hline $\begin{array}{l}\text { Evolution of sex } \\
\text { characteristics }\end{array}$ & $\begin{array}{l}\text { (22) Natural selection acted to ensure that } \\
\text { the differences between males and females } \\
\text { became encoded in our genes. }\end{array}$ & $-1(-0.65)$ & $1(0.35)$ & $\begin{array}{l}\text { Johnson, } \\
\text { Greaves, } \\
\text { and Repta } \\
(2009)\end{array}$ \\
\hline $\begin{array}{l}\text { Fundamental } \\
\text { differences }\end{array}$ & $\begin{array}{l}\text { (23) Rather than being distinctly male or } \\
\text { female, the brain is a unique "mosaic" of } \\
\text { characteristics. }\end{array}$ & $4(2.34)$ & $-1(-0.35)$ & Saini (2017) \\
\hline $\begin{array}{l}\text { Evolution of sex } \\
\text { characteristics }\end{array}$ & $\begin{array}{l}\text { (24) Sex as a biological concept can be } \\
\text { divided into smaller categories such as } \\
\text { brain sex, fetal sex, or gonadal sex. }\end{array}$ & $1(0.61)$ & $-1(-0.19)$ & $\begin{array}{l}\text { Fausto- } \\
\text { Sterling } \\
(2012)\end{array}$ \\
\hline $\begin{array}{l}\text { Genes/ } \\
\text { hormones/ } \\
\text { environment }\end{array}$ & $\begin{array}{l}\text { (25) Social and environmental cues after } \\
\text { birth affect gender but not sex. }\end{array}$ & $2(1.20)$ & $0(0.14)$ & $\begin{array}{l}\text { Fausto- } \\
\text { Sterling } \\
(2012)\end{array}$ \\
\hline
\end{tabular}

Statements with $*$ are not significant for either ideology at $\mathrm{p} \leq 0.05$.

\section{Participants}

Participants $(n=37)$ from an urban, Midwest public university in the United States were recruited through introductory English and Biology classes between Fall 2017-Fall 2018. These courses fill general education requirements for the university and most students enroll in one or the other early in their academic career. In total, 22 majors were represented with pre-healthcare students $(n=7)$ the most numerous. Most students identified as straight or cisgender $(n=20)$ or declined to respond $(n=11)$; the remaining 
students $(n=6)$ self-identified as LGBTQ+. Most students $(n=26)$ completed $\leq 1$ year of study at the university while the remaining students completed 2 years $(n=6)$ or 3 years $(n=5)$. Ages ranged from 18-27 years. Most students were $18(n=18)$ or $19(n=10)$.

Participants signed an informed consent letter before the Q-sort.

\section{Q-sort and analysis}

Participants read the 25-statement Q-set, then organized the statements into 3 categories: agree, disagree, and neutral/uncertain. After sorting the Q-set into the three superficial categories, they were presented with the pyramid-shaped forced-choice distribution with a +4 to -4 scale along the bottom (see Figure 1) and asked to sort the Qset onto this distribution. Once a participant confirmed that they were finished with the placement of the cards, their Q-sort was photographed, the area of 'uncertainty' recorded, and a structured interview was conducted. The guiding question "What do you believe about sex and gender?" was printed and placed in front of the participant for the duration of the activity. When participants completed the sort, they were asked three questions (below) used in other Q-sorts to prompt participants to discuss their thinking during the statement sorting process (Fuselier et al., 2019). Their interviews were audio recorded and subsequently, transcribed. The qualitative content of these interviews played an integral role in describing the ideologies that emerged.

(1) Referring to the items at the extremes of the distribution, -4 and +4 : What do these mean to you? Why do you feel so strongly about these statements?

(2) Are there any items toward the middle of the distribution that evoke an emotional response or have a personal meaning/significance to you?

(3) Were there any statements that you didn't understand or were unclear? Were there any items that you feel were omitted but should be included? 
Q-sorts were analyzed using PQMethod, a program designed specifically to analyze Q-method data (Schmolck, 2014). The program searches for shared patterns in the placement of statements along the forced-choice distribution and identifies these as Qfactors using correlation matrices and covariances similar to exploratory factor analysis (EFA) but using the position of cards on the distribution as the measured variable (Schmolck, 2014). The software reported Eigenvalues, between-Q-factor correlations (i.e., overlap between ideologies), and number of individual Q-sorts associated with a single Q-factor (called exemplars) that guided us in determining the number of valid ideologies in my study. My inclusion criteria for separate Q-factors were: Eigenvalue > 1.0, between-factor correlation $<40 \%$, composite reliability $>0.90$, and number of Qfactor defining Q-sorts (i.e., exemplars) > 5 .

Using a weighted average of each statement's relative sort position, the Z-score, PQMethod created an idealised Q-sort that characterised the typical placement of statements on the distribution; this was used in conjunction with grounded theory (B. G. Glaser, Strauss, \& Strutzel, 1968) to characterize the ideology represented by its respective Q-factor. I conducted a post-hoc evaluation of demographic characteristics using a one-sided Fisher's exact test (Overall, 1980) and RStudio.

\section{Ideology characterization}

The goal of Q-factor characterization was to detect, analyze, and understand the conceptual framework of each cluster of shared beliefs identified as relevant statistically, not to compare the Q-factors detected. In alignment with my grounded theory approach (Heath \& Cowley, 2004), I used a systematic approach called the crib sheet method (Watts \& Stenner, 2012) to develop an understanding of the ideologies represented by the 
Q-factors. Thus, each step of the characterization process was conducted independently for all significant Q-factors (as defined by the inclusion criteria from the previous section). First, I identified the statements ranked at the two extremes $(+4,+3$ and $-4,-3)$. Next, I listed all statements ranked higher on that ideology than any other, then did the same for statements ranked lower on that ideology than any other (Watts \& Stenner, 2012). As I created each Q-factor's crib sheet, I summarized the meaning of the statements based on their sort position, e.g., Q-factor 1 sorted statement 1 at -2 , so I summarized that as "disagree with behavior stereotype". In addition, I color coded the statements on the idealized Q-sort for each Q-factor according to the topic of the statements; in effect applying topic coding (Saldaña, 2016) that permitted me to visualize any sorting patterns that might be related to the statement's topic.

Once I prepared the PQMethod output to help guide my qualitative analysis, I collected the interview transcripts for participants that define each ideology and applied categorical coding (Saldaña, 2016) that associated the Q-set statements referenced in each interview with that portion of the transcript. In some interviews the participant would read the statement, allowing it to easily be associated with that portion of their transcript, e.g., "The one I agreed with the most, sex hormones control how our bodies look and how we perceive ourselves, I just see that as a very basic statement". However, in others they might not, e.g., "I noticed my +4 is probably a mix of what I know, scientifically is accurate". Therefore, a copy of the participant's Q-sort was referenced during this process to verify that each statement was properly associated with interview comments discussing it. For statements in the middle range (usually between +1 to -1 ), I relied on participant interviews and their description of agree/disagree boundaries to distinguish 
between "uncertain" areas and areas of neutrality/no opinion. Thus, both the placement of the Q-set statements and the remarks from the interviews were considered throughout the process of characterizing the beliefs represented by each Q-factor.

By asking participants why they chose to place statements where they did, I was able to gain insight into the intent behind their sorting of the statements. During my second stage coding, I began with the +4 and +3 statements from the crib sheet and excerpted all interview sections referencing those statements. Next, I read through the excerpts and used concept coding (Saldaña, 2016) to evaluate how participants rationalized their beliefs. As I did this, I tried to consolidate similar concepts, e.g., "for the ones I agreed with, they were the more biology based facts" and "it's been proven scientifically" would both be represented by the concept code "science authority". This process was applied the transcripts associated with each Q-factor ideology. After concept coding the transcripts, it was possible to sort the data based on the excerpt codes, the topic of the statements, or the statements referenced. This also enabled me to count the instances of each code and calculate frequencies.

In the results, I supported my interpretation of the sex/gender ideologies using placement of statements on the sort distribution and interview quotes. I also referenced concepts identified during the qualitative coding that were cited by students in rationalizing their beliefs. Participant numbers are preceded by a $\mathrm{P}$ and distribution location is expressed as a number ranging from +4 to -4 to represent the most agreed and disagreed upon statements, respectively. 


\section{RESULTS}

Two robust Q-factors with minimal overlap met the inclusion criteria of an Eigenvalue less than one $(E V>1.0)$, and together explained $38 \%$ of variation in the population. Q-factor 1 was defined by 18 participant sorts $(\mathrm{EV}=9.3$; composite reliability $=0.99)$ and $\mathrm{Q}$-factor 2 by 14 sorts $(\mathrm{EV}=4.6$; composite reliability $=0.98$; Figure 2$)$. Five participant sorts were not significant on either factor (those in the shaded region of Figure 2); these were not considered in characterisation of the two ideologies. The two Q-factors showed a low between-factor correlation, or ideological overlap, of only $27.6 \%$. Low correlations between the factors are considered ideal, and indicate that the viewpoints described by separate Q-factors are not simply alternative manifestations of one another (Watts \& Stenner, 2012, p. 143).

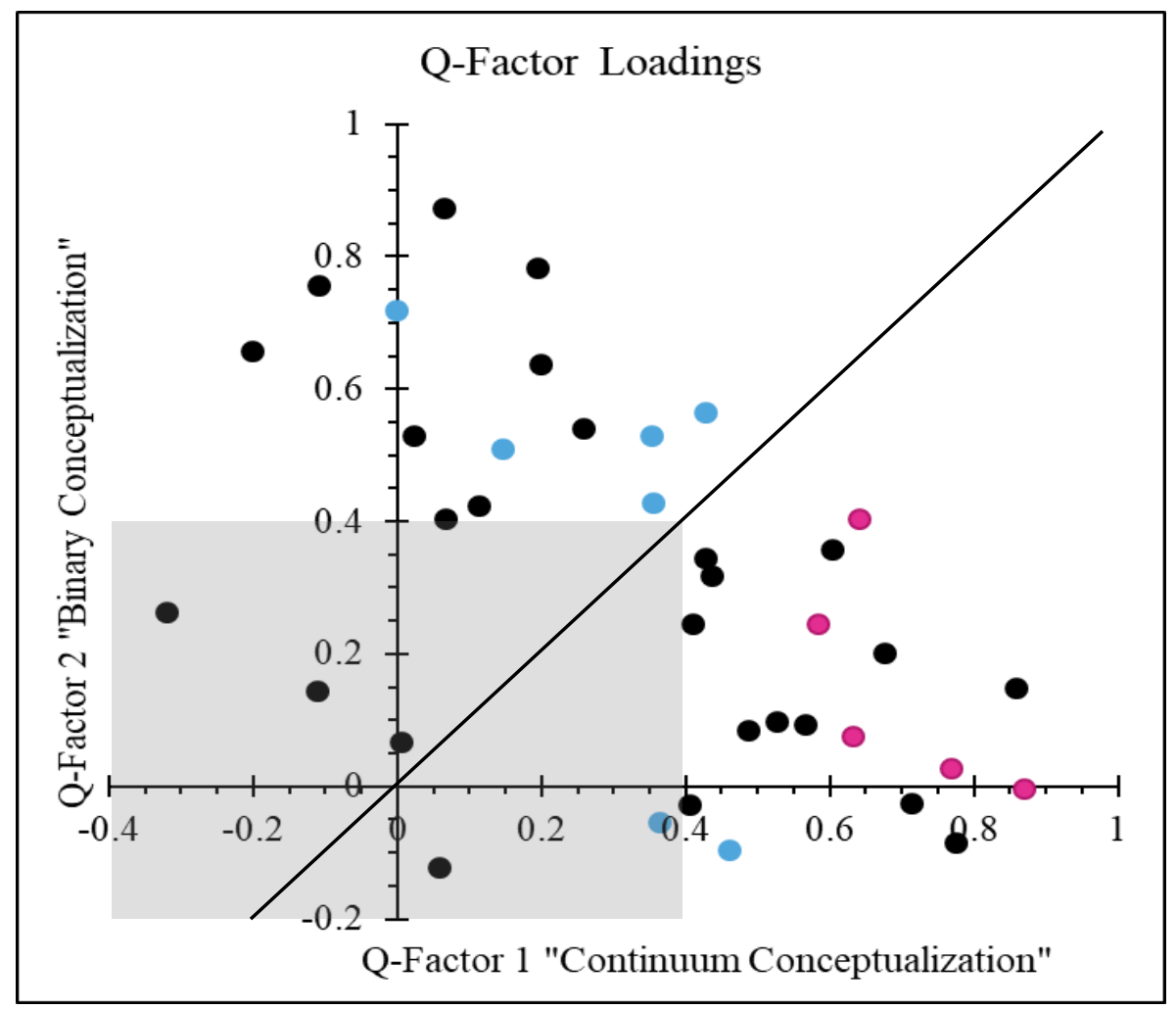


Figure 2. Q-factor loading graph.

Loadings are a correlation coefficient and represent the degree that a participant's Q-sort (dots) is associated with that ideology. The diagonal line bisecting the quadrants marks the separation of Q-factors 1 and 2 and sorts falling in the grey box are those not significantly correlated to either ideology. Blue markers represent pre-healthcare students and pink markers represent students with three or more years at the university.

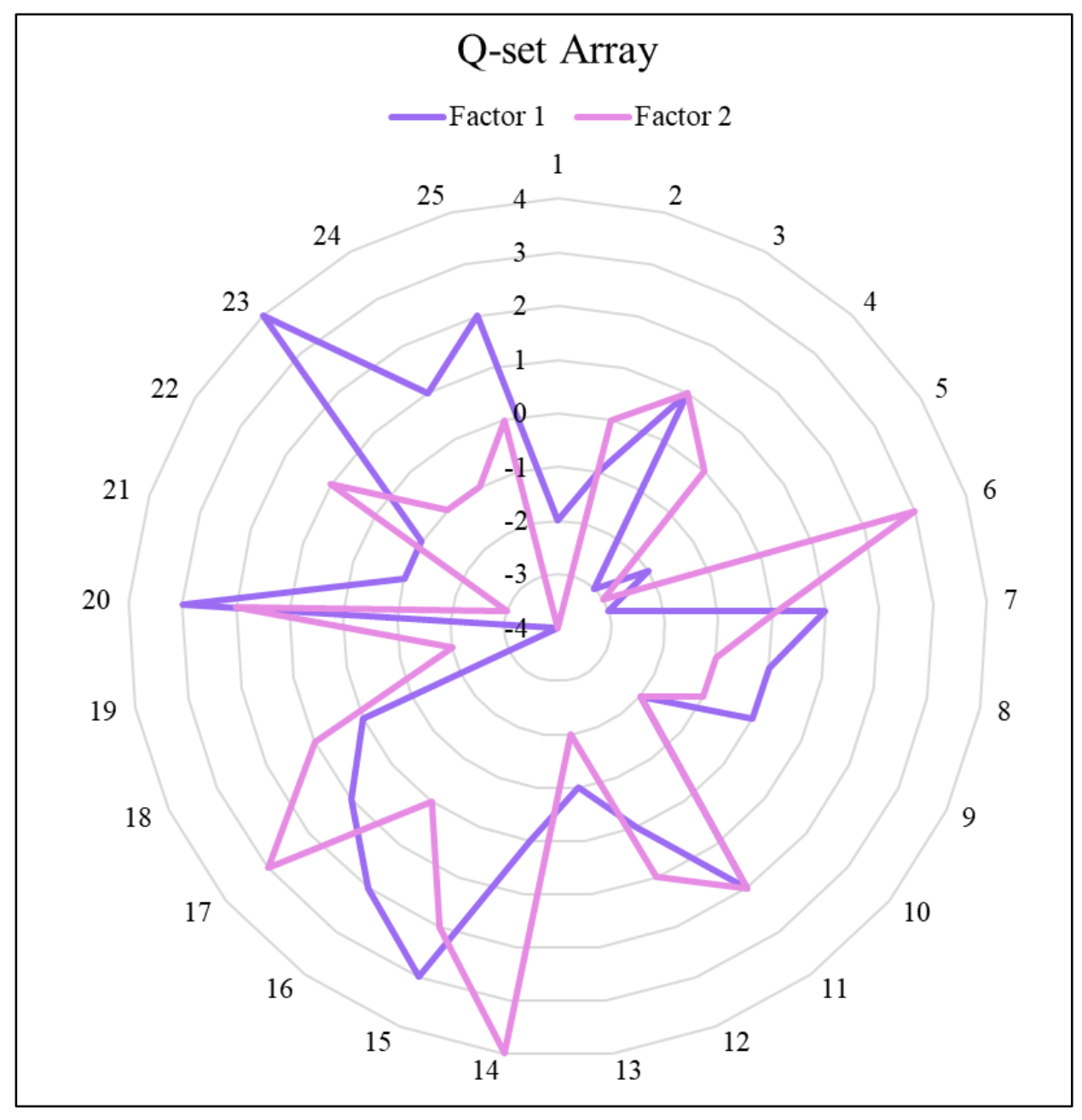

Figure 3. Q-set array

A visual representation of differences in 'idealized sort position' for the two ideologies.

The numbers around the outer perimeter correspond to the Q-set statement and the column of numbers in the center of the top half refer to the statement's position on the 
forced choice distribution. Only three statements $(3,9,10)$ did not differ significantly between the two ideologies detected. The other 22 statements were instrumental in characterizing the sex/gender ideologies represented by each Q-factor.

Of the 25-statement Q-set (see Table 1), 22 statements were significant in distinguishing between the two Q-factors; 20 were significant at $\mathrm{p}<0.01$ while two (statements 11 and 7) were significant at $p<0.05$. Three consensus statements $(3,9$ and 10) did not distinguish between the two ideologies (i.e., were shared among participants). This is visualized in Figure 3. Despite my pilot of the statements, some students struggled to understand the language in statements three and nine (about sex hormones and differences in brain structure). Although few students explicitly referenced these statements, in their interviews students remarked, "I had a hard time understanding it. I couldn't decide if I agreed or disagreed with that" (P5), "I put it in neutral because I was questioning it" (P30), and "a lot of them toward the middle [are there because] I didn't understand the statements" (P13). Thus, I believe these were likely consensus statements because they were not fully understood by participants.

On the other hand, for statement 10, both ideologies equally disagreed (-2) with the idea that sex hormone effects are fixed. Although only six students commented about their sorting of statement 10, students in both Q-factors referenced age related changes in hormones, e.g., "I know that, like, testosterone changes as age goes on. I'm pretty sure that something like that happens, not testosterone, but that happens for women too.” (P7) and "You know, testosterone and estrogen vary in people. ...The different medicines you take, there's menopause, you know." (P23). Only, two students commented that they were 
uncertain about the meaning of the statement, with one student saying, "I had no idea, so I put that [statement 10] closer to the disagree" (P27).

\section{Sex/gender ideologies}

The Q-factors that emerged from my Q-sort ultimately represented two different conceptualizations/ideologies of sex/gender. Notably, from an NMF perspective, the two ideologies should not be seen as separate, distinct domains but instead as points along a spectrum of the possible beliefs among students at that point in time. Accordingly, several concepts were consistently referenced by students rationalizing their beliefs about sex/gender during the Q-sort. As part of the concept coding, I was able to count coding instances and calculate frequencies for the two Q-factors. The cumulative totals for the two ideologies are given in Table 2.

\section{Table 2}

Concepts Used to Rationalize Beliefs Within the Two Ideologies

\begin{tabular}{lcc} 
Code & Q-Factor 1 & Q-Factor 2 \\
\hline Biological sex & 13 & 6 \\
Educational exposure & 6 & 4 \\
Confused/uncertain & 24 & 27 \\
Society & 10 & 4 \\
Personal experience & 10 & 10 \\
Science authority & 10 & 7 \\
Emotional appeal & 5 & 10 \\
Other & 8 & 7 \\
\hline
\end{tabular}

I named the two ideologies based on distinguishing beliefs that emerged during the analytic process. I labeled ideology one the "Continuum Conceptualization" because students that informed this ideology understood sex as a continuum rather than a binary, but they lacked the scientific knowledge to explain how this was so. Their acceptance of non-binary sex was coupled with a rejection of stereotypes typically associated with 
gender essentialism; for some students this rejection was grounded in recognition of systemic sexism associated with the stereotypes. I labeled ideology two the "Binary Conceptualization" because these participants held strongly to the understanding that there are only two sexes and they invoked genetic determinism to support this belief. Although they rejected sex/gender stereotypes, they did so based on emotional appeals and personal experience rather than awareness of systemic sexism.

\section{"Continuum Conceptualization"}

Sex/gender. Students that were associated with ideology one believed sex and gender were separate constructs (statement 19), gender was a social construct, sex was biologically determined (25) (Table 3). In their interviews, affirmation of the sex and gender distinction was evident, e.g., "I see them [sex and gender] as two different things" (P22), although there were differences within the ideology in how they framed the distinction. Some bound sex within biology and gender within culture, "I think that gender and sex are different, and I think that gender has to do with societal and cultural norms. Sex has to do with your biological makeup" (P15). Others framed sex as body and gender as mind, "I think that $\mathrm{X} / \mathrm{Y}$ determines sex, but that gender is picked based on how you feel" (P14). Regardless of how gender/culture/social was framed, sex was biological. "Somebody's sex is what they biologically are" (P6); "[my] perceptions of biological sex" (P9); "sex hormones control...biologically that's how we look" (P10); "sex has to do with your biological makeup" (P15). Feelings were likewise decoupled from sex, "I think that your emotions are your emotions, it doesn't really matter what sex you are" (P28). "I agree with the part that it [sex hormones] controls how our body looks, but not 
how we feel about ourselves" (P22); "I define sex as your genitals and gender is everything else" (P23).

These students saw gender as influenced by external pressures (statement 25) and possessing a flexibility not ascribed to sex. "When I think about sex, I think X/Y chromosomes. I'll say that maybe social/environmental effects won't change that. But with gender it's more fluid and influential. It might be affected by how you're raised, other people you encounter, you know" (P37).

\section{Table 3}

$\underline{\text { Statements Defining the Understanding of Biological Sex and Social Gender for the }}$ Continuum Ideology

\begin{tabular}{lcc}
\multicolumn{1}{c}{ Statement } & Viewpoint & Sort Position \\
\hline $\begin{array}{l}\text { (19) 'Gender differences' and 'sex differences' } \\
\text { are the same with respect to medical research. }\end{array}$ & Disagree & -4 \\
\hline $\begin{array}{l}\text { (23) Rather than being distinctly male or female, } \\
\text { the brain is a unique "mosaic" of characteristics. }\end{array}$ & Agree & +4 \\
\hline $\begin{array}{l}\text { (25) Social and environmental cues after birth } \\
\text { affect gender but not sex. }\end{array}$ & Agree & +2 \\
\hline
\end{tabular}

Interestingly, students adopting this ideology very strongly believed that brains are mosaics of male and female characteristics, implying a non-binary view of sex. "I don't think that the brain can be identified as either male or female despite any hormone balances" (P23). This conceptualization is further supported by their disagreement with statement 6 and strong agreement with statement 20 (Table 4). Two students in this Qfactor used examples of intersex people to justify their views, e.g., "Intersex people are more common than redheads. For us to ignore that as a sex is silly...To say we're a 
binary population is wrong. It makes me feel bad for intersex people to choose and we're forcing them to be what they weren't born as" (P31).

Their continuum characterization of sex locates intersex people between biological/chromosomal categories of $\mathrm{X} / \mathrm{Y}$ since the "only option [for intersex people] is in between somewhere. If I thought of them as discrete categories, then there wouldn't be a continuum" (P1). Thus, despite characterizing sex as biological, these students were averse to a binary system of sex classification.

\section{Table 4}

$\underline{\text { Statements Supporting the Continuum Ideology's Non-Binary View of Sex }}$

\begin{tabular}{lcc}
\multicolumn{1}{c}{ Statement } & Viewpoint & Sort Position \\
\hline $\begin{array}{l}\text { (6) There are two sexes, so we classify individuals } \\
\text { as belonging to one or the other. }\end{array}$ & Disagree & -3 \\
\hline $\begin{array}{l}\text { (20) An individuals' sex characteristics exist on a } \\
\text { continuum, with traits considered male or female } \\
\begin{array}{l}\text { occurring in different combinations depending on } \\
\text { the person. }\end{array}\end{array}$ & Agree & +3 \\
\hline
\end{tabular}

Scientific justification. Students struggled to give a science-grounded explanation for why they believed there are more than two sexes in humans (statement 12; Table 5). Although some of them mentioned intersex, most students could not use biology to explain sex as non-binary, even though they used scientific terminology about chromosomes and development. For example, one said, "If you want to look at sex as just $\mathrm{X} / \mathrm{Y}$ chromosomes you can, but I think it's more complicated than that" (P37) but did not elaborate on the complications. That same student also cited specific hormones but seemed to have misconceptions about the nature of those hormones, e.g., "I mean, biologically there's going to be some obvious differences with the way that hormones are introduced into the body. Testosterone versus estrogen, that one's obvious" (P37). On the 
other hand, three students cited a lack of scientific knowledge to explain their uncertainty, e.g., "I don't know a lot about biology." (P21).

\section{Table 5}

$\underline{\text { Statements Exemplifying Uncertainty About Scientific Claims in the Continuum }}$ $\underline{\text { Ideology }}$

\begin{tabular}{lcc}
\multicolumn{1}{c}{ Statement } & Viewpoint & Sort Position \\
\hline $\begin{array}{l}\text { (12) Males and females are different because they } \\
\text { have different levels of sex-biasing factors that } \\
\text { affect cells in differing amounts at different times. }\end{array}$ & Uncertain & 0 \\
\hline $\begin{array}{l}\text { (24) Sex as a biological concept can be divided into } \\
\text { smaller categories such as brain sex, fetal sex, or } \\
\text { gonadal sex. }\end{array}$ & Uncertain & +1 \\
\hline
\end{tabular}

When presented with categories to subdivide sex (statement 24), three students in this Q-factor explicitly stated that they were confused by the statement. "I got the nuance of it [the statement] but I was not sure what gonadal was" (P11), "That one I was confused on what you were talking about" (P24), and "I didn't know what brain sex, fetal sex...those meant" (P28). These knowledge gaps identify a deficit in these students' understanding of human biology.

Gender essentialism and stereotypes. These students rejected common sex/gender stereotypes, evidenced by disagreement with statements 1, 4 and 5. They tended to avoid sex/gender essentialization (Table 6). Based on their interviews, they associated these stereotypes with society rather than biology, since "society" was the most applied concept code $(\mathrm{N}=10,41.7 \%)$ for this category of statements, followed by "personal experience" and "emotional appeal" (both $\mathrm{N}=5,20.8 \%$ ). For example, one student made explicit distinctions between culture and biology, "Culturally speaking, they're [boys and girls] going to be different based on how they were raised, not how they were born" 
(P37). Another disagreed with a masculinity stereotype based on an emotional appeal, stating, "I feel like that's just a stereotype and that a lot of men have feelings too, but maybe they don't show it as often" (P28). In other instances, stereotypical claims were dismissed outright based on their culturally constructed nature, e.g., "Those are purely based on social constructs like the patriarchy and how women depended on men for survival..." (P23).

Critical consideration of new information featured in the dismissal of sex/gender stereotypes among adherents to this ideology. Some recognized bias in their thinking, "there are some implicit biases that I have that make me want to believe that is the truth" (P17), and actively sought to confront contradictory beliefs with new evidence. "I want to say, yeah they're true. But I fight that in myself, because I know that they're really not and it's just the social norm that we believe. Those things are definitely taught socially and within our culture. It was weird placing those; your go to is to believe them but they're not true. It's a battle within yourself to outgrow what you grew up knowing" (P31). They see the interaction of experiences, knowledge, and belief, even though they fall short of recognizing an NMF understanding of the entanglement of sex/gender.

\section{Table 6}

$\underline{\text { Students in the Continuum Ideology Rejected Gender Stereotypes }}$

Statement

(1) In romantic relationships, the man is more likely than the woman to "cheat" by seeking sex outside the relationship.

(4) Women experience more variation in their erotic and affectional feelings than men.
Viewpoint

Sort Position
Disagree $\quad-2$ $-2$

Disagree $\quad-3$


(5) Boys and girls manifest depression differently: boys have more angry outbursts and girls become more withdrawn.

\section{"Binary Conceptualization"}

Sex/gender. Students exemplifying this ideology strongly believed that sex is a result of biology and there are two distinct sexes with innate differences (statements 6, 14, 17) (Table 7). "I just think of it as male and female" (P34). What "defines your sex [is] whether you have ovaries or testes" (P7). These students held beliefs of genetic/biological determinism and viewed sex as determined by chromosomes or gonads (statement 17). "There's a very specific, divergent path between males and females during our whole process of getting to where we are now that got encoded in our genes the same way any other thing got encoded in our genes" (P19). In accord, they rejected societal or environmental contributions to differences between males and females. "You're born with certain traits and characteristics that made you either male or female. And not necessarily depending on how your parents treated you or something like that. It's just born into you. That's what I most agreed with because that's what I've always assumed or known" (P20).

In apparent contradiction to their description of binary sex, students in this ideology were uncertain about the statement that conceptualizing sex relies on the male/female binary (statement 2). Interviews revealed one student (P30) was confused about the meaning of the word "conceptualizing" and needed the researcher to define it. Nine students implied that they did not understand the statement and as such were "neutral" on the topic, "There were some I was neutral on that I just didn't understand so I put them in the neutral pile.” (P35).

\section{Table 7}


$\underline{\text { Statements Supporting the Binary Ideology's View of Sex as Binary }}$

\begin{tabular}{llc}
\multicolumn{1}{c}{ Statement } & Viewpoint & Sort Position \\
\hline $\begin{array}{l}\text { (6) There are two sexes, so we classify individuals as } \\
\text { belonging to one or the other. }\end{array}$ & Agree & +3 \\
\hline $\begin{array}{l}\text { (14) Boys and girls are born different; displaying } \\
\text { characteristics that are not just due to the way their } \\
\text { parents raised them and how society treated them. }\end{array}$ & Agree & +4 \\
\hline $\begin{array}{l}\text { (17) The most reliable definition of an individual's } \\
\text { sex is based on whether they have ovaries or testes. }\end{array}$ & Agree & +3 \\
\hline
\end{tabular}

As opposed to their beliefs about binary sex, these students exhibited a wide range of understandings of gender. Some construed gender as distinct from sex, "with sex there's male and female, gender is a different thing" (P32). But they did not describe gender as necessarily socially constructed. "I see them as different things because people can identify with gender. Sex is what you were born as. They're not the same in medical eyes" (P35). Some students conflated sex and gender, "we were born with a gender, but a lot of people change their gender, so I wasn't really sure about that" (P13). Others believed that gender changes, but sex does not. "I don't know what else you could be.... A guy can identify as a girl, but there's still genders. You can be born one thing and want to be another" (P25).

Scientific justification. In interviews, these students invoked biology and scientific "facts" to support their beliefs about sex and invoked science blindly as truth (Table 8). One student remarked, "the ones I agreed with, they were the more biology-based facts. The Y chromosome determines if it's a boy or a girl - that's science” (P35). Several students held misconceptions about evolution and human physiology. One student with a strong binary understanding of sex said, “okay, natural selection, like I've been learning about that in biology. I couldn't see how that would act on male or female" (P34). And 
another, "I haven't learned anything about that. I really didn't understand it. I just...I feel like this was right. I don't know if it is technically...the human $\mathrm{Y}$ chromosome, in men it determines sex" (P32).

Within this ideology, statement 15 was interpreted differently in terms of scientific justification. "I agree with same sex and opposite sex happening with most animals because it's been proven scientifically. I mean, male penguins will find an egg and raise it together" (P26). This student invoked an example of same sex parental care to support the idea that non-human animals have same-sex sexual encounters. Another disagreed with the same statement and said, "I knew what it was saying but I did not know if the animal part was true at all. I mean I've never heard of an animal having a same sex encounter" (P20).

Here again, understanding of the biology of sex/gender was lacking and students had trouble articulating what they meant by biological mechanisms they invoked. Because these students were tentative about their understanding of scientific concepts, the line between disagreement and confusion was tenuous. They were either uncertain about the brain as a mosaic (statement 23) or only expressed slight disagreement with the statement. "I think there are differences in brain chemistry and different things, but I think that there's like, more than just that, especially when it comes to brain chemistry. I mean, our brains are so diverse and just what it does [sic]. I think there's a lot of similarity between male and female brains but there's so much that goes into it" (P19).

\section{Table 8}

$\underline{\text { Statements Exemplifying Student Struggles with Scientific Claims in the Binary Ideology }}$

Statement Viewpoint Sort Position


(11) The human Y chromosome contains the gene that determines sex during fetal development.

Tentative $+2$

(22) Natural selection acted to ensure that the differences between males and females became encoded in our genes.

(23) Rather than being distinctly male or female, the brain is a unique "mosaic" of characteristics.

Uncertain $-1$

Gender essentialism and stereotypes. Ideology 2 participants very strongly disagreed with sex/gender stereotypes (statements 1, 13, and 21; Table 9). They invoked "emotional appeal" $(\mathrm{N}=10,40.0 \%)$ and "personal experience" $(\mathrm{N}=9,36.0 \%)$ more than "society" $(\mathrm{N}=4,16.0 \%)$ to support their views. For example, one student that explained, "[I'm male and] I've been cheated on twice, so I disagree with that one [statement 1]" (P7). Another student used her own experience with depression to evaluate statement 5, "I do have depression, so reading that, I can relate with the girls being withdrawn, but then again, I've had my outbursts of anger and confusion, so I don't fully agree with that statement" (P27). Personal experience was used both to contradict stereotypes and to validate them. For example, "I agree with boys and girls manifest depression differently. I've kinda seen that through personal experience too" (P7). However, some students did articulate a more societal understanding within their emotional appeal, "I don't agree with that. I feel like it's so sexist. Girls can be angry too; it goes both ways" (P4).

Unlike fixed physical/biological differences between the sexes, behaviors were viewed as highly variable among humans (statements 13,21). "All of the stuff I disagreed with; it's based on each person" (P32). This recognition fits within an NMF perspective but this reasoning is inconsistently applied. For example, students did not react strongly to statement 4, ("Women experience more variation in their erotic and affectional feelings than men") which limited behaviors to one sex or the other. It is possible that 
these simply fell outside of their personal experience, because the students that did reference this statement mentioned personal experiences informing their sorting decision, e.g., "I feel like, in my relationships, I've had more stronger feelings toward him, but that might have just been how I was open about it" (P27).

\section{Table 9}

$\underline{\text { Students in the Binary Ideology Rejected Gender Stereotypes }}$

$$
\text { Statement Viewpoint Sort Position }
$$

(1) In romantic relationships, the man is more likely than the woman to "cheat" by seeking sex outside the relationship.

(5) Boys and girls manifest depression differently: boys have more angry outbursts and girls become more withdrawn.

(21) A mate's physical attractiveness is far more important to men than it is to women.

Disagree $\quad-4$

\section{Post hoc analysis}

My post-hoc analyses found that students who had completed three or more years of college study were significantly more likely to be associated with the Continuum Conceptualization ( $p=0.04$, Fisher's exact), whereas being a pre-healthcare major was significantly associated with the Binary Conceptualization ( $\mathrm{p}=0.04$, Fisher's exact) of sex/gender. All other demographic characteristics (age, sex, gender, ethnicity, and LGBTQ+ identity) did not differ significantly across ideologies ( $p>0.05)$.

\section{DISCUSSION}

Undergraduate college students from a variety of disciplines held one of two different conceptualizations of sex/gender, one emphasizing a continuum and the other, an essentialistic view. Notably, the two Q-factors are not polar opposites, instead they 
reflect a spectrum of beliefs held by these students. Overall, students possessed complicated, sometimes conflicting, folk theories about sex/gender and lacked scientific understanding that would support conceptualizations more in alignment with an NMF view of sex/gender. All five students with three or more years of college experience held a continuum conceptualization of sex/gender, but the majority of pre-healthcare majors $(\mathrm{N}=5,83.3 \%)$ described a binary conceptualization of sex/gender. Both the continuum and binary conceptualizations ascribed essential characteristics to the biological construct "sex".

The perspective of students holding the continuum conceptualization aligned with the 'coatrack' construct of sex and gender as different but related constructs (Nicholson, 1994). Their "biological but non-binary" view reflected the evolving body of science knowledge about the diversity of human sexes, sexuality, and reproduction (Bashamboo, Eozenou, Rojo, \& McElreavey, 2017; Dumic et al., 2008; Shetty, 2018; Stévant et al., 2018) but only superficially aligned with a new materialist feminist (NMF) perspective of sex/gender because it was still dependent upon a biology/body/sex versus sociocultural/mind/gender delineation of sex/gender that failed to acknowledge the entanglement between the two.

On the other hand, students aligned with the binary ideology imagined sex as biologically essential, conflated sex and gender, and struggled to articulate a definition of gender. Though their lack of distinction between sex and gender superficially aligned with the NMF perspective, a more probable explanation is that these students embraced biological, rather than social gender theory (Coleman \& Hong, 2008) with essentialistic definitions of sex roles in alignment with gender norms (Carlson, 2013). 
The main area of ideological overlap between the two conceptions appeared in the students' beliefs about gender stereotypes. Although students that were associated with the binary conceptualization held essentialistic beliefs, they opposed gender stereotypes whereas, typically, the belief in the gender essentialism is strongly associated with acceptance of gender stereotypes (Keller, 2005). Students in the binary conceptualization expressed a greater aversion to most stereotype statements but students that aligned with the continuum conceptualization saw the broader role of society in the perpetuation of stereotypes; this is in accord with their more up-to-date conception of sex/gender (Rippon, 2019; Saini, 2017).

\section{Education implications}

Even though most students were in their first or second year of college and would not necessarily have completed many college science classes, they referenced science to validate their beliefs about sex/gender. They used terms like "ovaries/testes", "chromosome", "XX or XY", or "hormones" correctly, but exhibited only a superficial understanding of how these entities function (or interact) in relation to sex/gender. For example, students on both factors described hormone levels as dynamic throughout life but believed that females experienced more significant effects of hormones on the body than males. However, recent science show that the main hormonal distinctions fall along 'pregnant people' and 'non-pregnant people' rather than sex binaries (Hyde et al., 2018). In fact, women and men do not have different average levels of estradiol and progesterone (Liening et al., 2010; van Anders, 2010), and non-pregnant women have levels more like men than pregnant women (Tulchinsky et al., 1972). When considering testosterone levels, in actuality there is considerable overlap between average levels of 
men and women (Hyde et al., 2018). But by focusing only on "male hormones" and "female hormones" in their respective binary sex/gendered bodies, the overlap in average adult levels as well as any social factors associated with sex/gender are ignored (K. Karkazis \& Jordan-Young, 2018; van Anders, 2013).

Students associated with the continuum conceptualization held misconceptions such as over-emphasizing hormone influences on behaviors (e.g., sex hormones control behaviors) and reducing sex to chromosomes (e.g., $\mathrm{XX} / \mathrm{XY}$ as sex) but also recognized their lack of scientific understanding. Students associated with the binary conceptualization emphasized their trust in science's power to define normative ways of knowing and being (Birke, 2000). This was epitomized by one student's assertion that "The Y chromosome determines if it's a boy or a girl - that's science" (P35). This is problematic because common misconceptions about the binary nature of sex/gender alongside blind trust in science can be linked with discriminatory practices (K. Karkazis \& Jordan-Young, 2018). For example, the over-inflation of the sex hormone effects in conjunction with a lack of understanding that testosterone and estrogens are produced by all human bodies is cited to justify transgender athlete restrictions and limits on innate androgen levels in specific groups (K. Karkazis \& Jordan-Young, 2018). More exposure to sex/gender through $\mathrm{NMF}$ or other feminist/queer frameworks in science classes has the potential to shift these conceptualizations. However, this should be done deliberately, with care not to cram LGBTQ+ bodies into materials in ways that objectify or fetishize them and their experiences (Letts, 2002).

Student understanding of the social nature of science that emphasizes sciences as a human endeavor embedded in social contexts is critical for dismantling blind trust in 
science as an arbiter of truth (Erduran \& Dagher, 2014; Helen E. Longino, 2002). In educational settings, students may experience dissonance when presented with contemporary research about sex/gender that contradicts their beliefs and simultaneously carries strong emotional significance; in these situations understanding of the nature of science and epistemological sophistication mediates uptake of 'controversial' topics (Dunk, Petto, Wiles, \& Campbell, 2017). To give students the tools necessary to navigate questions of sex/gender in a scientific domain, educators need to center the role of social factors in the generation of science knowledge (Helen E Longino, Alcoff, \& Potter, 2002).

These students' inability to describe the biological foundation for their sex/gender beliefs may reflect the lack of exposure to sex/gender in the curriculum across all education levels (Mayo, 2016). At the college level, sex education is often framed in a health science context but not integrated into the core curriculum (Dubin et al., 2018; Mayfield et al., 2016; Taylor, Condry, \& Cahill, 2018); so, unless students choose to take elective courses to learn about LGBTQ+ healthcare topics, they may not be exposed to important concerns about the societal impact of sex/gender understandings during their undergraduate years.

Further, the existence of a binary conceptualization indicates that there is the potential for a non-inclusive culture in biology classrooms (Cooper \& Brownell, 2016) and in the larger context of healthcare (Dean, Victor, \& Guidry-Grimes, 2016). We know that people who endorse gender essentialist claims tend to accept gender role stereotypes (Heyman \& Giles, 2006), negatively self-stereotype (Coleman \& Hong, 2008), and discourage ideological dissent (Keller, 2005). Uncovering this binary and essentialistic 
conception among undergraduate, especially pre-healthcare students, is particularly problematic because biological gender beliefs contradict health science cultural competency standards (Rossi \& Lopez, 2017) and this should concern health educators. If students endorsing binary, essentialistic conceptions of sex/gender become practicing healthcare providers, any LGBTQ+ patients are at increased risk of receiving inaccurate information as well as experiencing microaggressions at that practice, since providers can hold implicit bias against LGBTQ+ people even if they don't show explicit bias (Burke et al., 2015).

Unfortunately, the view that binary sex traits are essential, fixed categories while ignoring the effect of environment (i.e., culture) on the body is commonly how textbooks and classroom materials present these ideas (Ah-King, 2013b; Bazzul \& Sykes, 2011; Campo-Engelstein \& Johnson, 2014). Beyond the impact on non-binary-genderconforming students of being rendered invisible in scientific contexts, their exclusion also impedes gender-conforming students from developing more complex, current understandings of sex/gender (de Bruin, 2020; Versteeg et al., 2020). The persistence of this perspective illuminates the need for textbooks to update these units to include the most recent findings about the complexity of sex/gender and add inclusive learning materials at all academic levels.

\section{Limitations}

Although this study meets all requirements for Q-methodology, a sample from a single university is a limitation. This Q-sort offers a snapshot of the subjectivities present in early undergraduate students from this specific university at the point in time that the study took place; it is not the type of analysis used to make broad associations. Using the 
Q-methodology itself is limiting in its small sample size because it does not leave room to robustly compare demographic groups within the Q-sort results. This Q-set described nearly $40 \%$ of the sex/gender beliefs in this undergraduate population with minimal overlap between the two factors, but a Q-set is always limited by the nature of the statements that constitute the sample. There is always a trade-off between participant patience and breadth of the Q-set when designing a Q-sort. My Q-set may not have included statements that describe other conceptualizations of sex/gender.

\section{Conclusions}

By expanding upon prior research focused mainly on gender roles and/or gender essentialism (Broussard \& Warner, 2019; Nagoshi et al., 2008; Stefurak et al., 2010; Whitley \& Ægisdóttir, 2000) I gained insights into contemporary views held by college undergraduates that illuminated educational needs related to teaching about sex/gender at the college level. Given the growing cultural acceptance of sex/gender diversity, and the known negative implications of gender essentialistic thinking, overt attention to gender essentialism and updated notions of sex/gender are needed in biology curricula. The focus on reducing human sexes into two discrete categories predicated on chromosomes or gonads fails to provide students with a comprehensive definition of sex/gender and neglects the effects of (physical and cultural) environment on the physical form. The over-emphasis of the role of genes as essential determinates of sex while ignoring environmental effects on gene regulation and function perpetuates the myth of a normative (read heteronormative, cis-gendered) body with immutable traits dictated by biological factors. 
Although sex determination in humans results from a complex of interacting biochemical pathways, the complexity of a topic has not been shown to alter students' uptake of material, as seen in the context of genetics (Wiley \& Klosterman, 2012). In fact, presenting the complexities of non-Mendelian genetics decreased gender essentialism associated with genetic determinism (Donovan et al., 2019). Delaying introduction of these ideas, especially for pre-healthcare students, serves to promote a less-inclusive science education and may have long lasting consequences in terms of cultural competencies of practicing healthcare workers.

Informed consent: Informed consent was obtained from all individual participants included in the study.

Ethical approval: All procedures performed in studies involving human participants were in accordance with the ethical standards of the institutional and/or national research committee (IRB Number: 17.1016) and with the 1964 Helsinki declaration and its later amendments or comparable ethical standards. 


\section{CHAPTER II}

\section{LGBTQIA+ INVISIBILITY IN UNDERGRADUATE NURSING ANATOMY/PHYSIOLOGY TEXTBOOKS}

\section{INTRODUCTION}

A fundamental aspect of professional nursing, caring requires empathy, connection, and patient-centered application of these traits (AACN, 2008). This has manifested as cultural competencies, or the practical skills that reflect a healthcare provider's ability to provide culturally sensitive, ethical care with awareness of the diversity of human populations (Brennan, Barnsteiner, de Leon Siantz, Cotter, \& Everett, 2012). For some time cultural competence focused on ethnicity or religious background (Cuellar, Brennan, Vito, \& de Leon Siantz, 2008) but recent scholarship in nursing education has called for more attention to lesbian, gay, bisexual, transgender, queer or questioning, intersex, asexual, and other sexual and gender identities (LGBTQIA+) in nursing curricula (Burton, Nolasco, \& Holmes, 2020) in concert with the integration of LGBTQIA+ health needs throughout the undergraduate curriculum (McNiel \& Elertson, 2018), and the recruitment and retention of LGBTQIA+ faculty and practitioners (Burke et al., 2015; Phelan et al., 2017). This aligns with fundamental principles of nursing ethics that advance justice and offer respect to all people (AACN, 2008) while contributing to safe and supportive learning environments for LGBTQIA+ healthcare 
students (Reiss, 2019). In accord with these principles, I suggest that educators need to consider if textbooks used in introductory undergraduate nursing courses are LGBTQIA+ inclusive.

\section{Sexuality, Sex and Gender}

I use the acronym "LGBTQIA+" to describe this population because it includes gender identity, sexualities, and diverse sex development; characteristics that distinguish members of the community from non-LGBTQIA+ people. Terms like lesbian, gay, bisexual, and asexual all refer to sexuality or sexual orientation; this is an individual's attractions and desires and, like the other LGBTQIA+ identities, this category goes beyond those commonly listed in the acronym (Burton et al., 2020). Though sex and gender are often used synonymously in biomedical contexts (Hammarstrom \& Annandale, 2012), typically sex refers to the material and biological characteristics of the body, and gender is the collective behavioral, social, and psychological characteristics of an individual (Frohard-Dourlent, Dobson, Clark, Doull, \& Saewyc, 2017). Intersex people are those whose chromosomes, hormones, or gonads do not match binary conceptions of human sex traits (Kessler, 1990).

Gender is a complex expression unique to the individual and need not fall along lines of feminine/masculine, although this understanding of gender has been historically neglected in health science research (Frohard-Dourlent et al., 2017). In contrast to a cisgendered person whose gender identity aligns with the sex assigned at birth, transgender and gender non-binary people are those whose gender identity does not align with the sex assigned to them at birth (Makadon et al., 2015). Someone may identify as transgender/non-binary, solely non-binary, or solely transgender, depending on their 
acceptance of binary gender categories (Frohard-Dourlent et al., 2017). For a comprehensive glossary of these terms presented in the context of nursing education, I recommend referring to Burton et al. (2020).

Despite differences among sex, gender identity, and sexuality (Mayer, 2016), from a medical perspective LGBTQIA+ people are a unique population because they manifest similar health disparities for similar reasons (Bazzul \& Sykes, 2011). The Fenway Guide to LGBT Health characterizes these disparities as resulting from barriers to care that occur at the individual, provider, and systemic levels and interact with other sociocultural factors (Makadon et al., 2015). Compared with cisgendered or heterosexual people, LGBTQIA+ individuals have an increased risk of physical and sexual assault, sexually transmitted infections (STIs), and mental health concerns (including but not limited to: depression, anxiety, post-traumatic stress disorder (PTSD), and suicide) (Makadon et al., 2015; Mayer, 2016). In fact, 40\% of transgender adults report having made a suicide attempt, and $92 \%$ of them made that attempt before the age of 25 (James et al., 2016). LGTBQIA+ people are also more likely to delay care or avoid it entirely due to fear of mistreatment from their healthcare providers (Makadon et al., 2015). For example, a provider that assumes their male patient that is sexually active is in a relationship with a woman will alienate a gay man, reducing the likelihood that patient will return (Nadal et al., 2016).

\section{Healthcare Education}

Although these health disparities and their association with social expectations are well established, health science education has been criticized for a lack of attention to LGBTQIA+ health needs (Brennan et al., 2012; Chinn, 2013; Eliason, 1998; Röndahl, 
Innala, \& Carlsson, 2004; Strong \& Folse, 2014). Adding LGBTQIA+ materials to the curriculum can improve nursing education by normalizing "the recognition and inclusion of LGBTQIA+ populations in the care environment and [supporting] students in learning about specific needs of LGBTQIA+ persons in this environment" (Burton et al., 2020, p. 5). But little time in an already packed curriculum is devoted to teaching cultural competencies related to LGBTQIA+ populations (Lim, Johnson, \& Eliason, 2015) and when material is included it is often superficial or solely references LGBTQIA+ in disease contexts (like HIV/AIDS) (De Guzman, Moukoulou, Scott, \& Zerwic, 2018). Beyond the need to train nurses to give culturally sensitive care to LGBTQIA+ patients, it is important to consider how classroom materials represent this diverse community. If learning environments fail to recognize and include LGBTQIA+ experiences, LGBTQIA+ students may be driven from those settings (Reiss, 2019), harming efforts to increase diversity and representation among nursing practitioners and faculty (Burke et al., 2015).

Much of the scholarship on LGBTQIA+ inclusion in nursing focuses on the development or improvement of the practitioner's cultural competence, the skills, knowledges, attitudes, and practices necessary to offer culturally sensitive care. (Brennan et al., 2012; Carabez et al., 2015; Cuellar et al., 2008; Kellett \& Fitton, 2017; McNiel \& Elertson, 2018; Traister, 2020). Exposure to LGBTQIA+ people and specific training in cultural competencies can reduce explicit bias, although it does not resolve the dramatically higher rates of implicit bias that emerges in practice (Burke et al., 2015). One of the key facets of competence (be it LGTBQIA+, ethnic, or religious) is knowledge (Rossi \& Lopez, 2017). Nurses cannot develop the skills and attitudes 
necessary to meet the professional standards for practice without adequate knowledge of LGTBQIA+ people.

From a teaching perspective, it is generally accepted that multiple exposures to accurate material are necessary for learning (Kang, 2016). This approach, called spaced repetition, improves the acquisition and retention of knowledge, particularly for topics that are complex (like human sex determination) (Kang, 2016). Furthermore, providing

details about intricate processes can reduce misconceptions as students learn the material (Wiley \& Klosterman, 2012). However, the accuracy of the material also matters, since it is more difficult to correct misconceptions in a student's prior knowledge rather than a lack of knowledge (Braasch, Goldman, \& Wiley, 2013). This is particularly relevant in the context of science knowledge because the body of knowledge is meant to change in response to advances in our understanding (Helen E. Longino, 1990).

\section{Body of Knowledge}

As the body of science knowledge changes, educators must update classroom materials (Rossi \& Lopez, 2017). A number of factors cast doubt on the validity of the binary sex/gender model prevalent in science (Fausto-Sterling, 2018). First, by their very existence, intersex people challenge the sex binary model (Kessler, 1990). And, although the frequency of noticeable intersex traits (i.e., visible, external genitalia) is between 1 in 1500 and 1 in 2000 live births (Fausto-Sterling, 2000), it is likely that the actual frequency of intersex characteristics is far greater than estimated because cryptic intersex traits may only be detected much later in a person's life (if at all) (Lee et al., 2013; Prakash, Khurana, \& Narula, 2009). Additionally, since intersex people can conceive 
offspring, unless they are sterilized at a young age (Kessler, 1990), these traits can also occur in their children (Dumic et al., 2008).

Furthermore, the sex binary model is strongly influenced by the historical malefocus of science research, which limited the development of knowledge about 'female' topics (European Commission. Directorate-General for, 2013; Zucker \& Beery, 2010). For example, although the motility of sperm is well established, researchers have only recently begun to explore the oocyte's active role in selecting sperm for fertilization (Firman, 2018; Fitzpatrick et al., 2020). When considering the collective characteristics used to define 'sex,' such as gonads, chromosomes, hormones, genitalia, and secondary sex characteristics, these are more accurately described as occurring along a spectrum rather than discrete and internally consistent categories of male/female (Fausto-Sterling, 2018; Stévant et al., 2018).

A commonly cited sex-based difference, 'sex hormones' are said to occur at significantly different levels along female/male lines (Hyde et al., 2018). In actuality, the main hormonal distinctions more accurately fall along 'pregnant people' and 'nonpregnant people', with non-pregnant females having 'sex hormone' levels more similar to those described in males (Hyde et al., 2018; Tulchinsky et al., 1972). Specifically, studies show that average levels of estradiol and progesterone do not significantly differ across human males and females (Liening et al., 2010; van Anders, 2010), the 'female hormone' estradiol plays a critical role in male sexual function (Schulster, Bernie, \& Ramasamy, 2016), there is considerable overlap in adult testosterone levels (Granger, Shirtcliff, Booth, Kivlighan, \& Schwartz, 2004), and testosterone (rather than estrogen) is the most abundant active 'sex hormone' throughout a female's lifetime (R. Glaser \& Dimitrakakis, 
2013). Furthermore, despite research seeking to link hormone levels with brain structures and aspects of personal identity (Choleris et al., 2018; Nguyen et al., 2019), there is no evidence to suggest brain differences can consistently be correlated to sexuality, sex, or gender identity (Hyde et al., 2018; McCredie, 2011). Advances in genetics has shown how environmental effects can mediate changes in gene expression (Stévant et al., 2018), one way that social and cultural differences (i.e., gender norms) can influence healthcare outcomes (Health, 2011).

\section{Anatomy and Physiology}

To determine what type of content undergraduate nursing students received about LGBTQIA+ health concerns, I considered how nursing anatomy/physiology textbooks present LGBTQIA+ people. I focused on human anatomy/physiology for nurses because this is a common first or second year course for all undergraduate nursing students and also includes concepts related to student understanding of sex/gender and sexuality. Human anatomy/physiology courses are ripe for both good and misinformation about LGBTQIA+ populations because they typically include lessons on sex determination, sexual reproduction, reproductive systems and sex characteristics that may not include updated information about these topics.

Textbooks are important to study because they shape what is taught in the classroom (Fifield \& Letts, 2019) and communicate to students what material is and is not relevant in their field of study. Decades of previous efforts analyzing biology or medical textbooks for gender bias and LGBTQIA+ inclusivity have repeatedly detected problematic themes: they omit LGBTQIA+ identities, emphasize a male norm, scientifically validate gender roles and stereotypes, or construct sex/gender along a strict 
binary (Ah-King, 2013b; Alexanderson, Wingren, \& Rosdahl, 1998; Bazzul \& Sykes, 2011; Campo-Engelstein \& Johnson, 2014; De Guzman et al., 2018; Lawrence \& Bendixen, 1992; Mendelsohn, Nieman, Isaacs, Lee, \& Levison, 1994; Parker, Larkin, \& Cockburn, 2017; Røthing, 2017; Snyder \& Broadway, 2004). Medical textbooks have been criticized for their gender bias and androcentric norms (Alexanderson et al., 1998; Lawrence \& Bendixen, 1992; Mendelsohn et al., 1994; Parker et al., 2017). On the other hand, biology textbooks across many academic levels have been criticized for presentations of sexual relationships that naturalize heteronormative sex encounters, the perpetuation of gender norms as scientifically validated, and the omission of LGBTQIA+ topics from discussion of human biology outside of disease contexts (Ah-King, 2013b; Bazzul \& Sykes, 2011; Campo-Engelstein \& Johnson, 2014; De Guzman et al., 2018; Røthing, 2017; Snyder \& Broadway, 2004).

In nursing, health assessment textbooks portrayed LGBTQIA+ people only in general terms or in disease contexts (De Guzman et al., 2018). De Guzman et al. (2018) found that two widely adopted health assessment textbooks had very few total pages with at least one sentence that covered LGBTQIA+ health and assessment: 11 of 896 pages in one book and 14 of 736 pages in the other. This omission communicates to students in general and LGBTQIA+ populations in particular that members of this community do not warrant inclusion in the body of science knowledge unless they are the examples of abnormality or pathology (Santavicca et al., 2019). Education researchers argue that LGBTQIA+ competence and inclusion in the classroom cannot be attained if students do not see comprehensive LGBTQIA+ representation in their textbooks (De Guzman et al., 2018; Røthing, 2017). 


\section{Queer Theory}

I adopted queer theory as my theoretical framework for the textbook content analysis. Queer theory traces its lineage to feminist works that challenged the socially constructed nature of gender roles, gendered bodies (Butler, 1990; Rubin, 1975), and cultural mores that naturalize male-focused, heterosexual perspectives as the moral or scientific normal (Birke, 2000; Foucault, 1978). There is not a singular definition of queer theory, but in practice it operates by "deconstructing the socially constructed aspects of identity, fracturing binaries, and interrupting heteronormativity" (Snyder \& Broadway, 2004, p. 619). This is not a "gay agenda" (Snyder \& Broadway, 2004, p. 619), but rather seeks to apply a transformative perspective to nursing education and practice (Burton et al., 2020) and more accurately portray the most current scientific understandings.

As an active process, applying queer theory, i.e., queering something (like textbooks), involves deviating from a normalized view promoted by the status quo (Snyder \& Broadway, 2004). In the classroom, queering sex/gender and sexuality enables educators to "provide a curriculum and a pedagogy more appropriate for all students" (Reiss, 2019, p. 257). Looking at the textbooks used in introductory nursing anatomy/physiology classes through the lens of queer theory pushes back against the biomedical construct of a 'normal human' body and asks who is excluded and included in the language and images used to convey scientific concepts. Although queer theory has multiple dimensions that can be applied to critical analysis (Ferguson, 2018), to limit the scope of my study I focused on how heteronormativity, sex/gender binaries, androcentric content, and gender norms manifest in anatomy/physiology textbooks. 


\section{Heteronormativity}

Science presentations of human sexuality are heteronormative in that they assume heterosexual attractions and desires (Scholer, 2002). In healthcare practice, heteronormativity is associated with systemic and provider barriers to care (Dean et al., 2016), because presuming heterosexuality creates a non-inclusive healthcare environment for LGBTQIA+ patients (Bidell \& Stepleman, 2017). Of relevance to my study, queering challenges the heterosexual perspective that describes the act of sex based on penis-invagina intercourse. It recognizes that, as a consequence of this 'heteronormative' perspective, people whose pairings will not result in reproduction are seen as "unnatural" and thus outside the purview of medical science (Ah-King, 2013b) or in need of correction (such as conversion therapy) to emulate a 'natural' state (Bidell \& Stepleman, 2017). This framework also calls attention to the exclusion of LGBTQIA+ people from discussions of reproductive technologies that may play pivotal roles in their family planning efforts (F. E. Council, 2019).

\section{Sex/gender binary}

Rather than being an objective truth of the human experience, the human sex binary functions as a tool for perpetuating a natural/unnatural dichotomy that polices sexualities or bodies that fall outside this norm (Burton et al., 2020; Gilbert, 2001) and neglects the variability and plasticity of human sex traits (Stévant et al., 2018) while ignoring the way social factors, like gender norms, contributed to these ideas (Birke, 2000). For example, in a binary system, intersex and other non-binary bodies are considered 'unnatural' so they are framed as "neither man nor woman" or a "third-sex" (Santavicca et al., 2019, p. 303). But this view ignores the significant overlap between the 
two bimodal categories of male and female sex traits (McCredie, 2011), and both neglects contemporary understandings of how gonadal state is maintained throughout life (Minkina et al., 2014; Uhlenhaut et al., 2009) and the relative frequency that intersex characteristics occur in humans (about 1.7\% of births) (Fausto-Sterling, 2000). Around 1 in 2000 infants (approximately $0.05 \%$ of people) are born with visible genital differences (Fausto-Sterling, 2000) that have led medical providers to urge parents to subject their infant to unnecessary and invasive medical procedures, including forced sterilization, to conform with the male/female binary (Kessler, 1990).

Biology has also been criticized for perpetuating a binary, biological conception of gender (Lemke, 2011). In many biology textbooks, language equating biological sex and social gender roles manifests in the conflation of the terms sex (i.e., females/males) and gender (i.e., women/men or girls/boys) (Campo-Engelstein \& Johnson, 2014). As I did in chapter one, rather than separating or interchanging sex and gender, I continue to use sex/gender in reflection of the dynamic and continuous ways that environment and body co-create sex/gender (Birke, 2000; Fausto-Sterling, 2012). Within my theoretical framing, acknowledgment of this sex/gender entanglement is important because it rejects the nature or nurture and science or social dichotomies historically used to justify the omission of topics judged to be outside embedded cultural norms (Sedgwick, 2008). However, there will be cases where I separate the concepts to discuss the ways that sex, gender, or sex/gender are characterized in the textbooks I analyzed, like when sex and gender are conflated in a scientific context (Hammarstrom \& Annandale, 2012).

\section{Androcentrism}


An historical male, or androcentric, focus of health science research limited the development of scientifically-validated knowledge about female bodies and experiences and how that impacts health (European Commission. Directorate-General for, 2013; Zucker \& Beery, 2010). Consequently, the studies that inform biomedical textbooks often exclude females (Zucker \& Beery, 2010). Be it text or visual representations, in human anatomy/physiology textbooks males are the central focus, females the periphery, and females exist only for comparison to the normative male (Lawrence \& Bendixen, 1992; Mendelsohn et al., 1994; Parker et al., 2017). This 'male-first' perspective positions people with female and non-binary identities as "other" (Frohard-Dourlent et al., 2017; Gilbert, 2001). Adopting a queer lens refocuses both healthcare and educational efforts on these marginalized identities and encourages equity in representation in nursing materials.

\section{Gender Norms}

By queering science materials I reveal how stereotypical social behaviors are perpetuated in classrooms and curricula where male systems are "active and streamlined" but female systems are passive and with little autonomy (Reiss, 2019, p. 259). Queer theory critiques how reproduction and gestation are cast as female responsibilities, consistent with the expectation that women function to produce offspring (CampoEngelstein \& Johnson, 2014) while ignoring non-binary and transgender identities in considerations of reproduction (and perpetuating heteronormativity).

At the foundation of these gendered presentations is the notion that essential, gender-specific characteristics like behaviors and appearances are biological, fixed, and natural (Bohan, 1993) which often manifests in stereotypes justified by scientific claims, 
like the suggestion that there are essential differences in brain structures between men and women that are the result of biological (rather than environmental) factors (Hyde et al., 2018; Rippon, 2019). From an educational perspective, gender essential views are associated with stereotyping, prejudice and discrimination (both within and between groups) (Coleman \& Hong, 2008; Heyman \& Giles, 2006), greater difficulty accepting LGBTQIA+ peers (Broussard \& Warner, 2019), and impede the development of cultural competence (Fuller, 2002). On the other hand, a successful application of cultural knowledge would be the avoidance of essentialism, since it is linked with stereotypes that can be harmful to patients (Papadopoulos \& Lees, 2002).

\section{Research Questions and Predictions}

Based on a queer theory framework and the issues identified by researchers in both nursing education and critical analysis, I developed research questions to guide my inquiry:

1) Do four widely adopted nursing anatomy/physiology textbooks contain presentations of reproductive subjects that promotes heteronormativity, sex/gender binaries, androcentrism, and/or gender norms? Alternatively, do the textbooks include references to LGTBQIA+ populations in positive terms that resist rigid binaries and promote equal representation and non-stereotypical notions of sex/gender?

2) Are there differences in how these themes manifest in the four textbooks?

I predict that books will continue the historical silence of the medical community regarding LGBTQIA+ health needs (De Guzman et al., 2018; McNiel \& Elertson, 2018), present binary conceptions of sex/gender (Bazzul \& Sykes, 2011), describe the act of sex as heterosexual and reproductive (Ah-King, 2013b; Røthing, 2017), and use language and 
images that convey sociocultural gender roles as scientifically imperative (Lawrence \& Bendixen, 1992; Mendelsohn et al., 1994; Parker et al., 2017).

\section{MATERIALS AND METHODS}

To establish the scope of my analysis (Neuendorf, 2011), I used U.S. News' 2019 rankings to identify universities with top ranked nursing master's programs in the USA. I then used the university's website to determine the textbook adopted in the nursing anatomy and physiology courses (see Table 10). Among the top five programs I found textbook information for four. In all cases, I used the most recent electronic (pdf) edition of the textbook available when this project began in 2018. The textbooks I chose are required texts for undergraduate and graduate courses in nursing programs in public and private institutions. Based on publicly available program enrollments, at these four universities alone nearly 2,500 students each year will use one of these four textbooks as an undergraduate student. I designated the textbooks A, B, C, and D for ease of reference.

\section{Table 10}

\section{Undergraduate Nursing Anatomy/Physiology Textbooks Analyzed}

School Name \& Rank ID Textbook

1) Johns Hopkins University

3) University of Pennsylvania

4) Emory University

5) University of North Carolina - Chapel Hill
Saladin, K. S., Gan, C. A., \& Cushman, H. N. (2018).

A Anatomy \& physiology: the unity of form and function (8th ed.). McGraw-Hill

B Marieb, E. N., \& Hoehn, K. (2018). Human anatomy \& physiology (11th ed.). Pearson

C Tortora, G. J., \& Derrickson, B. (2017). Tortora's principles of anatomy \& physiology (15th ed.). John Wiley \& Sons VanPutte, C. L., Regan, J. L., Russo, A. F., Seeley, R. R.,

D Stephens, T., \& Tate, P. (2017). Seeley's anatomy and physiology (11th ed.). McGraw-Hill

I narrowed the scope of my textbook analysis (Neuendorf, 2011) to those textbook sections most likely to include content on sex/gender and sexuality. These 
included: reproductive system anatomy/physiology, sex determination, human development, steroid hormones, and human sexuality. I utilized the index to identify pages in each book that contained or were related to these key concepts. Although I always included the reproduction and development units/chapters in my analysis, my review was not limited to these chapters because key concepts were spread among differently organized sections in each book.

To be certain I did not miss any un-indexed mentions of LGBTQIA+ identities I digitally conducted a constrained search (i.e., terms were placed inside parentheses to limit related search terms from entering the results) to evaluate the presence/absence within the books of common terms used to refer to these populations. I chose "lesbian", "gay", "bisexual", and "transgender" based on the Fenway Guide to Lesbian, Gay, Bisexual, and Transgender Health definition of sexual minorities and I elected to include "heterosexual", "homosexual", and "intersex" to represent the language more commonly used in a medical/health science context (Health, 2011). Sections of textbooks that included these terms but were not already included in my selection of textbook materials were included in analyses.

\section{Content Analysis}

For the content analysis, two researchers highlighted sentences, paragraphs, section titles, figures, images, or captions containing examples of heteronormativity, sex/gender binary, androcentrism, and gender norms. While using descriptive coding with these pre-determined categories (Saldaña, 2016) to categorize text excerpts, images, and figures to the four themes, I noticed that some excerpts overlapped themes. For example, language that describes the act of sex as the male "penetrating" while a female 
"receives" is both heteronormative and perpetuates gender norms, so it was described as exhibiting both themes.

To establish inter-rater reliability (IR) for the descriptive coding two researchers independently categorized text, figure legends, and figures, compared results and determined the proportion of the text that was coded similarly. Excerpts were coded iteratively until IR for book A was $90 \%$ or greater. Next, we conducted a second stage of coding to determine the context in which gender and sexuality language emerged in the text to identify subthemes nested within the four themes and developed a codebook to guide subsequent analyses (Table 11). Two researchers examined excerpts from each book and described the context used to present them; ultimately these were distilled into three subthemes within each theme. After subcoding excepts from all four texts, we returned to books A-C to comprehensively apply the subcodes to each one. I again scored interrater reliability as proportion coded similarly and achieved IR greater than $90 \%$ for the second stage coding.

\section{Table 11}

Themes, Subthemes, and Examples of Anatomy/physiology Textbook Content

\begin{tabular}{|c|c|}
\hline Theme & Subtheme and Example \\
\hline \multirow[t]{3}{*}{ Heteronormativity } & $\begin{array}{l}\text { Purpose of sex (act) } \\
\text { "The chief phases of the male sexual response are: 1) Erection of the } \\
\text { penis, which allows it to penetrate the female vagina 2) Ejaculation, } \\
\text { which expels semen into the vagina." (book B, p. 1067) }\end{array}$ \\
\hline & $\begin{array}{l}\text { Function of sex organs and systems } \\
\text { "It [the vagina] is the receptacle for the penis during sexual } \\
\text { intercourse..." (book C, p. 1081) }\end{array}$ \\
\hline & $\begin{array}{l}\text { LGBTQIA + identities or healthcare needs mentioned } \\
\text { "In the United States, most cases [of HIV] occur in men who have sex } \\
\text { with other men..." (book A, p. 838) }\end{array}$ \\
\hline Sex/gender binary & Two (essentially different) sexes \\
\hline
\end{tabular}




\begin{tabular}{|c|c|}
\hline & $\begin{array}{l}\text { First unit in the male reproduction chapter is titled "The Two Sexes" } \\
\text { (book A, p. 1029) }\end{array}$ \\
\hline & $\begin{array}{l}\text { Intersex inclusion/exclusion } \\
\text { "These individuals failed to develop normally as males because their } \\
\text { SRY gene was defective." (book C, p. 1141) }\end{array}$ \\
\hline & $\begin{array}{l}\text { Sex and gender conflated } \\
\text { "Gender is a common way that we classify people. Just think of all the } \\
\text { times you have had to check a box for male or female while filling out } \\
\text { a form... (book D, p.1029) }\end{array}$ \\
\hline \multirow[t]{3}{*}{ Androcentrism } & $\begin{array}{l}\text { Male-specific content receive more coverage in text/figures } \\
\text { "The neurological and vascular controls of the female response are } \\
\text { essentially the same as in the male and need not be repeated here." } \\
\text { (book A, p. 1076) }\end{array}$ \\
\hline & $\begin{array}{l}\text { Framing of homologies } \\
\text { "Each testis is approximately } 1.6 \text { inches long by } 1 \text { inch wide..." (book } \\
\text { B, p. 1048) versus "Shaped like an almond and about twice as large, } \\
\text { each ovary...." (book B, p. 1061) }\end{array}$ \\
\hline & $\begin{array}{l}\text { Androcentric language or examples } \\
\text { "Anyone lacking a Y is classified as female." (book A, p. 1026) }\end{array}$ \\
\hline \multirow[t]{3}{*}{ Gender Norms } & $\begin{array}{l}\text { Female depicted meek or passive; males as strong or active } \\
\text { Woman shown on her back with a penis inserted into her vagina to } \\
\text { illustrate female sexual response; same book illustrated the male sexual } \\
\text { response with the man standing upright (book A, p. } 1077 \text { and 1047) }\end{array}$ \\
\hline & $\begin{array}{l}\text { Reproduction framed as female role } \\
\text { "The reproductive system in the male serves to produce sperm and } \\
\text { introduce them into the female body. The female reproductive system } \\
\text { produces eggs, receives the sperm, provides a place for the union of } \\
\text { these gametes, harbors the fetus, gives birth, and nourishes the } \\
\text { offspring." (book A, p. 1026) }\end{array}$ \\
\hline & $\begin{array}{l}\text { Pregnancy concerns linked only to females } \\
\text { "'Do you know if it is a boy or a girl?' Expectant mothers answer this } \\
\text { question continuously throughout their pregnancies." (book D, p. 1029) }\end{array}$ \\
\hline
\end{tabular}

\section{Scoring Rubric}

I adopted the Gendered Language Rubric of Campo-Engelstein and Johnson

(2014), to quantitatively rank the books we reviewed; not to directly compare them but to

be able to have a fruitful discussion about the different ways sociocultural norms

manifest in science textbooks. I modified the rubric (Table 12) to include LGBTQIA+

representation by adding a category that considered presence/absence of LGBTQIA+ 
identities, the context of presentation, and assumption of heterosexuality as the key ideas

from our subthemes that were not already represented in the original scale.

\section{Table 12}

Gendered Language Rubric ${ }^{1}$

Scoring Scale

\begin{tabular}{|c|c|c|c|}
\hline Categories & Poor (1) & Passable (2) & Excellent (3) \\
\hline Structure & $\begin{array}{l}\text { Female gametes and/or } \\
\text { reproductive system } \\
\text { almost always passive; } \\
\text { male gametes or } \\
\text { reproductive system } \\
\text { placement always } \\
\text { comes before female }\end{array}$ & $\begin{array}{l}\text { Female gametes and/or } \\
\text { reproductive system } \\
\text { roughly equally passive } \\
\text { and active; male } \\
\text { gametes or reproductive } \\
\text { placement usually } \\
\text { comes before female }\end{array}$ & $\begin{array}{l}\text { Female gametes and/or } \\
\text { reproductive system } \\
\text { almost always active; } \\
\text { male gametes or } \\
\text { reproductive system } \\
\text { placement alternates } \\
\text { equally with female }\end{array}$ \\
\hline $\begin{array}{l}\text { Amount of } \\
\text { Information }\end{array}$ & $\begin{array}{l}\text { Explanations almost } \\
\text { always unequal; facts } \\
\text { almost always } \\
\text { unbalanced }\end{array}$ & $\begin{array}{l}\text { Explanations somewhat } \\
\text { unequal; facts } \\
\text { somewhat unbalanced }\end{array}$ & $\begin{array}{l}\text { Explanations always } \\
\text { equal; facts always } \\
\text { balanced }\end{array}$ \\
\hline Neutrality & $\begin{array}{l}\text { Frequent use of } \\
\text { unnecessary } \\
\text { commentary or } \\
\text { comparison; frequent } \\
\text { use of unbalanced } \\
\text { adjectives }\end{array}$ & $\begin{array}{l}\text { Infrequent use of } \\
\text { unnecessary } \\
\text { commentary or } \\
\text { comparison; infrequent } \\
\text { use of unbalanced } \\
\text { adjectives }\end{array}$ & $\begin{array}{l}\text { No unnecessary } \\
\text { commentary or } \\
\text { comparison; no } \\
\text { unbalanced adjectives }\end{array}$ \\
\hline $\begin{array}{l}\text { LGBTQIA+ } \\
\text { Inclusion }^{2}\end{array}$ & $\begin{array}{l}\text { LGBTQIA+ people are } \\
\text { not explicitly } \\
\text { mentioned in any way; } \\
\text { heterosexuality is } \\
\text { assumed }\end{array}$ & $\begin{array}{l}\text { Limited mention of } \\
\text { LGBTQIA+ people } \\
\text { (e.g., only in disease } \\
\text { contexts or examples of } \\
\text { abnormalities); } \\
\text { heterosexuality is } \\
\text { defined rather than } \\
\text { assumed }\end{array}$ & $\begin{array}{l}\text { LGBTQIA+ people are } \\
\text { explicitly mentioned in } \\
\text { multiple, non- } \\
\text { pathological contexts } \\
\text { (e.g., sexual responses } \\
\text { and reproductive } \\
\text { technologies) }\end{array}$ \\
\hline
\end{tabular}

${ }^{1}$ Campo-Engelstein and Johnson (2014)

${ }^{2}$ My addition to the scoring rubric.

With the addition of the LGBTQIA+ inclusion category the revised scoring rubric included all four broad themes I identified. Like the original rubric, the intra-category scores ranged from 1-3 and I used these to generate an average score to describe each book overall. I characterized these scores as poor (1), passable (2), and excellent (3) for 
each category rather than using "worst" and "best" like Campo-Engelstein and Johnson (2014). Note that an "in between" score would be possible if the researchers determined it would best describe the content. For example, if a book defined heterosexuality but made no explicit mention of LGBTQIA+ people it could be scored as 1.5 in the LGBTQIA+ Inclusion category. An overall, average score of 3 would mean that the book did not use androcentric, gendered, or heteronormative language, examples, and structures and discussed LGBTQIA+ populations in normative contexts. On the other hand, the lowest possible average score of 1 would represent a book that was found to present a solely heteronormative, male-focused, gender essential perspective and entirely omit LGBTQIA+ populations.

As with the theme coding, the quantitative scoring was conducted independently by two researchers using the same excerpts as the content analysis. We assigned scores for each rubric category independently, using the examples from the text to support the assigned scores. We compared our individual scores for all four textbooks for consensus (Table 13) based on the scoring scale parameters and found that we had attained 94\% IR for this stage, measured as percent scored similarly. We discussed examples and the scoring rubric until we agreed on the score awarded in all rubric categories.

\section{Table 13}

Consensus Textbook Scores

\begin{tabular}{ccccccc} 
Textbook & Year & Structure & $\begin{array}{c}\text { Amount } \\
\text { of Info }\end{array}$ & Neutrality & $\begin{array}{c}\text { LGBTQIA+ } \\
\text { Inclusion }\end{array}$ & Average \\
\hline A & 2018 & 1 & 1 & 1 & 2 & 1.25 \\
B & 2018 & 1 & 2 & 1 & 2 & 1.5 \\
C & 2017 & 2 & 2 & 2 & 1 & 1.75 \\
D & 2017 & 2 & 3 & 2 & 1 & 2 \\
\hline
\end{tabular}




\section{RESULTS}

Despite the calls for LGBTQIA+ representation in nursing curricula, I found that these four, commonly used books all assumed heterosexuality and none of the books presented same-sex encounters in a positive manner, if mentioned at all. This omission does not align with the fundamental ethnical principles of nursing education and practice and hampers students' ability to develop cultural competence related to this demographic. Furthermore, none of the textbooks framed sex/gender as non-binary, instead conceptualizing it along a biologically essential male/female binary that again interferes with the development of cultural competence. All books reinforced cultural sex/gender norms as scientifically validated through language, figures, and formatting (e.g., using pink for female and blue for male).

\section{Heteronormativity}

All four books assumed heterosexuality by framing the purpose of sex as procreative, defining organ function in relation to heterosexual encounters, and excluding or pathologizing LGBTQIA+ people. None of the books mention same-sex couples in the text or depicted same-sex couples in images. Sexual intercourse was defined as a solely heterosexual, procreative encounter.

Each book framed the purpose of sex as reproductive when they claimed that the only completely reliable method of preventing pregnancy was to avoid all sexual intercourse (emphasis added) (book A, p. 1087; book B, p. 1119; book C, p. 1092; book D, p. 1068), thus defining intercourse as heterosexual. Heteronormativity also manifested in the language used to define the function of organs. The penis was consistently defined as a structure that "deposits" (book A, p. 1037; book C, p. 1076) or "delivers" (book B, 
p. 1050) sperm or semen specifically into "the female" (book A, p. 1026) or "the vagina" (book A, pp. 1037, 1048, 1061; book B, pp. 1053, 1066; book C, pp. 1067, 1076, 1081, 1091; book D, pp. 1054, 1064). Particularly in describing the functions of these systems, this subtheme overlapped with gender norms that reinforced the male as the active agent who "expels" (book B, p. 1053), “introduces” (book A, p. 1026), or "penetrates" (book B, p. 1053) the passive female who "receives" (book A, p. 1061; book B, p. 1066; book D, p. 1054) or is a "receptacle" (book C, p. 1081).

Though all the books assumed heterosexuality through their descriptions of the act of sex and the function of reproductive organ systems, only two books explicitly used the term heterosexual. Book $\mathrm{C}$ defined heterosexual intercourse in a way that excluded transgender identities while simultaneously placing non-heterosexual encounters outside of 'normal' coitus: "The insertion of the erect penis into the vagina is called heterosexual sexual intercourse or coitus" (p. 1067).

Book A used the term "heterosexual" three times: twice in the context of HIV and once in the context of reproductive assistance. "Heterosexual" was contrasted with "men who have sex with other men" (p. 838) or "heterosexual versus homosexual transmission" (p. 839). The sidebar, that highlighted assisted reproductive technologies entitled "Reproductive Technology_Making Babies in the Laboratory," established heterosexual readers as their target audience with the very first sentence, "Fertile heterosexual couples who have frequent intercourse and use no contraception have a 90\% chance of conceiving within 1 year" (book A, p. 1121) but did not mention how these technologies can help LGBTQIA+ people conceive. 
Book A was the only book to use the term homosexual but did so in the immune system chapter in the context of HIV risk. Texts occasionally used the more neutral term partner when describing sexual encounters, but framed it in an explicitly heteronormative context by associating ejaculation with a partner's vagina, e.g., "Reception of the ejaculate provides little stimulus for a female, especially if she is not already at the plateau phase; this is why a female partner does not automatically experience orgasm simultaneously with her partner" (book C, p. 1092). The only time book B used the term partner in the context of sexual encounters, it was heterosexual, "During ejaculation, a man expels millions of sperm into his partner's vagina" (p. 1093). Although other books mentioned partner in the context of sexual encounters and sexually transmitted infections or hormonal controls they implied 'heterosexual' before partner. For example, when describing the hormone oxytocin (OT), book A used the term partner immediately after describing oxytocin's role in "the propulsion of semen through the male reproductive tract and stimulating uterine contractions that help transport sperm up the female tract. OT also functions in feelings of sexual satisfaction and emotional bonding between partners" (p. 634-35). In these contexts, partner referred to a malefemale pairing for reproductive sexual encounters.

\section{Sex/gender binary}

All the books described sex/gender along a biologically essential female/male binary, framed intersex bodies as deviations from the female/male norm, and conflated sex and gender. Chapters and their subtopics were separated along a male/female binary. In book A, a sex binary was explicitly defined by the first unit in the male reproduction chapter entitled "The Two Sexes" (p. 1029). Only book C discussed sexual response as 
"Human Sexual Response" instead of separated into male and female. Sexes were defined based solely on the presence or absence of a Y chromosome, solidifying a binary view. "The two sex chromosomes - a large $\mathbf{X}$ chromosome and a smaller $\mathbf{Y}$

chromosome - determine the genetic sex of an individual" (book C, p. 1095). By using the term "destined", "If an egg is fertilized with an X-bearing sperm, it produces an XX zygote that is destined to become a female" (book A, p. 1027), this construction of genetic sex perpetuated the idea of essential sex traits and a male/female binary. It was notable that none of the textbooks mentioned that genes on chromosomes other than the $\mathrm{X}$ or $\mathrm{Y}$ also play pivotal roles in sexual development.

Like chromosomes, hormones were (binary) sexed and ascribed agency to create essentially different brains and bodies, "Sex hormones masculinize or feminize the brain..." (book B, p. 1099). Hormones and the genes for their production were linked directly to behavior:

“... genes may greatly affect such complex outcomes as behavior, since testosterone strongly influences such behaviors as aggression and sex drive. In short, DNA codes only for RNA and protein synthesis, yet it indirectly controls the synthesis of a much wider range of substances concerned with all aspects of anatomy, physiology, and behavior. (book A, p. 125)

Though book D associated testosterone directly with behavior, "It [testosterone] also influences behavior," (book D, p. 1045) it later qualified this claim by introducing other influences on behavior including estrogen: "Androgens and possibly estrogens affect cells in the brain, especially in the hypothalamus, to influence sexual behavior. However, androgens and estrogen alone do not control sex drive...Psychological factors 
also affect sexual behavior" (book D p. 1064). Notably, even when estrogens were mentioned in the context of sexual behavior their role was diminished relative testosterone (i.e., "androgens and possibly estrogens").

Whether the books defined female and male using genes, gonads, or hormones, they all represented intersex people as deviations from the binary norm. Although only book B explicitly used the term intersex, it used a simplified, narrow definition of intersex, contrasting intersex people against the norm of a binary sex: "Individuals with external genitalia that do not "match" their gonads are intersex. Intersex individuals sometimes have surgery to match their outer selves (external genitalia) with their inner selves (gonads)" (p. 1084). The other books implied the existence of deviations from the male/female binary by defining an explicitly normal form, e.g., "a normal female" (book D, p. 1113). Intersex bodies were described as occurring because of "defective" genes (book C, p. 1141) that resulted in "abnormalities" (book A, p. 1084). However, despite not using the term intersex within the text, there was an example of an intersex-inclusive image in book D. Meant to highlight the major endocrine organs, the image (book D, p. 577) included ovaries and testes within the same (male-bodied) anatomical outline rather than separating them into different drawings.

In addition to perpetuating a binary conception of human sexes that pathologizes intersex people, all four books conflated sex and gender in explicit and implicit ways. In Book A, the figure caption "Boy meets girl: the union of sperm and egg (SEM)" (book A, p. 1093) conflated gender (boy and girl) with sex (production of sperm and egg) in association an image of ovum and sperm. Other figure captions provided an explanation without gendered commentary, e.g., "Sperm surrounding an oocyte" (book B, p. 1093). 
Alongside the captions of images, I considered the messages embedded in the image choices for these models. These implied binary gendered expectations, like when textbook A color-coded embryonic development using blue and pink backgrounds for male and female gonad development, respectively (p. 1029).

Though book A never explicitly used the term gender in the body of the textbook, in the index under "Erythrocyte(s)" there was a subcategory "gender differences" (p. I19) that led to a paragraph that discussed differences between men and women (p. 677). Although the use of the terms "men and women" align with the use of gender rather than sex, the textbook does not make the same distinction anywhere else, despite interchanging "men and women" with "male and female" throughout the book and indicating conflation of sex and gender.

The remaining three textbooks also interchanged the terms "male and female" with "men and women," often within the same paragraph or description:

"The major event that signals puberty's onset in males is enlargement of the testes and scrotum between the ages of 8 and $14 \ldots$ ln the meantime, the young man has unexpected erections and occasional nocturnal emissions ("wet dreams") as his hormones surge and the hormonal control axis struggles to achieve a normal balance.” (Book B, p. 1084)

Books B and C displayed explicit conflation of sex/gender. For example, in book C, gender is described as a risk factor for osteoporosis because of differing levels of androgens and estrogens between males and females (book C, p. 154). And in book B, gender is used where sex would be more appropriate: 
"As the brain and spinal cord grow and mature throughout the prenatal period, gender-specific areas appear. For example, certain hypothalamic nuclei concerned with regulating typical male sexual behavior and clusters of neurons in the spinal that serve the external genitals are much larger in males.” (Book B, p. 482).

\section{Androcentrism}

Males were consistently mentioned first in the reproductive system units of all four books. Book A separated males and females into separate chapters, with a third chapter devoted to development. The other three books began their single reproductive systems chapter with males and concluded with females while also separating development into its own chapter.

As a result of the male-first structure, some topics received unequal coverage. For example, book B used 112 words to describe male puberty and only 43 words in the subsequent paragraph to describe female puberty (p. 1084). This also manifested in the way that book A divided "sexual response" by males versus females. Male sexual response received three pages of coverage while female response received two.

Furthermore, the index privileges male sexual response as the default/norm experience by subdividing male responses but not female:

Sexual response female, 1076, 1077

Sexual response male, 1046-1049

aging and, 1040-1041 anatomical foundations of, 1046 excitement phase of, 1047, 1048 neural control of, 1047 orgasm in, 1047, 1049 plateau phase of, 1048 refractory period of, 1049 resolution phase of, 1047, 1049 
Within the text itself, this disparity was dismissed because, "the neurological and vascular controls of the female response are essentially the same as in the male and need not be repeated here" (p. 1076).

Even when the word counts implied that female topics received more coverage, they contained references to the male systems that were not present in the male descriptions. For example, although book A appeared to give more representation to oogenesis (628 words) than spermatogenesis (475 words) in their separate chapters, none of the 475 words in the spermatogenesis unit mentioned oogenesis or oocytes. In the oogenesis section, $26 \%$ (166 words) were devoted to comparing female gametes to male gametes. In addition, the book immediately follows the spermatogenesis unit with one describing the spermatozoon while not describing the oocyte itself until the separate development chapter. While the unit describing spermatozoon did contain a single sentence (16 words) referencing penetration of the oocyte (book A, p. 1044), this made up only $6.1 \%$ of the total count (263 words).

Books also praised natural selection for creating prolific, small gametes without mentioning the features of oocytes that are just as intriguing: e.g., "The spermatozoon is an example, par excellence, of the unity of form and function — shaped by evolution for lightness, streamlining, motility, and the effective delivery of its cargo of DNA" (book A, p. 1026), "It seems that nature has made sure that the human species will not be endangered for lack of sperm!" (book B, 1054), and "Mature sperm cells are streamlined cellular 'torpedos' [sic]” (book B, p. 1053).

In books $\mathrm{B}$ and $\mathrm{C}$, androcentric narratives emerged through subtle omissions that privileged the male form over the female. "Each testis is approximately 1.6 inches long 
by 1 inch wide..." (book B, p. 1048) versus "Shaped like an almond and about twice as large, each ovary...." (book B, p. 1061) and "The testes are paired oval glands measuring about 2 in. long and 1 in. in diameter, a mass of 10-15 grams each" (book C, p. 1057) versus "The ovaries are paired glands that resemble unshelled almonds in size and shape..." (book C, p. 1070). In each example, the male is measured and quantified, and the female compared to an edible commodity.

In contrast, book D avoided androcentric bias by describing male and female organs similarly: "The testes are small, oval-shaped organs, each about 4-5 cm long" (p. 1033) and "The two ovaries are small organs about $2-3.5$ cm long and $1-1.5$ cm wide" (p. 1048). It did the best at presenting equivalent explanations within the text itself, discussing organs and their functions using detailed, balanced descriptions. It avoided discussing structural and functional homologies in reproductive organs within the body of the text. However, it did privilege males as the normative body in the glossary when it defined labial structures: "labium majus; pl. labia majora - One of two rounded folds of skin surrounding the labia minora and vestibule; homolog of the scrotum in males" (book D, p. G-13). The definition for the homologous male structure does not reference the female one: "scrotum; pl. scrota, scrotums - Musculocutaneous sac containing the testes" (book D, p. G-22). Regardless of where homologies are introduced in the textbook, all four books mentioned and used males 5-10 times as a comparison throughout the female reproductive systems, despite not making equivalent comparisons within the male dedicated sections.

Language used to characterize the differences between males and females often had an androcentric bias, such as the claim that "anyone lacking a $\mathrm{Y}$ is classified as 
female" (book A, p. 1026). This situates the female as "less than" the male as opposed to a male classified as lacking one $\mathrm{X}$ chromosomes. Females are again described in terms of "lacking' relative to a male norm during development:

"Both female and male embryos develop identically until about 7 weeks after fertilization. At that point, one or more genes set into motion a cascade of events that leads to the development of a male; in the absence of normal expression of the gene or genes, the female pattern of development occurs. It has been known since 1959 that the $\mathrm{Y}$ chromosome is needed to initiate male development.” (book C, p. 1140-41)

Androcentrism also manifested in the types of examples chosen to describe shared traits, like when textbook A used only male animal examples to describe secondary sex characteristics: "From the call of a bullfrog to the tail of a peacock, these are well known in the animal kingdom" (book A, p. 1027). The female was left out of the description of secondary sex characteristics.

When describing the sex act, ejaculation was a male characteristic: "Ejaculation is the propulsion of semen from the male duct system" (book B, p. 1054). Only book A introduced the concept of ejaculation in females but placed it in quotation marks, which it never did when describing the default ejaculate associated with males. "The anal and urethral sphincters constrict, and the paraurethral glands, homologous to the prostate, sometimes expel copious fluid similar to prostatic fluid ("female ejaculation")" (book A, p. 1076). 


\section{Gender norms}

Females were often framed as passive, nurturing figures and males as virile, strong figures within the four textbooks. For example, women were depicted in images holding offspring whereas male forms were shown as muscular and strong (but uninvolved in childcare). This framing was not restricted to discussions of sex-based differences in muscles mass (which would be a reasonable context to illustrate relative muscle size). Rather, this was observed in the images chosen for chapter headers, within sidebars illustrating clinical implications or deeper insight, and in the figures used to depict key concepts.

Books A and B depicted the female reproductive system as passive; receiving the actions of the male: "... a sperm locates and fertilizes the egg” (book A, p. 1094). Sperm are active: "The activated sperm now thrash with their tails and crawl up the mucosa of the vagina and uterus" (book A, p. 1046). Book C described ejaculation as "the powerful release of semen..." (p. 1067). They used language to describe sperm or egg that conveyed cultural expectations or anthropomorphized specific cells: "The small motile one-little more than DNA with a propeller-is the sperm (spermatozoon), and the large nutrient-laden one is the egg (ovum)" (book A, p. 1026) or "Sperm "pack" lightly-they only carry what they absolutely need" (book B, p. 1072).

While books C and D had occasional examples of the female system being active, in book $\mathrm{C}$ the activity of the female system relied on the male system stimulating the female to shift from passive to active state:

The passage of sperm through the rest of the uterus and then into the uterine tube results mainly from contractions of the walls of these organs. Prostaglandins in 
semen are believed to stimulate uterine motility at the time of intercourse and to aid in the movement of sperm through the uterus and into the uterine tube (book C, p. 1108).

While factually correct, the one-sided nature of these portrayals diminish the powerful innate controls over sperm and fertility exerted by uterine systems and the ova itself (Firman, 2018; Fitzpatrick et al., 2020). Instead, the female action is given qualifiers to diminish its role. "The forces responsible for moving sperm cells through the female reproductive tract include the swimming ability of the sperm cells and possibly the muscular contractions of the uterus and the uterine tubes" (book D, p. 1064) (emphasis ours).

The female gamete does not "travel" or "migrate to" the uterus; they have no agency to "locate" or "unify" with sperm. Instead, an oocyte is a passive spectator with "feminine" features that and must be acted on by outside forces in order to perform its reproductive function: "The oocyte is carried toward the uterus by a combination of muscular peristalsis and the beating cilia" (book B, p. 1062). Even when active verbs are used to describe ovulation, "In the last day or so, the oocyte and cumulus break away and float freely in the antrum, ready for that momentous event in its life- ovulation" (book A, p. 1071), the ovum does not "emerge", or even "begin a journey." Gendered perspectives extend to the female reproductive system, e.g., "It [the uterine tube] swells with edema; its fimbriae envelop and caress the ovary in synchrony with the woman's heartbeat; and its cilia create a gentle current in the nearby peritoneal fluid" (book A, p. 1071). 
In addition to framing the act of sex as heterosexual, in these descriptions the vagina passively receives the active, penetrating penis during the sex process. This manifested in images as well. While only textbook A used figures to illustrate male and female sexual response, the male was shown standing upright in his images and no female form was included (p. 1047) but the woman was depicted supine (on her back) with a penis penetrating the vagina (p. 1077).

Images in the reproduction chapters exhibited gendered behaviors. In a pair of figures illustrating reproductive organs, the female reference figure (book C, p. 1078) in the bottom right of the image has her hip cocked in a provocative manner while the male reference (book C, p. 1065) in the top left of his image stands squarely in anatomical position. Other than implying gendered behaviors, the figures present equivalent representations of the respective anatomical structures.

Omissions also perpetuated gendered behaviors and appearances. For example, by mentioning anabolic steroids only in male contexts, the outcomes of using them, like increased muscle strength and improved athletic performance, were framed as explicitly male characteristics (book D, p. 1046).

Some books explicitly described the female role as a servant of reproduction: e.g., that females "transport or otherwise serve the needs of the reproductive cells and a developing fetus" (book B, p. 1060) and "The female reproductive system produces eggs, receives the sperm, provides a place for the union of these gametes, harbors the fetus, gives birth, and nourishes the offspring" (book A, p. 1028).

In some books, this was more implicit, such as the assumption that only mothers are asked about the sex/gender of their child. "Do you know if it is a boy or a girl?" 
Expectant mothers answer this throughout their pregnancies" (book D, p. 1029).

Furthermore, by framing gestation as a female act (e.g., expectant mothers rather than expectant parents), it excluded LGBTQIA+ people that are transgender, intersex, or nonbinary gender that are all capable of carrying offspring without identifying as a "mother". Only book D introduced the idea that the systems described in these units need not be framed as solely reproductive: "In addition, even in people who do not reproduce, the reproductive system plays important roles" (p. 1030).

All four books relegate the burdens of fertilization and gestation to females. Book A explicitly included pregnancy and childbirth in the female reproductive chapter rather than the separate development one. Books A and D placed contraception with the female reproductive systems, while only book B placed contraception in the development chapter. Although book $\mathrm{C}$ placed contraceptives in the reproductive chapter, it was after "human sexual response" and not a female-specific unit.

By centering reproduction as the female role, mothers alone were to blame for any issues that arose during gestation, even problems outside of reasonable control.

Alongside sensible admonishments to refrain from alcohol, drugs, and cigarettes, the mother must also be accountable for her exposures to pathogens:

"Because many potentially harmful substances can cross placental barriers and enter the fetal blood, a pregnant woman should be aware of what she is taking into her body, particularly during the embryonic period when the body's foundations are laid down. Teratogens, factors that may cause severe congenital abnormalities or even fetal death, include alcohol, nicotine, many drugs 
(anticoagulants, sedatives, antihypertensives, and others), and maternal

infections, particularly rubella." (Book B, p. 1113)

Notably, because pregnant people can catch rubella from any non-vaccinated person, reducing risk of 'maternal infections' like rubella requires vaccination of all people (CDC, 2019), not just those that plan to become pregnant. Book $\mathrm{C}$ also listed multiple examples of teratogens; all are framed as maternal concerns, including the disease exposures (p. 1127).

\section{Additional Observations}

During our review of textbook material, we made additional observations related to intersectional analyses that were outside the scope of my original research questions but are worth mentioning. People of color were seldom depicted in illustrations or photographs and when they were, the effect was less than positive. For example, textbook A directly compared an Asian woman and a chimpanzee side by side to illustrate facial expressions (p. 178) but used a white skin tone in the drawn figure comparing primate and human hands (p. 10). While not inherently problematic (depending on the context), we found that this was one of only five photographs or figures in chapters 1-6 that could be explicitly identified as including people of color, out of sixty-five total images or figures that had clearly identifiable skin. In the first chapter of book A, the single figure that included a person of color was a photograph of a black man ultrasound technician conducting a sonogram on a white family in a sidebar at the end of the chapter (book A, p. 23).

Most books used white skinned outlines in anatomical drawings, but book $\mathrm{C}$ used varied skin tones and appearances for the outlines of anatomical images while also 
including people of color as models in photographs. One series of images in book A used the same cartoonish drawing to illustrate different organ systems and changed only the skin tone for one model to give the appearance of a darker-skinned figure. However, they didn't change the features, hair, or other characteristics from when they used the white skin tone on the model. In contrast, textbook D used actual photographs, highlighting a diversity of human bodies. However, like books A and B the outlines often were lighter skinned, even if paired with a photograph of a person of color.

Book B omitted people of color when describing a general human characteristic - vellus hair. By describing this feature as "The body hair of children and adult females is pale, fine vellus hair" (p. 159), it ignores the darker hair found on people of color.

\section{Rubric Scoring}

Based on the original scoring rubric from Campo-Engelstein and Johnson (2014) that I modified to consider LGBTQIA+ inclusion, the textbooks analyzed had average scores from 1.25-2 (see Table 12). This indicated that none of the books avoided binary, androcentric, heteronormative depictions of human sex/gender and sexuality and also aligned with the findings from the qualitative content assessment. Because an 'excerpt' could inform more than one scoring category and could be a sentence, paragraph, phrase, image, figure, or caption, there would be little meaning to reporting word, sentence, or page counts. Instead, I chose to count the excerpts themselves as a single entity, be it an image or a three-sentence description from the text (Table 14).

Out of the four textbooks in the study, textbook D received the highest score. Based on the use of equivalent language for the genders and the balanced amount of information between male and female units while avoiding repeated, one-sided analogies, 
it contained the fewest issues with amount of information (see Table 14). However, it reinforced cultural expectations of heterosexuality and omitted LGBTQIA+ identities entirely. By contrast, the lowest scoring books all had 'passable' scores for LGBTQIA+ inclusion but only poor to passable scores in other categories. While they did mention homosexuality or intersex identities specifically, they did so in ways that alienate these individuals rather than including them.

\section{Table 14}

\section{Count of Excerpts Informing Rubric Scores}

\begin{tabular}{lcccc} 
& Structure & Amount of Info & Neutrality & LGBTQIA+ Inclusion \\
\hline Book A & 9 & 26 & 24 & 16 \\
Book B & 8 & 17 & 25 & 12 \\
Book C & 4 & 9 & 17 & 14 \\
Book D & 3 & 3 & 13 & 10 \\
\hline
\end{tabular}

\section{Structure}

All four books placed males before females within the reproduction, endocrine, and urinary chapters, a structural decision that created a default male norm. Furthermore, all of the textbooks used passive language to describe females and female reproductive anatomy and active language for male bodies and functions, e.g. The penis serves to deposit semen in the vagina" versus "The vagina is a tube about 8 to $10 \mathrm{~cm}$ long that allows for the discharge of menstrual fluid, receipt of the penis and semen, and birth of a baby" (book A pg. 1037 and 1061). Compared to books A and B, textbooks C and D had fewer examples of this structure ( $n=4$ and $n=3$, respectively). The language choices, particularly the types of verbs chosen to describe anatomical functions and structures, perpetuated social norms about strong, virile males and passive, nurturing females, but in different ways depending on the textbook's style. For example, where sperm 'swim,' 
'penetrate,' or 'thrash,' ova 'float freely' until 'swept' into a uterine tube. In these cases, the excerpts informed both structure and neutrality scores.

\section{Amount of Information}

The poor and passable scores for books A, B, and C were strongly influenced by one-sided nature of the comparisons in the textbooks, e.g., females were compared to males and males were mentioned in female chapters whereas the opposite was not true. This manifested in the ways that homologies were discussed in detail only in female units

for books A, B, and C. However, book D only mentioned homologies in the glossary and very few excerpts in book $\mathrm{D}(\mathrm{n}=3)$ were categorized as problematic according to this category's rubric. Unequal explanations were most common in book A (n=26), e.g., female controls of sexual response "need not be repeated here" after male sexual response was described. In contrast, although book D stated, "The neural pathways, both sensory and motor, involved in controlling sexual responses are the same for males and females" (book D, p. 1064), this statement was followed by a paragraph summarizing those pathways.

Like book A, textbook B also had difficulty with balancing the amount of information ( $\mathrm{n}=17)$. This was apparent in the context of puberty, e.g., 112 words to explain "male puberty" and 43 words to explain "female puberty" (book B, p. 1084). Intriguingly, both textbook B and C contained the exact same disparities in the type of language used to describe ovaries and testes, e.g., describing the "male" gonads with quantified measurements but the "female" gonads with food-based analogies. 


\section{Neutrality}

Books A and B frequently used unnecessary commentary $(n=24$ and $n=25$, respectively). In one example, rather than providing an insight into historical contraceptives that worked, this anecdote presents Egyptian women in a negative light: "Some Egyptian women used vaginal pessaries made of crocodile dung and honey, but crocodile dung is difficult to find in pharmacies these days, limiting the modern usefulness of this idea" (book A, p. 1088). In book B, these unnecessary comments related to the characterization of sperm, "they swim toward warmer temperatures at the far end of the tube, and, like a dog following a scent trail, sperm use olfactory receptor proteins to "sniff" chemicals released by the oocyte and its surrounding cells" (p. 1093).

Besides the androcentric treatment of reproductive system homologies all four books, there were other instances where the male-female dichotomy was unnecessarily invoked in comparisons, for example: "In a young well-conditioned male, muscle accounts for $90 \%$ of the cross-sectional area of the midthigh, whereas in a frail 90-yearold woman, it is only 30\%" (book A, p. 1115). The same example could be made using a frail 90-year-old man. This comparison was also categorized as containing unbalanced adjectives when describing a "frail woman" versus a "well-conditioned male" (not man).

Although the term pudendum was given in each book as an alternative name for the vulva, only books A and B included its definition, 'shameful,' in their description of female external genitalia. The neutrality scores took into consideration these unbalanced adjectives and ones like 'abnormal,' 'defective,' or 'mismatched' that were applied to intersex people. However, I also considered the implied adjectives; e.g., "a normal female 
has two X chromosomes (XX) in each somatic cell” (book D, p. 1113) suggests the existence of an "abnormal" female.

LGBTQIA+ Inclusion

Although books A and B used terms we identified as LGBTQIA+ inclusive (homosexual and intersex), both terms were framed in a disease context. While book B implied the existence of non-heterosexual intercourse by specifying "heterosexual intercourse," there was no explicit mention of LGBTQIA+ people. No other LGBTQIA+ identities were mentioned, even in areas of importance to their healthcare needs.

\section{DISCUSSION}

Despite repeated calls to include LGBTQIA+ people, health disparities, and history throughout undergraduate nursing education, I found the same problems (heteronormative, binary, gendered, and male-focused perspectives) that prior studies examining textbook presentations of sex, gender, and sexuality identified (Ah-King, 2013b; Alexanderson et al., 1998; Bazzul \& Sykes, 2011; De Guzman et al., 2018; Lawrence \& Bendixen, 1992; Mendelsohn et al., 1994; Parker et al., 2017; Røthing, 2017; Snyder \& Broadway, 2004). Rather than contributing to nursing students' LGBTQIA+ cultural competence, these books still present human sex, gender, and sexuality as binary, biologically essential, and exclusively heterosexual.

Because these four textbooks are widely adopted by public and private institutions across the United States, every year thousands of health science and LGBTQIA+ students are exposed to classroom materials that frame human anatomy/physiology as heteronormative and androcentric, omit LGBTQIA+ people, and perpetuate gender stereotypes that maintain a binary view of human bodies and desires as epistemically 
validated by science. The combination of content analysis and use of a published scoring rubric revealed concerns for LGBTQIA+ representation that were not included in the original Gendered Language Rubric (Campo-Engelstein \& Johnson, 2014) but were consistent with other textbook analyses (Ah-King, 2013b; Bazzul \& Sykes, 2011; De Guzman et al., 2018; Røthing, 2017; Snyder \& Broadway, 2004).

The Essentials of Baccalaureate Education for Professional Nursing Practice says, "Knowledge is increasingly complex and evolving rapidly" (2008, p. 30). But textbooks aren't keeping up with modern understandings of these topics, as when they omit the sex development pathways controlled by other chromosomes and characterize sex chromosomes as solely responsible for sex determination. Continuing to present human sex traits as binary, essential categories fails to provide nursing students with the foundation of cultural knowledge necessary for them to develop the cultural competence necessary to provide equitable healthcare to all people. Furthermore, these textbooks do not support the professional values of ethical nursing; they violate human dignity, integrity, and social justice considerations through the (in)visibility of certain groups in language, images, structures, and concepts within the book.

Simultaneously, these books contribute to a learning environment that casts homosexuality as a disease risk, intersex bodies as disordered, and heterosexual desires as default, to the detriment of LGBTQIA+ students. Because the "discourses involving sexuality operate according to not just what is said, but also what is not said" (original emphasis) (Bazzul \& Sykes, 2011, p. 270), bodies that are neither written nor depicted can be erased as if they do not exist (Letts, 1999). Language like "boy meets girl" and "penis into vagina" made explicitly clear that sexual contact occurs between a man and a 
woman for the purposes of producing offspring and erased LGBTQIA+ bodies and desires from the human experience. This does not promote an inclusive, comprehensive understanding of sexuality, a trait considered to be "basic to the physical, mental and social development of humans"(N. R. Council, 1996, p. 198).

Language, both visual and spoken, is viewed as one of the most overlooked fundamentals of competent healthcare practice (Rossi \& Lopez, 2017). But by framing homosexuality only as risky behavior rather than an expression of human desires, these books do not use language that is culturally sensitive to LGBTQIA+ diversity.

Furthermore, the absence of transgender applications for breast reduction or augmentation or of LGBTQIA+ contexts for reproductive assistance technologies in all four books disregards the vital importance these scientific advances have on the quality of life experienced by these populations; over $40 \%$ of LGBTQIA+ individuals expect to consider assisted reproductive technologies to have children in the future (F. E. Council, 2019). Language, images, and structure situated males as the default body for the exploration of differences between males and females and created textbooks where males were centered, females fell along the margins, and LGBTQIA+ people do not exist.

I believe it is necessary to share my findings with the textbook authors and publishers and the educators that adopt these books. I recognize that it is not a simple endeavor to restructure our ways of thinking about human bodies, either as educators or textbook producers. However, by pointing out instances in which these books support gender norms, suggest sex/gender binaries, or maintain heteronormativity and then explaining the impact these have on students and patients, I hope content creators and 
users will be more mindful of these discursive acts and be receptive to changing their books and classroom presentations to be more inclusive in the future.

\section{Limitations}

My analysis evaluated only four textbooks out of many available on the market. Due the subjective nature of a textbook analysis, the personal positionality of the researchers on this project informed the excerpts we chose and the subtexts we read from implicit examples.

\section{Conclusions}

The experiences of LGBTQIA+ people are personal and unique; to capture this perspective, creators need to partner with individuals from this population, allowing them to make recommendations for inclusion. I caution teachers, publishers, and authors against trying conveniently tuck diversity into the chinks of the curriculum (Letts, 2002), particularly in the context of underrepresented groups like LGBTQIA+ populations. I encourage the use of sidebars and case studies because I believe that even small-scale changes can make a difference for LGBTQIA+ inclusivity but I warn against pathologizing LGBTQIA+ by highlighting these populations in limited contexts while excluding them from the body of the text that describes structures and functions, the way that intersex people are currently described in many textbooks.

My textbook analysis aligns with equity and social justice considerations essential to professional nursing practice. I hope that it leads faculty to recognize the ways that social norms are reproduced in classroom materials and to critically consider how and why we continue to accept (and use in the classroom!) these inaccurate, non-inclusive materials. 


\begin{abstract}
CHAPTER III
MEASURING LGBTQIA+ PHOBIAS, ATTITUDES, AND CULTURAL COMPETENCE AMONG BIOLOGY UNDERGRADUATES AND THE EFFECT OF INTERSEX CASE STUDIES ON COMPETENCE AND STUDENT CONCEPTIONS OF HUMAN SEXES
\end{abstract}

\title{
INTRODUCTION
}

In chapter one, I found that students with more time in college described sex/gender along a "Continuum Conceptualization" where sex traits can occur in various combinations among individuals. On the other hand, some students held an essentialist, binary conceptualization of sex/gender that they validated through science authority. Notably, this ideology was significantly associated with pre-healthcare majors. When I analyzed the content of common sources of biology knowledge (i.e., textbooks) in chapter two, I found that they promoted gendered, binary, and exclusionary conceptions of sex/gender and sexuality that both exclude LGBTQIA+ people and are contrary to the principles of nursing ethics (AACN, 2008). These conceptions impede the development of cultural competence, or the skills, attitudes, and practices necessary to provide culturally sensitive healthcare (Brennan et al., 2012). Furthermore, because these perspectives also contradict medical and psychological ethical guidelines (APA, 2009), 
this issue is not constrained to nursing. Rather, it should be seen as a health science concern.

\section{Background and Significance}

Endorsement of binary sex/gender beliefs and biological essentialism is linked with transphobia and homophobia (Makwana et al., 2018; Nagoshi et al., 2008; Warriner, Nagoshi, \& Nagoshi, 2013), so health science educators must explicitly refute these perspectives in the classroom. Unfavorable attitudes matter, both for their contributions to negative healthcare experiences and barriers to care for LGBTQIA+ patients (Nadal et al., 2016) and because they compromise inclusivity in the classroom, which in turn deters students from pursuing STEM degrees (Harrison \& Tanner, 2018). Significantly, we know that the 'two sexes' model underlying the Q-sort's "Binary Conceptualization" and in human anatomy/physiology textbooks does not reflect the burgeoning body of knowledge contradicting this essentialistic dichotomy.

Previously, I described queer theory as a transformative perspective that challenges the normative status quo (Snyder \& Broadway, 2004). Of relevance to this study, this application of queer theory aligns well with the tenets of scientific inquiry, particularly efforts to recognize social and cultural influences on the construction of scientific knowledge (Helen E. Longino, 1990). The status quo dictates what type of research is done and why, allowing it to exert considerable influence over what constitutes science knowledge (Helen E. Longino, 1990). This was exemplified in chapter two through the invisibility and pathologizing of LGBTQIA+ people and the representation of social norms as biologically dictated characteristics. However, as a source of scientific knowledge, health science educators have significant power in 
challenging or reinforcing students' understanding of sex/gender and sexuality (Kaiser, 2016). For example, if textbooks say that "sex hormones masculinize or feminize the brain..." (Marieb \& Hoehn, 2018, p. 1099), this can be countered with research showing that, though testosterone levels are typically higher in males than females, there is significant overlap across the sexes (Granger et al., 2004), testosterone is the most abundant active sex hormone in all humans (R. Glaser \& Dimitrakakis, 2013), estrogen levels do not significantly differ among the sexes (Liening et al., 2010; van Anders, 2010), and brain differences cannot be correlated to sexuality, sex traits, or gender identity with any sort of internal consistency (Hyde et al., 2018; McCredie, 2011). Despite the evidence of hormonal similarities between the sexes, testosterone remains associated with masculinity, estrogen with femininity, and hormone levels are leveraged to enforce social norms and to punish those who do not conform (K. Karkazis \& JordanYoung, 2018).

Complicating efforts to shift students away from an essentialist emphasis on differences, prior knowledge based on misconceptions (like an outdated model) can be more difficult for educators to correct than a lack of knowledge (de Bruin, 2020; Versteeg et al., 2020). However, even a brief educational intervention can improve attitudes and strengthen the knowledge needed for healthcare students to develop LGBTQIA+ cultural competence (Strong \& Folse, 2014). Since essentialism opposes the development of inclusive attitudes and practices (Fuller, 2002), I wanted to see if we could counter binary, essentialist conceptions of human sexes by using intersex case studies. I chose case studies because they are scientific reports with established usage in science teaching (Herreid, 2005) and are recommended as a tool for introducing 
LGBTQIA+ topics to health science students (Brennan et al., 2012). Based on the two ideologies described in chapter one, some students do view sex in a non-binary way while others see discrete categories of female and male without overlap between. By leveraging the power of science knowledge to explicitly challenge the sex/gender dichotomy (Kaiser, 2016), I hope to push back against the binary and essentialistic beliefs that are correlated to negative views about LGBTQIA+ people (Makwana et al., 2018; Nagoshi et al., 2008; Warriner et al., 2013) and encourage the non-binary "Continuum Conceptualization" of human sex traits that better reflects the current body of knowledge.

Binary and essentialist sex/gender beliefs are not the only factors correlated with different attitudes about LGBTQIA+ people. When compared with cisgendered women, cisgendered men have significantly higher measures of homophobia and transphobia (Nagoshi et al., 2008), while coming from a Black ethnic background has also been associated with higher measures of homophobia and transphobia (M. J. Hill, 2013; Logie, Bridge, \& Bridge, 2007; Rosario, Schrimshaw, \& Hunter, 2004). On the other hand, people who self-identify as LGBTQIA+ have significantly more positive attitudes and beliefs compared with non-LGBTQIA+ (Warriner et al., 2013), although there are reported differences in attitudes between groups under the LGBTQIA+ umbrella relating to binary conceptions of sexuality/attractions (e.g., same sex or opposite sex) or sex/gender (e.g., female/male or woman/man) (Garelick et al., 2017; Weiss, 2003).

However, before I can understand what factors among students might be associated with different views about LGBTQIA+ people, I must first have an instrument for characterizing their phobias, attitudes, and cultural competence. I especially wanted to consider cultural competence, because it is a fundamental part of healthcare education 
and practice (AACN, 2008) and better cultural competence is correlated with more positive attitudes about LGBTQIA+ people (Strong \& Folse, 2014). Finding an appropriate instrument was challenging, because of the history of excluding LGBTQIA+ people from biomedical research (Makadon et al., 2015) means that there are some similar studies but none that look at all of the facets I wanted to consider. For example, while not explicitly consider provider cultural competence, Greene et al. (2018) looked at medical, dental, and nursing school students' preparedness for treating LGBT patients, but does not consider attitudes or phobias. On the other hand, Burke et al. (2015) analyzed medical students' explicit and implicit bias about gays and lesbians but didn't consider any other sexuality or gender-diverse identities. And Strong and Folse (2014) looked at undergraduate nursing students' attitudes and competence caring for LGBT patients, but they did not consider non-binary gender identities, which is problematic because non-binary identities are an under-studied and underrepresented group in biomedical research (Frohard-Dourlent et al., 2017). Since I could not find an instrument that contained all of the aspects I wanted, I elected to revise an existing instrument used for measuring phobias, attitudes, and cultural competence among social work students (Logie et al., 2007).

\section{Research Questions and Predictions}

There were two key facets to this study, with associated research questions. The first was the validation of the tool I modified to measure LGBTQIA+ phobias, attitudes, and cultural competence, i.e., to determine if I could replicate the methods and findings from the LGBT Assessment Scale (LGBTAS) (Logie et al., 2007) and whether the inclusion of non-binary gender identity impacted the reliability of the instrument. If the 
tool is valid and reliable, I wanted to look for differences the phobias, attitudes, and cultural competence of undergraduate biology students based on established correlates (e.g., gender). Second, I evaluated the effects of a classroom intervention using case studies on cultural competence and student conceptions of human sexes in terms of reproductive anatomy/physiology. Specifically, I asked:

1) Is my instrument to measure LGBTQIA+ phobia, attitudes, and cultural competence valid?

2) Are there significant differences in scores and if so, what factors are associated with them?

3) Does exposure to intersex case studies improve cultural competence measures?

4) Based on the case study assigned (control/treatment), do students differ in their characterizations or knowledge of the sexes?

With regard to my first research question, I expect that my instrument will be reliable and provide valid measures of phobia, attitudes, and cultural competence. For the second research question, because I found in the Q-sort that college major and educational experience were associated with different conceptions of sex/gender, I predict that my sample will have differences between phobia, attitudes, and cultural competence based on the course I sampled from (as an analog for science coursework experience) and academic major. Based on prior research (Warriner et al., 2013), I hypothesize that members of the LGBTQIA+ community will score better on phobia, attitude, and cultural competence. And, since ethnicity (Logie et al., 2007; Rosario et al., 2004) and gender (Nagoshi et al., 2008) are associated with differences in measures of 
phobia or attitudes towards LGBTQIA+ people, I also expect to see an effect from these factors.

In considering my third and fourth research questions, I hypothesize that students given the intersex case studies will have better measures of cultural competence compared to those in the control group, because challenging essentialism can improve cultural competence (Fuller, 2002). In accord with the results of my textbook analysis in chapter two, I predict that the open responses of students who are not given an intersex case study (i.e., the control group) will focus on dissimilarities and differences, place males first, and describe a binary view of sex/gender. On the other hand, I predict that students reading the treatment case studies will mention intersex more often than those in the control group, and that their answers will be more likely to claim the sexes are similar and will avoid using binary or essentialist examples in supporting their responses.

\section{METHODS}

\section{Study Context and Population}

The study was carried out in the biology department of a public Midwestern university in the United States. Notably, this particular university is nationally recognized for its efforts at LGBTQ+ inclusion on its campuses (Index, 2020). This department offers courses meeting general education requirements for non-biology majors, classes required for biology majors including pre-medical track students, and introductory (lower division) core classes for pre-healthcare majors such as nursing, dental hygiene, or exercise science.

My target group consisted of pre-healthcare majors so, using convenience sampling, I recruited students from three different biology courses representing 
introductory, intermediate, and advanced biology academic levels respectively. The introductory course, BIOL 102 "Biology: Current Issues and Applications," fulfills a general education requirement, does not have prerequisites beyond admission to the university, is required for pre-nursing students, and is commonly taken by freshmen or sophomore students early in their undergraduate enrollment. Thus, I would expect students in this class to have the least college-level science experience. The intermediate and advanced courses have both biology and chemistry prerequisites. My intermediate course, BIOL 262 "Human Anatomy \& Physiology Lab," requires students to have completed one semester introductory biology and associated lab, and chemistry courses with labs (these could be 'for science majors' courses or the ones designed fulfill general education requirements like BIOL 102) as well as completion of or concurrent enrollment in the associated anatomy/physiology lecture courses (BIOL 260 and 261). These requirements functionally limit the academic level of students in this course to sophomore or greater, and students typically take it while applying for admission to upper division nursing programs, because these are required courses for admission to nursing school. The final course, BIOL 465 "Principles of Physiology," has the most prerequisites for enrollment; in addition to requiring two semesters of majors' introductory biology and two semesters of chemistry lecture and lab, students must have completed BIOL 329 "Cellular and Molecular Biology". Consequently, most of these students are junior or seniors who have completed more college-level biology classes than either of the other groups.

Between spring and summer semesters in 2019 the study was offered online to 318 students and 120 students responded (37.7\% response rate). Time to complete the 
study ranged from twenty-five minutes to two hours. Students received a digital informed consent in accord with the IRB guidelines for approval to use human subjects.

\section{Educational Intervention}

\section{Case Studies}

I developed four case studies; two controls focused on either ectopic pregnancy or testicular torsion and two experimental case studies focused on intersex topics. I searched PubMed for actual case studies or reports because I wanted to adapt genuine publications in an effort to avoid caricaturizing any people or populations in creating my case studies de novo. I selected a case study describing a successful live birth after an ectopic pregnancy inside of a caesarean section scar (Ahmadi, Moinian, Pooransari, Rashidi, \& Haghighi, 2013). I used a report about the diagnosis and treatment of testicular torsion (Ringdahl \& Teague, 2006) to create a case study about the topic. One intersex case study reported on three siblings with complete androgen insensitivity that resulted in a female phenotype despite their XY genotype; the condition was not noticed until the eldest had issues conceiving with her husband (Kemp, 2013). The other was the case of an intersex teenager who had been raised as a female but reported that he was male and ultimately received medical and psychological support for what was termed sex reassignment (Reiner, 1996).

I standardized all four articles to $1027-1033$ words, renamed the patient to be identified by initials and replaced some medical jargon with common terminology. Additionally, the title and author information were formatted to be identical among case studies and I included a disclaimer that the article has been edited to meet study criteria along with the exact word count of that article. Case studies are in supplemental materials 
(Appendix 1). Students were randomly assigned a case study based on their birth month; more than half of students $(55 \%)$ were in the treatment group $(n=65)$ and $45 \%$ were in the control group $(\mathrm{n}=53)$. The case study opened in another browser window or tab; students were instructed to close the case study after reading it, before proceeding forward with the survey.

Assessment

After reading the case study, each student completed a multiple-choice question designed to verify they read the article, four multiple-choice anatomy/physiology content questions, and an open-response question (Figure 4). To assess these student's prior knowledge of human reproductive anatomy, I included four multiple-choice questions sourced from past examinations in BIOL 262. These specific questions were chosen because they included topics about human sexes that are covered across all three courses or should have been covered as part of K-12 schooling (Kentucky Academic Standards:

Science, 2020). I used the questions exactly as they were written by the course instructor, without any modifications to language or structure. Since there was only one correct answer for each question, the reading comprehension question was scored as correct or incorrect; this permitted us to divide control and treatment groups based on the reading comprehension question. The anatomy/physiology knowledge questions were assigned a value of one if correct and zero if incorrect; these scores were summed. Thus, the highest score possible for the knowledge questions was four (all correct) and the low was zero (none correct). The open response question at the end of the section asked, "In terms of human reproductive anatomy and physiology, are the sexes more similar or dissimilar? 
Explain your answer in detail." There is no 'correct' answer to this question, because it is asking students their opinion which must then be supported with evidence.

Based on the framing of the open response question, I expected answers containing similar, dissimilar, or both. Therefore, I first analyzed the content of the open responses using provisional coding to apply one of the three categories (Saldaña, 2016). Next, I turned my attention to the examples used to justify the responses. Since presentations of anatomy/physiology have been criticized for their male focus (Lawrence \& Bendixen, 1992; Mendelsohn et al., 1994; Parker et al., 2017) I coded the examples cited in the responses as male first, female first, or neither.

After I coded responses for these two factors, the author and a research assistant used concept coding (Saldaña, 2016) to evaluate the types of evidence students cited to justify their response. As we coded the responses, we tried to use selected codes repeatedly and subsume codes into broader, inter-related conceptual categories (Saldaña, 2016). Thus, the code "different sex or accessory organs" can subsume responses that reference gonads, glands, or genitals as well as those mentioning the more general 'dissimilar reproductive anatomy'. We also evaluated the language students used in their responses for binary framings of human sexes (e.g., 'both sexes,' 'the two sexes,' or 'males have testes and females have ovaries') as well as gendered terms like women/men (e.g., 'women give birth'). We counted the number of instances that coding categories (e.g., similar chromosomes) occurred to calculate proportion of responses that contained a given concept code.

To establish inter-rater reliability (IR), the researchers independently coded a portion of the open responses then compared results to determine the percent agreement 
(Lavrakas, 2008); we found IR=94\%. Once we ensured IR, we coded the remaining responses. In instances of coding conflict, we discussed and resolved coding disagreement (Allen, 2017).

\section{Survey}

LGBTQ+ phobias, attitudes, and cultural competency

I modified the LGBT Assessment Scale (LGBTAS) (Logie et al., 2007) by making changes to language and statements that better reflected my target study population of undergraduate pre-healthcare majors (as opposed to social work graduate students). I also added items to the phobias and attitudes portions to include non-binary people in the assessment. To preserve internal consistency, the attitudes/phobia statements were formatted to use the same language and framing as the existing, validated assessment. However, the cultural competency portion was entirely revised to meet undergraduate nursing students' cultural competence objectives; specifically "sensitivity to various identities, understanding current challenges of the LGBTQ population, and increasing self-awareness" (McNiel \& Elertson, 2018, p. 313). In creating my cultural competence instrument I used scenarios and situations where providers failed to provide inclusive care, such as misgendering or assuming heterosexuality (Nadal et al., 2016). I also referenced skills necessary to nursing practice, such as asking patients about sexual activity (AACN, 2008). Cultural competence items were divided into two subscales: gender identity and sexuality. I included a question where students were prompted to select "Strongly Disagree" for one statement, to verify they were carefully reading each statement before responding. Failure to do so resulted in 
that study being excluded. I refer to the revised survey as the updated LGBTAS

(uLGBTAS).

My first draft of the uLGBTAS was reviewed by a convenience sample of 39 volunteers with a variety of academic backgrounds (high school through $\mathrm{PhD}$ ); they were recruited through social media. No other demographic information was collected as part of the pilot. To assess the reliability of my modified scale, I conducted Cronbach's alpha on the first draft using RStudio. I found high internal congruence within the phobia (0.97) and attitude (0.88) scales. Although my cultural competency statements had a lower alpha (0.64), this was still higher than the uncorrected (0.30) and corrected (0.59) alpha values associated with the original tool (Logie et al., 2007). I made language adjustments to the attitude and cultural competency scales based on volunteer feedback to clarify the intention of the questions; the final alphas were 0.92 and 0.78 respectively (table 15 ). The final version of the uLGBTAS (see Figure 4) consists of 41 statements ranked on a 5point Likert scale with strongly agree $=5$ and strongly disagree $=1$.

Case Study Intervention

1. Case study comprehension question. Specific questions are given at the end of the respective case study (Appendix 1).

2. Which of the following describes the normal production of estradiol in a man's body?

a. It is not made in his testes but is released in small amounts from his adrenal glands.

b. It is produced only in pathological situations when cells are unable to make testosterone.

c. It is normally made in small amounts in his testes.

d. It was made from testosterone during embryonic development but should not be produced after birth.

3. During typical fetal development, what would have happened to the testes if the person has XX chromosomes instead of XY?

a. They would have been destroyed in an apoptosis process.

b. They would have remained at a tiny fetal size, undetectable within the abdominal cavity.

c. They would have become an ovary.

d. They would have become part of a uterine tube.

4. If an embryo has XX chromosomes instead of XY, where should corpora cavernosa tissue be found?
a. The ovary
b. The labia majora
c. The clitoris 


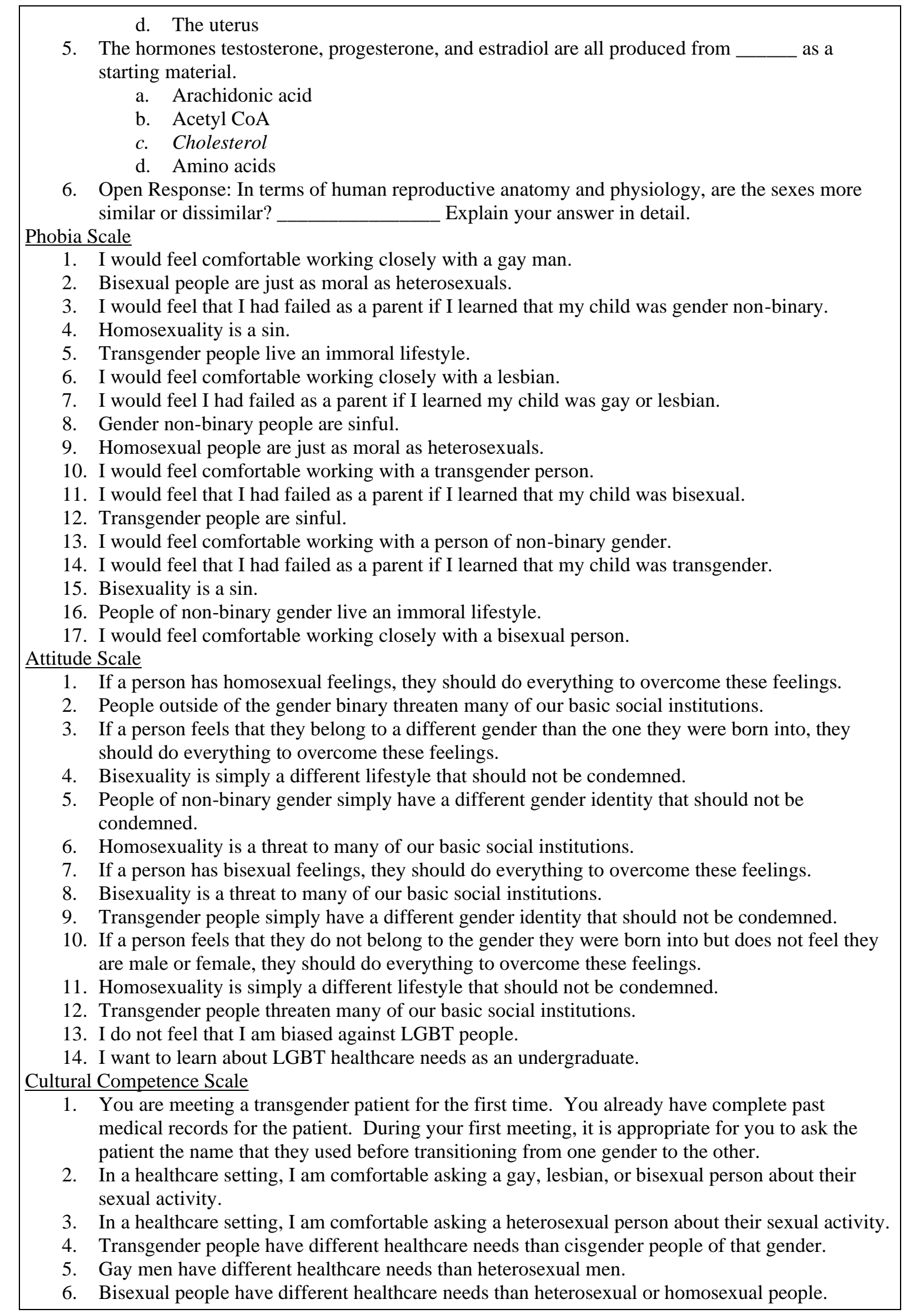


7. Transgender people do not need access to contraceptives (birth control).

8. A new patient at your office informs you that they are non-binary (neither male nor female). You think it is appropriate to tell them that they must identify as male or female based on the sex assigned at birth or you will be unable to provide informed healthcare.

9. Healthcare providers are responsible for recognizing barriers to service for their LGBT patients.

10. Lesbians have different healthcare needs than heterosexual women.

Figure 4. Case study intervention and uLGBTAS items

Note: the survey program randomized the answers for multiple choice questions (i.e., the correct answer was not "c" for every question).

At the conclusion of the survey, I offered students an open response to provide demographics: age, sex, gender, ethnicity, major, and LGBTQ+ identity. They were given multiple-choice options for time enrolled at the university (less than one year, one year, two years, three years, four years, other), and "Do you identify as LGBTQ+?" (Yes, No, Uncertain/Questioning, and Decline).

\section{Data management and statistical analysis}

For purposes of data analysis, I used the three ethnicity categories from the original study design: white, black, and other responses (Logie et al., 2007). Responses for sex were (in order received): Female, F, male, M, heterosexual, XX, straight. I consolidated sex responses "female, F, XX" into "Female Sex" and "male, M" into "Male Sex". I omitted "heterosexual/straight" responses to sex, as I did not have enough information to categorize those individuals. As with sex I consolidated similar gender responses "female, F, women, woman, cisgender female" into "Female Gender" and 'male, M, 'same thing as sex, male', 'gender is the same as sex, stop being ideologues male', man heterosexual male" into "Male Gender". Where individuals responded "cisgender" I referenced the sex provided, since cisgender identity is equated to gender alignment with sex assigned at birth. I placed "genderneutral" into the category "NonBinary/Transgender" reflecting the umbrella gender identity that it conventionally falls 
under. I chose not to call this category "Other" in recognition of the linguistic bias embedded in that term.

Because pre-healthcare students are the primary focus of my study, I divided academic majors into three broad categories: pre-healthcare, non-healthcare, and undecided majors. Pre-healthcare majors included: biology, nursing, public health, dental hygiene, exercise science, and psychology. Non-healthcare majors included: accounting, business, communications, sports administration, marketing, education, anthropology, music, history, political science, and social work. Undecided were those students who have not yet declared a major. Lastly, all individuals that self-identified as LGBTQ+ $(\mathrm{n}=11)$ opted to provide their specific identities: gay $(\mathrm{n}=2)$, bisexual $(\mathrm{n}=8)$ and asexual genderneutral $(\mathrm{n}=1)$ although I did not include these specific identities in Table 15.

\section{Table 15}

\section{Demographic Summary}

\begin{tabular}{lll} 
Demographic Variable & Number of respondents $(\mathbf{N})$ & Percent $(\%)$ \\
\hline Total Respondents & 112 & 100 \\
\hline Age & 37 & 33.0 \\
$18-19$ & 69 & 61.6 \\
$20-22$ & 5 & 4.5 \\
$23-26$ & 1 & 0.9 \\
42 & & \\
\hline Sex & 79 & 70.5 \\
Female & 27 & 24.1 \\
Male & 6 & 5.4 \\
Heterosexual/straight & & \\
Gender & 85 & 75.9 \\
Female & 26 & 23.2 \\
Male & 1 & 0.9 \\
Non-binary/Transgender & & \\
\hline Self-identify as LGBTQ+ & 11 & 9.8 \\
Yes, or Questioning/Uncertain & 101 & 90.2 \\
No & & \\
\hline Ethnicity & 73 & 65.2 \\
White/Caucasian & 14 & 12.5 \\
Black/African American & 21 & 18.8 \\
Other Response & 4 & 3.6 \\
No Response & & \\
\hline
\end{tabular}




\begin{tabular}{lll}
\hline Academic Major $(\mathbf{n = 1 1 2})$ & & \\
Pre-healthcare (n=73) & 27 & \\
$\quad$ Biology & 28 & 24.1 \\
$\quad$ Nursing & 4 & 25.0 \\
$\quad$ Public Health & 5 & 3.6 \\
$\quad$ Dental Hygiene & 2 & 4.5 \\
$\quad$ Exercise Science & 7 & 1.8 \\
$\quad$ Psychology & 34 & 6.3 \\
Non-healthcare & 4 & 30.4 \\
Undecided & 1 & 3.6 \\
No response & & 0.9 \\
\hline Time at University & 22 & \\
Less than one year & 30 & 19.6 \\
One year & 17 & 26.8 \\
Two years & 32 & 15.2 \\
Three years & 7 & 28.6 \\
Four years & 3 & 6.3 \\
Five years & 1 & 2.7 \\
No response & & 0.9 \\
\hline
\end{tabular}

I knew that one camp argues that Likert data should only be analyzed as ordinal categories because the interval between scale values is not equal (Jamieson, 2004).

Because Likert scales are collections of Likert-type items, in order for Likert scale data to be considered continuous (and thus for parametric statistical procedures to be appropriate), certain assumptions must be met (Lubke \& Muthén, 2004). Logie et al. (2007) addressed the validity of their scale groupings via Cronbach's alpha, but only for the three primary measures: phobia, attitudes, and cultural competencies. However, they also subdivided their three primary scales into three "cohorts" or subscales but did not test the reliability of the subscale divisions. Despite this, there is reason to believe that parametric analysis, even if the data does not fit a Gaussian distribution, can still produce valid results (Mircioiu \& Atkinson, 2017). For this reason, I utilized parametric tools.

Another aspect of my study, response rate, was calculated as a percentage based the number of participants from each course divided by the total enrollment for that course. I acknowledge that this is not a random selection of students, because those who respond to a given survey are systematically different from those that did not (Nulty, 
2008). To ensure that I have adequate response rates to draw conclusions, I estimated the required number of respondents from each course, based on that course's enrollment total (Nulty, 2008). Under 'liberal conditions,' defined as $10 \%$ sampling error and $80 \%$ confidence level (Nulty, 2008), to adequately represent my population I will need at least twenty-two responses from BIOL 102, seventeen responses from BIOL 262, and twentythree responses from BIOL 465.

I prepared all data for analysis using Microsoft Excel. Where necessary, I reversed the response order of certain to reflect my response scales ( $1=$ high phobia, 5=low phobia; $1=$ high attitude, $5=$ low attitude; $1=$ low competence, $5=$ high competence). For example, if the survey question stated "I would feel that I had failed as a parent if I learned that my child was bisexual," I adjusted the responses as though the question had read "I would not feel that I had failed as a parent if I learned that my child was bisexual". Thus, someone that strongly agreed with the original statement would be categorized as strongly disagreeing with the reversed statement.

I used GraphPad Prism 8.4.3, Microsoft Excel, and RStudio for statistical analyses and data visualization. $\mathrm{R}$ packages for generating and comparing the general linear models included "rcompanion" (Mangiafico, 2020) and "Ime4" (Bates, Mächler, Bolker, \& Walker, 2015). I measured the reliability of the three scales as well as their respective subscales via Cronbach's alpha (Gliem \& Gliem, 2003). Then I conducted correlation analysis followed by a profile analysis with repeated measures to test for differences among phobia and attitude subscales. I used this model because this test is used if the variables analyzed are matched, as in my data, or repeated (Motulsky, 2020). If a difference was detected, I planned to use Tukey's multiple comparisons test to 
determine where those differences exist (Motulsky, 2020). Post-hoc analysis for significant effects used t-tests or ANOVA as appropriate for the factors involved. Because I only had two subscales for cultural competence, I utilized a paired t test to test for difference means, since the two subscales are paired (i.e., matched) like the subscales for phobia and attitude (Motulsky, 2020).

In alignment with my research goals and to limit the scope of my analysis I designated categories for my analyses as: course, LGBTQIA+ identity, academic major, gender, and ethnicity. I used a general linear model for each scale to determine which factors influence scores. I compared models using the "CompareGLM" command from rcompanion (Mangiafico, 2020) to find the model of best fit. Then I characterized the significant factors using Welch's correction for t-tests or Brown-Forsythe ANOVA test where necessary to account for categories with $n<50$ (Motulsky, 2020). In situations where I used the Brown-Forsythe ANOVA I used Dunnett tests to account for the smaller sample size in my groups (Motulsky, 2020). Lastly, where appropriate I used a chi-square test of proportions to evaluate differences between control/treatment groups with regard to their open response answers.

\section{RESULTS}

Like Logie et al. (2007), I had fewer than 200 respondents; over two semesters I collected 120 responses, giving a $37.7 \%$ overall response rate. Seven of these were incomplete or otherwise failed to meet inclusion criteria i.e., where the participant consented to the study and then submitted without responding or did not select "strongly disagree" when prompted to confirm attention to question. Final analysis included 113 individual responses for an adjusted response rate of 35.5\%. Despite the seemingly low 
total response rate, I exceeded the minimum number of responses needed, as calculated based on the course enrollment (Nulty, 2008). By course, BIOL $102(n=51)$ had a 38.1\% response rate, BIOL $262(\mathrm{n}=30)$ had a $68.2 \%$ response rate, and BIOL $465(\mathrm{n}=32)$ had a $22.9 \%$ response rate. The variation in response rate is likely as result of the convenience sampling method used to identify participants, the different incentives offered by the course instructors, and the academic term the survey was administered. Offering the survey earlier in the semester was associated with the two courses with the lowest response rate; on the other hand, the anatomy/physiology students were offered the study shortly before their final exam where the extra credit may have been more impactful.

Only one student declined to provide any demographic information. The average age was 20.3 and underrepresented minorities made up $31 \%$ of my participants. I had almost equal representation of one year $(n=30)$ and three years $(n=32)$ at the university, while less than one year $(n=22)$ and two years $(n=17)$ were my next largest grouping. Within my sample, $9.8 \%$ of students $(n=11)$ self-identified as LGBTQ+ or questioning, although distribution varied by course. A larger portion of Anatomy/Physiology students $(20 \%, \mathrm{n}=6)$ self-identified as LGBTQ+ than Introductory Biology $(5.9 \%, \mathrm{n}=3)$ or Human Physiology $(6.3 \%, \mathrm{n}=2)$. My primary demographic for study, pre-healthcare students $(n=73)$, made up $65.2 \%$ of the population sampled with biology $(n=27)$ and nursing $(n=28)$ the most represented majors.

\section{uLGBTAS}

My three primary scales, attitude (Cronbach's alpha=0.96), phobia (Cronbach’s alpha $=0.92)$, and cultural competency (Cronbach's alpha=0.78) were reliable according to this measure (see Table 16), thus it was suitable to analyze scales rather than individual 
items (Gliem \& Gliem, 2003). For their analysis of the original LGBTAS, Logie et al. (2007) correlated the average phobia and attitude scores in addition to (in their study) three subscales (gay/lesbian, bisexual, and transgender), however, they did not report the reliability of the subscales so I cannot directly compare my alpha values to theirs. I did find that most of my subscales could reliably be combined for analysis. The reliability of the instrument and my awareness that parametric and non-parametric measures of Likert scale data can produce similar results (Mircioiu \& Atkinson, 2017), supports my decision to approximate the parametric analysis performed by Logie et al. (2007).

\section{Table 16}

Cronbach's Alpha Values for Scales and Subscales

\begin{tabular}{llllll}
\hline All Phobias & 0.96 & All Attitudes & 0.92 & All Competencies & 0.78 \\
- Gay/Lesbian & 0.80 & - Gay/Lesbian & 0.63 & - Sexuality & 0.80 \\
- Bisexual & 0.84 & - Bisexual & 0.55 & - Gender Identity & 0.51 \\
- Transgender & 0.88 & - Transgender & 0.69 & & \\
- Non-binary & 0.86 & - Non-binary & 0.72 & & \\
\hline
\end{tabular}

Scales and subscales

Based on my scale ranks (1=high phobia; $5=$ low phobia) I found a fairly low measure of total phobia $(\mathrm{M}=4.17, \mathrm{SD}=0.82)$. Subgroup scores (i.e., transgender phobia) varied based on the measure (see Table 17). Attitude (1=negative attitude; $5=$ positive attitude) was moderately low $(\mathrm{M}=3.90, \mathrm{SD}=0.78)$ and again subgroup scores varied. For cultural competency ( $1=$ low competence; $5=$ high competence), I had approximately the same score as the original study (Logie et al., 2007); my average total cultural competency score $(\mathrm{M}=3.46, \mathrm{SD}=0.66)$ was very close to the 3.50 they reported.

\section{Table 17}


Mean, SD, and SEM for Scales and Subscales (1=high phobia, 5=low phobia; $1=$ negative $\underline{\text { attitude, } 5=\text { positive attitude; } 1=\text { low competence, } 5=\text { high competence) }}$

\begin{tabular}{llll} 
Scale/subscale & Mean $(\mathrm{n}=113)$ & SD & SEM \\
\hline Total Phobia & 4.17 & 0.82 & 0.08 \\
-Gay/Lesbian & 4.29 & 0.77 & 0.07 \\
-Bisexual & 4.20 & 0.86 & 0.08 \\
-Transgender & 4.04 & 0.97 & 0.09 \\
-Non-Binary & 4.10 & 0.86 & 0.08 \\
Total Attitude & 3.90 & 0.78 & 0.07 \\
-Gay/Lesbian & 4.04 & 0.83 & 0.08 \\
-Bisexual & 4.04 & 0.77 & 0.07 \\
-Transgender & 3.81 & 0.95 & 0.09 \\
-Non-Binary & 3.81 & 0.91 & 0.09 \\
Total Cultural Competency & 3.46 & 0.66 & 0.06 \\
-Sexuality & 3.36 & 0.82 & 0.08 \\
-Gender Identity & 3.53 & 0.77 & 0.07 \\
\hline
\end{tabular}

Like Logie et al. (2007) and as predicted by prior research (D. B. Hill \& Willoughby, 2005; Nagoshi et al., 2008), I found moderate to high positive correlations (0.62-0.86) between phobia and attitudes, as well as their subscales (Table 18), indicating a strong linear relationship between these categories. Although most of my subscale correlations were lower than those reported by Logie et al. (2007), after accounting for differences in rounding (they reported 0.855 versus my 0.858 ), I found the same correlation value between total phobia and attitudes as the original paper, validating the addition of non-binary gender subscales.

\section{Table 18}

Correlation of Students' LGBTQ+ Phobia and Attitudes (All correlations are statistically significant at $\mathrm{p} \leq 0.001)$ 
Attitudes

\begin{tabular}{|c|c|c|c|c|c|c|}
\hline & & $\begin{array}{c}\text { Total } \\
\text { Average }\end{array}$ & Gay/Lesbian & Transgender & $\begin{array}{c}\text { Gender } \\
\text { Non-binary }\end{array}$ & Bisexual \\
\hline \multirow{5}{*}{$\begin{array}{l}\frac{a}{0} \\
\frac{\pi}{0} \\
\frac{0}{2}\end{array}$} & Total Average & 0.86 & 0.74 & 0.78 & 0.81 & 0.72 \\
\hline & Gay/Lesbian & 0.76 & 0.74 & 0.68 & 0.69 & 0.63 \\
\hline & Transgender & 0.84 & 0.71 & 0.79 & 0.80 & 0.68 \\
\hline & Gender Non-binary & 0.80 & 0.68 & 0.76 & 0.78 & 0.62 \\
\hline & Bisexual & 0.83 & 0.71 & 0.73 & 0.74 & 0.69 \\
\hline
\end{tabular}

A repeated measures one-way ANOVA was used to analyze differences between phobia subscales (gay/lesbian, bisexual, transgender, and non-binary); it detected significant differences in the mean scores $(\mathrm{F}=12.6 ; \mathrm{p} \leq 0.001)$. Tukey's multiple comparison identified significant differences (all $\mathrm{p} \leq 0.001$ ) between bisexual-transgender, gay/lesbian-non-binary and gay/lesbian-transgender mean phobia scores (Table 17).

Unlike Logie et al. (2007), my repeated measures one-way ANOVA did detect significant differences between mean attitude scores $(F=13.7 ; \mathrm{p} \leq 0.001)$. I again used Tukey's multiple comparison and detected significant differences (all $\mathrm{p} \leq 0.001$ ) between gay/lesbian-transgender, gay/lesbian-non-binary, bisexual-transgender, and bisexual-nonbinary mean attitude scores. In all cases I saw lower phobia and more positive attitudes toward gay/lesbian/bisexuals than toward transgender/gender non-binary people; in effect what I did not see was a significant difference between transgender and non-binary scores or between gay/lesbian and bisexual scores for either scale (i.e., phobia/attitude).

Although the LGBTAS did not evaluate subscales in cultural competence (Logie et al., 2007), I were able to consider two facets, sexuality and gender identity, in addition to reporting the average total cultural competence scores. Using a paired t test, I found that sexuality-based cultural competence scores (Mean=3.36, $\mathrm{SD}=0.816$ ) were 
significantly lower $(\mathrm{t}=2.22, \mathrm{df}=112, \mathrm{p}=0.028)$ than gender-identity competence scores $($ Mean=3.53, SD=0.770).

\section{General Linear Models}

To identify which factors influenced each of the three scales (phobia, attitudes, and cultural competence), I compared general linear models for each scale. First, I modeled all factors being considered: course, ethnicity, gender, academic major, and LGBTQIA+ identity. Then I dropped non-significant terms and compared the models. Based p-value and lowest AIC, I concluded that phobia and attitude were influenced by ethnicity, gender, and LGBTQIA+ identity and cultural competence were influenced by course and LGBTQIA+ identity (Table 19).

\section{Table 19}

\section{General Linear Models and Fit Criteria}

1) "Phobia Course + Ethnicity + Gender + Identity + Major"

2) "Phobia Ethnicity + Gender + Identity"

\begin{tabular}{ccccc}
\hline Model & Rank & Df.res & AIC & p Value \\
\hline 1 & 9 & 97 & 251.1 & 0.017 \\
2 & 5 & 101 & 246 & 0.003 \\
\hline
\end{tabular}

1) "Attitude Course + Ethnicity + Gender + Identity + Major"

2) "Attitude $\sim$ Ethnicity + Gender + Identity"

\begin{tabular}{ccccc}
\hline Model & Rank & Df.res & AIC & p Value \\
\hline 1 & 9 & 97 & 241.6 & 0.034 \\
2 & 5 & 101 & 237.3 & 0.009 \\
\hline
\end{tabular}

1) "Competence Course + Ethnicity + Gender + Identity + Major"

2) "Competence $\sim$ Course + Identity"

\begin{tabular}{ccccc}
\hline Model & Rank & Df.res & AIC & p Value \\
\hline 1 & 9 & 97 & 203.3 & 0.071 \\
2 & 4 & 102 & 201.1 & 0.028 \\
\hline
\end{tabular}

\section{Ethnicity}

I first used Brown-Forsythe ANOVA test to see if ethnicity was associated with different average phobia, attitude, and cultural competence scores. I found that there was 
a significant difference in phobia $(F=9.15, \mathrm{DFn}=2.00, \mathrm{DFd}=69.2, \mathrm{p}<0.001)$ and attitude $(\mathrm{F}=9.75, \mathrm{DFn}=2.00, \mathrm{DFd}=68.5, \mathrm{p}<0.001)$ scores. Although the original study found that Black students had higher phobia and more negative attitudes against LGBTQIA+ people compared to white or other response categories (Logie et al., 2007), a Dunnett comparison of my population found that white students $(n=73)$ had significantly higher phobia $(\mathrm{p}<0.001)$ and more negative attitudes (mean=3.74, $\mathrm{p}<0.001)$ than students in the other response $(n=21)$ category. Black students $(n=14)$ did have significantly more negative attitudes $(\mathrm{p}=0.041)$ compared to the other response group but this was not true for phobia (see Table 20).

Table 20

$\underline{\text { Main Effects of Ethnicity and Scores }}$

\begin{tabular}{lllll} 
& \multicolumn{2}{c}{ Total Phobia } & \multicolumn{2}{c}{ Total Attitude } \\
\hline Mean $(\mathrm{SD})$ & $\mathrm{p}$ Value & Mean $(\mathrm{SD})$ & $\mathrm{p}$ Value \\
\hline White $(\mathrm{n}=73)$ & $3.99(0.893)$ & $<0.001$ & $3.74(0.838)$ & $<0.001$ \\
Black $(\mathrm{n}=14)$ & $4.34(0.505)$ & & $3.90(0.462)$ & \\
Other Responses $(\mathrm{n}=21)$ & $4.58(0.450)$ & & $4.34(0.523)$ & \\
\hline
\end{tabular}

\section{Gender}

I compared only female $(n=85)$ and male $(n=26)$ gender identities because I had just one 'non-binary' response. I used unpaired t-tests with Welch's correction to account for the size of the male sample. There were significant differences in average phobia and attitude based on gender identity (shown in Table 21). I found that males had significantly greater phobia measures than females $(\mathrm{t}=2.24, \mathrm{df}=36.4, \mathrm{p}=0.031)$ and that males also had significantly poorer attitudes than females $(t=2.27, d f=33.6, p=0.026)$.

\section{Table 21}


$\underline{\text { Main Effects of Gender and Scores }}$

\begin{tabular}{lcccc} 
& \multicolumn{2}{c}{ Phobia } & \multicolumn{2}{c}{ Attitude } \\
\hline Mean (SD) & p Value & Mean (SD) & p Value \\
\hline Male $(n=26)$ & $4.25(0.776)$ & 0.031 & $3.95(0.715)$ & 0.026 \\
\hline
\end{tabular}

\section{LGBTQIA+ Identity}

I used unpaired t-tests with Welsh's correction for groups with $\mathrm{n}<50$ to compare the total phobia, attitude, and cultural competence scores between students that selfidentified as LGBTQIA+ $(\mathrm{n}=11)$ and those that did not $(\mathrm{n}=101)$. Because I predicted that LGBTQIA+ individuals will have higher competence and lower phobia and attitudes, I used a one-tailed test. For all three scales I found that LGBTQIA+ identity was associated with significantly higher competence, lower phobia, and more positive attitudes (see Table 22).

\section{Table 22}

Main Effects of LGBTQIA+ Identity and Scores

\begin{tabular}{lcccccc} 
& \multicolumn{2}{c}{ Phobia } & \multicolumn{2}{c}{ Attitude } & \multicolumn{2}{c}{ Cultural Competence } \\
\hline & Mean (SD) & $\mathrm{p}$ Value & Mean $(\mathrm{SD})$ & $\mathrm{p}$ Value & Mean (SD) & $\mathrm{p}$ Value \\
\hline LGBTQIA+ $(\mathrm{n}=11)$ & $4.81(0.311)$ & 0.002 & $4.47(0.485)$ & 0.004 & $4.03(0.752)$ & 0.001 \\
$\begin{array}{l}\text { Non-LGBTQIA+ } \\
(\mathrm{n}=101)\end{array}$ & $4.09(0.823)$ & & $3.82(0.774)$ & & $3.39(0.618)$ & \\
\hline
\end{tabular}

Course

One-way Brown-Forsythe ANOVA detected significant differences in cultural competence $(\mathrm{F}=7.55, \mathrm{DFn}=2.00, \mathrm{DFd}=95.7, \mathrm{p}=0.009)$ among courses (see Table 23). These differences were identified using Dunnett's comparison; BIOL 102 had significantly lower competence than BIOL $262(\mathrm{p}=0.002)$ and BIOL $465(\mathrm{p}=0.013)$ 
Interestingly, when only pre-healthcare majors are included in this analysis, I detected the same differences in cultural competence.

\section{Table 23}

Main Effect of Course and Cultural Competence

Cultural Competence

\begin{tabular}{lll}
\hline & Mean (SD) & p Value \\
\hline BIO $465(n=32)$ & $3.64(0.668)$ & \\
BIO $262(n=30)$ & $3.70(0.588)$ & $<0.001$ \\
BIO $102(n=51)$ & $3.21(0.617)$ & \\
\hline
\end{tabular}

Individual survey items (not part of subscale analysis)
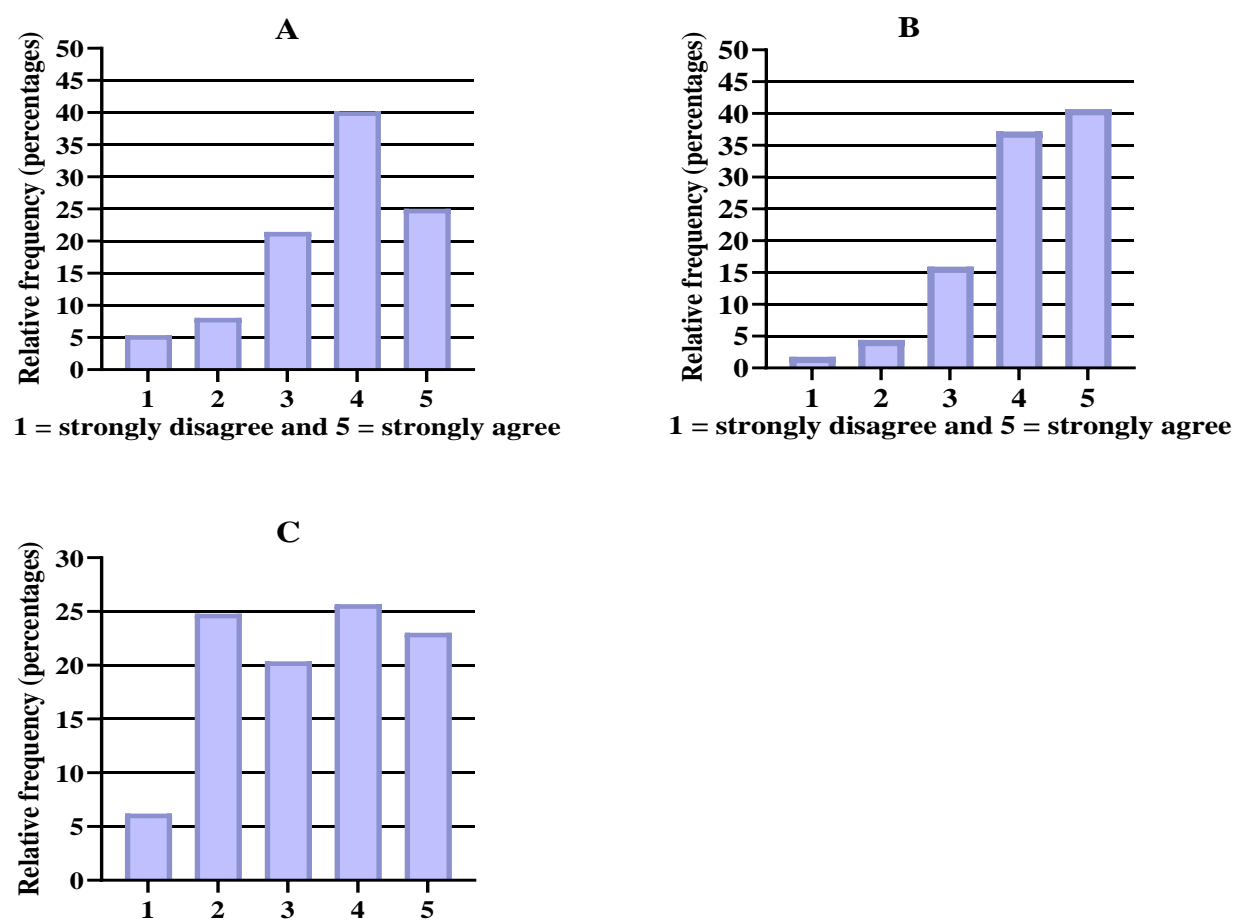

$1=$ strongly disagree and $5=$ strongly agree

Figure 5. Frequency distributions of individual item responses

A: Healthcare providers are responsible for recognizing barriers to service for their

LGBT patients; B: I do not feel that I am biased against LGBT people; C: I want to learn about LGBT healthcare needs as an undergraduate. 
When I asked students if healthcare providers are responsible for recognizing barriers of care for LGBTQ+ patients, I found that four of the fifteen respondents that disagreed were pre-healthcare majors (Figure 5A). Almost one third of students (31.0\%; n=35) did not want to cover those topics and more than half of those thirty-five students were pre-healthcare majors $(57.1 \%$; $n=20)$ (Figure 5B). Worryingly, three of the seven students that responded that they believe that they are biased against LGBTQ+ people (Figure 5C) were pre-healthcare majors.

\section{Educational Intervention}

\section{Quantitative findings}

To evaluate if exposure to intersex case studies increased cultural competence, I used t tests with Welch's correction to see if higher cultural competence scores were associated with treatment group. I found no difference in competence score between control and treatment $(\mathrm{p}=0.297)$. However, I noticed that thirteen students in both control and treatment got the case study comprehension question wrong. When I evaluated cultural competence within the control $(n=50)$ and treatment $(n=62)$ groups based on whether the student got the case study comprehension question correct I found that students in the treatment group that correctly answered the comprehension question $(n=49)$ had significantly better cultural competence than those that answered incorrectly $(\mathrm{p}=0.031, \mathrm{t}=2.34, \mathrm{df}=18.6)$. This difference was not present in the control group $(\mathrm{p}=0.464)$, implying that students given an intersex case study that comprehended the article (or read it thoroughly) had better cultural competence than those that did not.

Nineteen students failed to answer any of the four multiple-choice questions correctly and twenty-four only answered one question correctly. Forty-three students 
correctly answered half the questions, twenty-two students correctly answered three questions, and only five students answered all four questions correctly. The five students that correctly answered all four questions were in BIOL $262(n=2)$ or BIO $465(n=3)$. Although students from BIOL $102(\mathrm{n}=10)$ made up more than half of the students that got no questions correct, students from BIOL $262(\mathrm{n}=5)$ and BIOL $465(\mathrm{n}=4)$ also failed to answer any questions correctly. Using the Brown-Forsythe ANOVA test, I did not find any associations between 'content knowledge', as measured by the number of anatomy/physiology multiple choice questions answered correctly, and cultural competence $(\mathrm{p}=0.471)$. A t test with Welch's correction found there was also no difference between case study group and anatomy/physiology multiple choice score $(\mathrm{p}=0.926)$.

Open response

I collected 97 answers to my open response question. Following my provisional coding, I found that half of the students answered 'similar' $(51.5 \%, \mathrm{n}=50)$ while the remainder answered 'dissimilar' $(35.1 \%, \mathrm{n}=34)$ or 'both' $(13.4 \%, \mathrm{n}=13)$ (see Table 24$)$. When I compared responses to the question by case study control or treatment, I found that around half of each group had answered 'similar' (control: 55.0\%, $\mathrm{n}=22$; treatment: $49.1 \%, n=28)$. However, only $25 \%$ of the control group $(n=10)$ answered 'dissimilar' compared to $42.1 \%$ of the treatment $(n=24)$ and a greater portion of the control group answered 'both' $(20.0 \%, n=8)$ compared to the treatment group $(8.8 \%, n=5)$ (see Figure 6). A Chi-square test of proportion revealed that there were no statistically significant differences. I conclude that case study treatment does not appear to influence how students view the sexes in the context of human reproductive anatomy/physiology. Of 
interest, most LGBTQIA+ individuals that responded to the open response question $(n=10)$ viewed the sexes as 'similar' or 'both' $(n=8)$.

\section{Table 24}

Cumulative, Control, and Treatment Coding Counts for 'Similar', 'Dissimilar', or 'Both'

\section{$\underline{\text { Open Responses }}$}

\begin{tabular}{lrrrr} 
Cumulative & Similar & Dissimilar & Both & Total \\
-Count & 50 & 34 & 13 & 97 \\
\hline Control & Similar & Dissimilar & Both & Total \\
-Count & 22 & 10 & 8 & 40 \\
\hline Treatment & Similar & Dissimilar & Both & Total \\
-Count & 28 & 24 & 5 & 57 \\
\hline
\end{tabular}

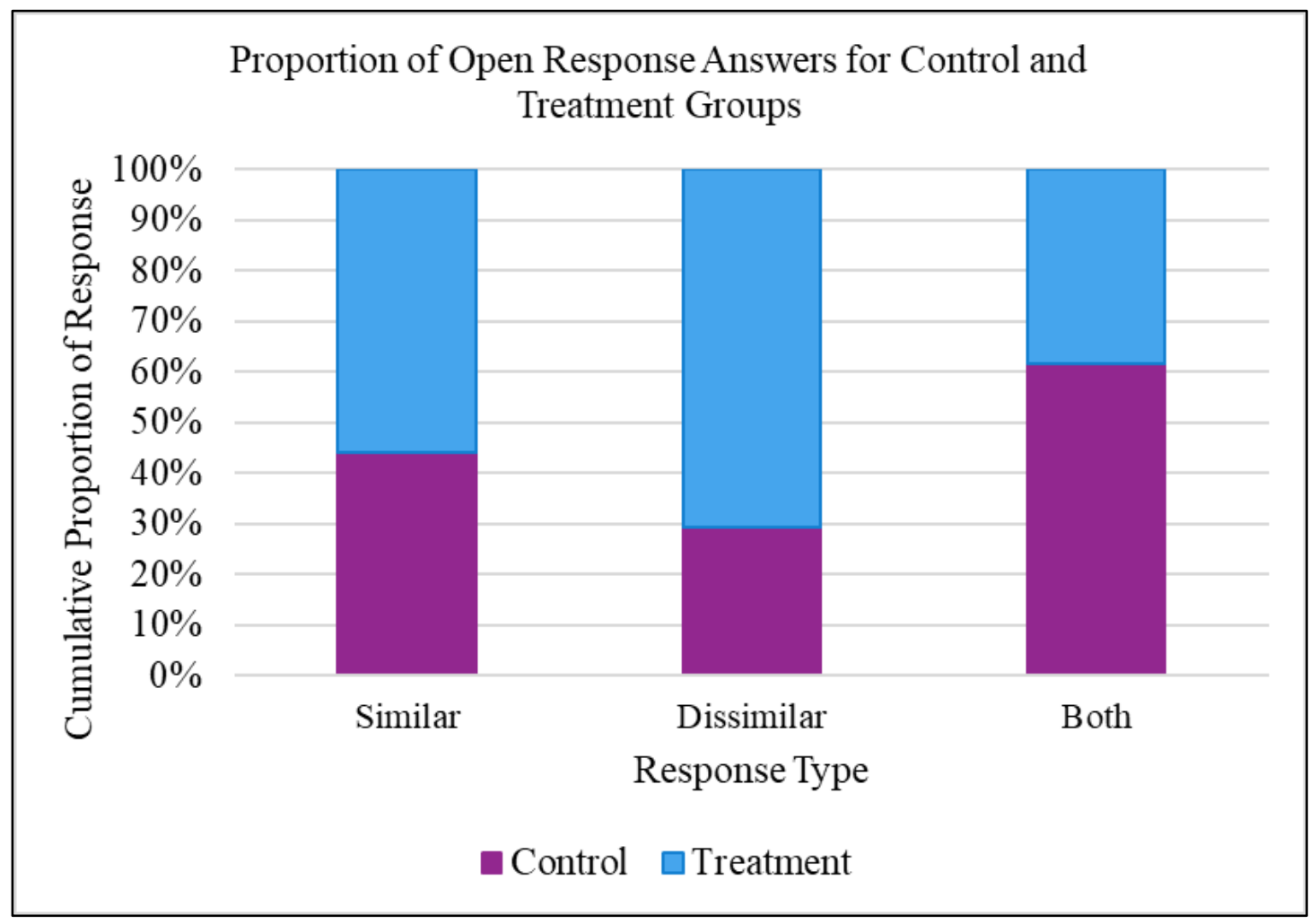

Figure 6. Proportion of open response answers by group

This figure illustrates the different proportions of open response type based on the case study assigned. 
Half of the open responses $(50.5 \%, \mathrm{n}=49)$ did not mention 'female' or 'male' (or 'women' and 'men'). However, of those that did, more students mentioned males first $(29.9 \%, n=29)$ than females first $(19.6 \%, n=19)$ (see Table 25). This trend was true when

I separated responses based on control or treatment (Figure 7). Again, a chi-square test of proportion did not detect statistically significant differences between control and treatment groups. Only $27 \%$ of responses avoided all binary language like 'both' or 'two' sexes, 'females and males', or 'women and men;' e.g., 'Prior to birth, and more specifically prior to the progression of either the Mullerian or Wolfian [sic] ducts, the sexes are quite similar. Prior to puberty, the sexes have similar chemical makes ups that begin to diverge at the onset of puberty." Further, just $3.2 \%$ of responses $(n=4)$ referenced intersex people to justify their answer. However, of those four responses, three referenced intersex to support their stance that the sexes are more similar than dissimilar, and all four were in the treatment group that received intersex case studies.

\section{Table 25}

Cumulative, Control, and Treatment Coding Counts for 'Female First', 'Male First', or 'Neither' Open Responses

\begin{tabular}{lrrrr} 
Cumulative & Female First & Male First & Neither & Total \\
-Count & 19 & 29 & 49 & 97.0 \\
\hline Control & Female First & Male First & Neither & Total \\
-Count & 7 & 13 & 20 & 40 \\
\hline Treatment & Female First & Male First & Neither & Total \\
-Count & 12 & 16 & 29 & 57 \\
\hline
\end{tabular}

I found that $8.1 \%$ of the responses $(n=10)$ used terms associated with gender. For example, one student explained that "all fetuses start as female and then the secretion of testosterone from the $\mathrm{X}$ chromosome is picked up by the receptor on the $\mathrm{Y}$ that then makes it a boy;" suggesting that the counterpart to female is not male, but instead 
gendered category 'boy'. On the other hand, $6.5 \%$ of responses $(\mathrm{n}=8)$ explicitly conflated gender to sex, e.g., "We can see that there are indeed differences between the two genders, they had both started out with the same exact developmental aspects prior to the completion of their development. We can see this with the gonads testis and ovaries belonging to male and female respectively starting out as the same exact structure." or "The sexes both arise from the sex cells of parents with structural and functional differentiation only coming later. The development of structures begins the same with genes producing a gender specific development pathway".

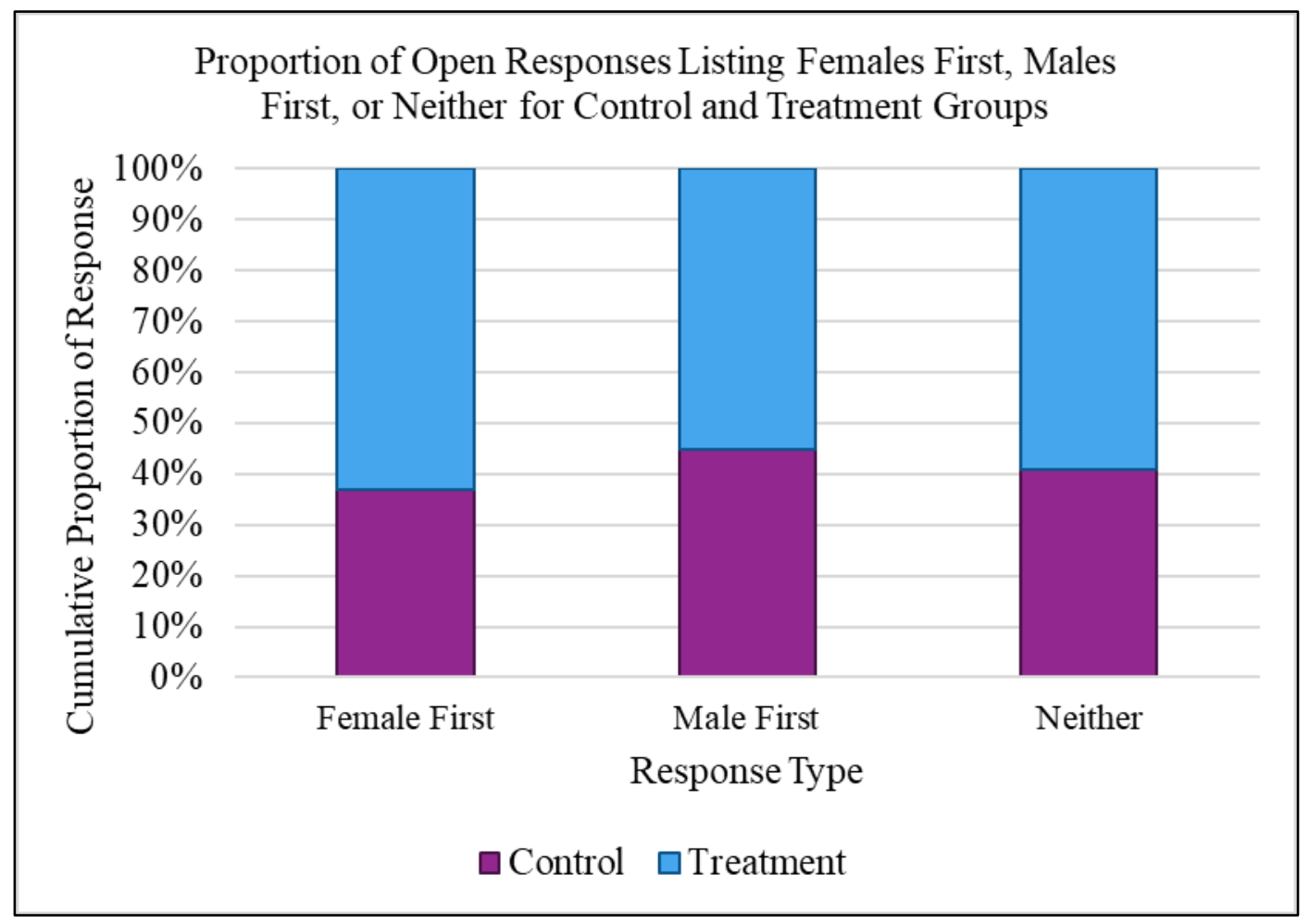

Figure 7. Proportion of open responses listing females first, males first, or neither

This figure illustrates the different proportions of open responses mentioning female or males first or neither based on the case study assigned.

The concept coding found that the types of evidence students used to justify their open responses could be broadly categorized as similarities or differences. Within the 
code 'similarities' I identified eleven recurring subgroups with significant overlap between the twelve subgroups subsumed in the 'differences' code (Table 26). The structure and function of sex or accessory organs, and hormones were the most commonly cited justifications regardless of whether the student referenced the sexes as similar or different. For example, one student may suggest the sexes are dissimilar because they have different gonads that produce different hormones and different gametes, e.g., "Different. Though functionally they both work towards reproduction, they use different hormones and are structurally different. Not to mention that a female can physically carry the baby once her eggs are fertilized. The hormones used for each is also different, so I can't see them as being similar." But another might argue that they are similar because gonads are homologous structures that perform the same functions: "More or less, I believe they are similar because they have equivalents in each system. Both have 2 gonads (ovary or testes) which pump out hormones, both have external genitalia (specialized for function), and both undergo change during puberty due to change in hormones." Of interest, the students quoted above were enrolled in BIOL 465 and BIOL 262 respectively; however, I saw similar levels of detail and response from students in BIOL 102. For example, this non-healthcare BIOL 102 student correctly describes chromosomes, gonads, and gametes in justifying their response, "According to human reproductive anatomy the sexes are similar in some ways but are very different. They both carry an $\mathrm{X}$ chromosome, but males carry a $\mathrm{Y}$ and females carry a second $\mathbf{X}$. They both produce gonads, but the output is different. Females produce an egg and polar body while males produce sperm."

\section{Table 26}




\section{Concept Counts and Frequencies of Similarities and Differences Cited in Open}

$\underline{\text { Responses }}$

\begin{tabular}{lrr} 
Similarities & Count & Frequency \\
\hline Sex or accessory organs & 23 & 18.5 \\
Hormones & 14 & 11.3 \\
Functions & 27 & 21.8 \\
Chromosomes & 2 & 1.6 \\
Gametogenesis & 2 & 1.6 \\
Appearance & 12 & 9.7 \\
Embryonic origin & 21 & 16.9 \\
Fetal development & 2 & 1.6 \\
Development (e.g., puberty) & 4 & 3.2 \\
Procreation as purpose & 11 & 8.9 \\
Structural or developmental homologies & 6 & 4.8 \\
\hline & & \\
Differences & & Frequency \\
Sex or accessory organs & 34 & 23.3 \\
Hormones & 15 & 10.3 \\
Functions & 19 & 13.0 \\
Chromosomes & 8 & 5.5 \\
Gametes & 14 & 9.6 \\
Gametogenesis & 5 & 3.4 \\
Appearance & 13 & 8.9 \\
Embryonic origin & 7 & 4.8 \\
Fetal development & 17 & 11.6 \\
Development (e.g., puberty) & 8 & 5.5 \\
Menstruation & 3 & 2.1 \\
Female complexity & 3 & 2.1 \\
\hline
\end{tabular}

Gametes, fetal development, and outward appearance were common differences cited in responses: e.g., "Men have sperm and women have eggs", "the only difference is that we develop differently depending on our sex determination when we develop in the uterus", and "there are anatomical differences between the sexes; cell size, bone shape, etc. that distinguish the sexes." On the other hand, shared embryonic origin, procreation as purpose, and appearances were cited as commonalities between the sexes: e.g., "in the beginning because they both develop from a bipotential gonad", "both 
reproductive systems have one key purpose: making babies", and "many of the reproductive organs in sexes resemble each other tremendously."

Some students explicitly perpetuated gender essentialist stereotypes in their responses, emphasizing male strength as a biologically determined difference: "I would say men and women reproductive systems are pretty different. Women produce eggs and they [ova] will die off. Men produce sperm indefinitely and tend to be naturally stronger." and "Dissimilar. Men and women have many similarities, but many physical things separate us. Men are built for heavy lifting and women are made with wider hips to give birth (which also make it easier to hold the child)." Others expressed more implicit gender stereotypes: "I think that the sexes are more similar because they have some of the same features and they sometimes share similar emotions and characteristics."

\section{DISCUSSION}

The first part of this study describes the phobias, attitudes, and cultural competence of undergraduate biology students towards members of the LGBTQ+ community. In updating the LGBTAS to consider non-binary gender identities, I deliberately included a population that historically has been (even) more neglected than transgender people who identify along a female/male binary (Frohard-Dourlent et al., 2017).

Overall, the lack of significant differences in phobia and attitude scores between gay/lesbian and bisexual or between transgender and non-binary average subscale scores in conjunction with the strong positive correlation between subscales suggests that, for future efforts, they can be consolidated into 'sexuality' and 'gender identity' without 
compromising the instrument. By reducing the total number of statements in those categories, I could increase the representation of other "hidden" identities, like asexual and intersex, without dramatically increasing the size of the survey itself. This could improve the scales' overall usefulness to both researchers and the LGBTQIA+ community.

The lack of significant differences between gay/lesbian and bisexual subscales suggests that there has been an ideological shift among students since the LGBTAS was published thirteen years ago (Logie et al., 2007). This could be due to increases in bisexual visibility as celebrities and other public figures openly identify as bisexual, thus creating a sociocultural shift toward acceptance. On the other hand, my finding that participants had significantly more negative attitudes and higher phobia toward both transgender and non-binary people aligns with research suggesting that gender diversity is a neglected topic in health science contexts (de Vries, Kathard, \& Müller, 2020; Kellett \& Fitton, 2017) and that heterosexual and gay/lesbian populations perpetuate binary gender norms (Weiss, 2003), albeit with different factors correlated to their attitudes (Warriner et al., 2013).

The tendency of my 'naïve' sample, BIOL 102 students to have higher phobia, more negative attitudes, and lower cultural competence scores than both BIOL 262 and BIOL 465 students' implies that something happens that shifts their perspective sometime prior to entering intermediate and advanced undergraduate courses. Notably, although I did see that non-healthcare majors had significantly higher phobia, more negative attitudes, and lower cultural competence than pre-healthcare majors, the significant difference in cultural competence between intermediate/advanced and 
introductory courses persisted even when I removed non-healthcare majors from the analysis. Therefore, the cause of the difference cannot be assigned to the greater number of non-healthcare majors in the BIOL 102 sample. This parallels my Q-sort finding that more academic experience was associated with a non-binary understanding of sex/gender even when non-healthcare majors are included in the sample. It also reifies the importance of including LGBTQIA + topics in at all levels of undergraduate education (Kang, 2016; Versteeg et al., 2020).

I were not surprised that LGBTQIA+ identity was associated with lower phobia, more positive attitudes, and better cultural competence scores since research shows greater LGBTQIA+ acceptance from within the LGBTQIA+ community than from heterosexuals (Warriner et al., 2013). Furthermore, the unique perspectives gained from LGBTQIA+ lived experiences underlies the importance of recruiting and retaining of LGBTQIA+ students and faculty in developing sexuality and gender-inclusive healthcare and classroom settings (Burke et al., 2015; Lim et al., 2015).

Like other studies reporting gender differences in measures of attitudes and phobias toward LGBTQIA+ people (Broussard \& Warner, 2019; Nagoshi et al., 2008; Norton \& Herek, 2013; Warriner et al., 2013), I detected significant differences between male and female gender identities. The trends I observed aligned with research indicating that female gender identity is associated with lower phobia and more positive attitudes towards members of the LGBTQIA+ community (Norton \& Herek, 2013).

Among Black Americans, sociocultural factors like religious and cultural traditions have been associated with lower acceptance of LGBTQIA+ people (M. J. Hill, 2013; Rosario et al., 2004). However, I found that white students had the greatest 
measures of phobia, which may be related to the increases in white nationalist rhetoric within the United States, since right-wing, conservative ideologies are correlated with anti-LGBTQIA+ sentiment (Makwana et al., 2018; Nagoshi et al., 2008; Warriner et al., 2013). Finding that Black students had significantly better phobia measures than white students suggests that efforts to promote unity and cohesion within Black communities by explicitly uplifting Black LGBTQIA+ experiences (M. J. Hill, 2013) have been fruitful in reducing negative phobias and attitudes.

Although both heterosexual and LGBTQIA+ medical, dental, and nursing students agree that their health science education did not adequately prepared them to treat the LGBTQIA+ community (Greene et al., 2018; Strong \& Folse, 2014), nearly one third of the participants had no desire to learn about LGBTQIA+ healthcare needs. Even more concerning was the large number of pre-healthcare students with this stance. I believe this opinion will persist as long as LGBTQIA+ healthcare, history, and experiences are offered as health science electives rather than integrated as required aspects of the educational experience.

My finding that seven students acknowledged their bias against LGBTQIA+ people can be interpreted as only $6.2 \%$ percent of the students in the sample were explicitly biased. However, research shows that students have implicit bias even if they do not show explicit bias (Burke et al., 2015); the fact that I found more than seven students with high phobia and negative attitudes toward LGBTQIA+ people (based on their uLGBTAS scores) supports this claim. Regardless, no healthcare providers should hold bias against prospective patients, because this would violate the fundamental ethical principles of healthcare practice (APA, 2009; Bell, 2015). 
The second part of this study considered the effect of intersex case studies on students' conceptions of human reproductive anatomy/physiology, content knowledge, and cultural competence scores. My efforts to measure content knowledge using multiple-choice questions was not fruitful. Although no students from BIOL 102 answered all four questions correctly, students from both BIOL 262 and 465 also failed to get any questions correct. Although the results were not useful for this study, there are concerning implications related to my finding that even the advanced students lacked the prior knowledge they should have about the science of human sex characteristics (Kentucky Academic Standards: Science, 2020).

My finding that, for the treatment group, correctly answering the case study comprehension question was associated with significantly higher cultural competence scores may hint at a comprehension or language barrier that limits the effect of the treatment case studies, especially among early undergraduates. Although only a small number of the students mentioned intersex in their open responses $(n=4)$, all of them had read an intersex case study. This suggests that introducing intersex case studies can be successful, but since students require spaced repetition with multiple exposures throughout time to learn (Kang, 2016), they need more than a one-off case study before I should expect to see meaningful changes in perspective. Educators must devote time and attention to refuting common misconceptions (de Bruin, 2020) and give students time to develop alternative conceptions (Kang, 2016).

Although I was surprised that $50.5 \%$ of the open responses did not mention females or males, I was not surprised that male-first was the next largest group, based on the persistent male-before-female structure of anatomy/physiology textbooks 
(Alexanderson et al., 1998; Campo-Engelstein \& Johnson, 2014; Lawrence \& Bendixen, 1992; Mendelsohn et al., 1994; Parker et al., 2017). Likewise, there were implicit and explicit sex/gender binaries, as evidenced by the prevalence of phrases like "both sexes," "the two sexes," or "boys and girls" in the open responses, that shows how deeply embedded in biological contexts that these concepts remain (Lemke, 2011). Based on the 'Binary Conception' from the Q-sort and its association with pre-healthcare majors, I had expected to see binary and essentialist views in the open responses. In addition, the conflation of sex and gender along dichotomous lines that emerged from my Q-sort and textbook analysis also appeared in students' open responses, making clear that these conceptions persist in spite of the scientific evidence disproving them e.g., FaustoSterling (2005); Hyde et al. (2018); Stévant et al. (2018).

Because I did not ask about sexuality in the open response, I did not predict the heteronormative 'procreation as purpose' that emerged as a commonly cited similarity between the sexes. This ideology is emblematic of the way that heterosexuality is both assumed and perpetuated within biomedical contexts and aligns with both chapter two and other textbook analyses e.g., Bazzul and Sykes (2011); De Guzman et al. (2018). It also serves as a reminder that sex, gender, and sexuality are intersectional facets of human identity even if these considerations are often neglected in health science classrooms, to the detriment of all students (Gunckel, 2019).

Whether arguing for similarity or dissimilarity, I was heartened to see that even non-healthcare majors were able to make scientifically grounded arguments for their answers and correctly used scientific terminology like chromosomes or gonads to defend their responses. In particular, students from all three academic levels were able to 
articulate more in-depth, mechanistic reasons for their beliefs, compared to the participants in the Q-sort. My finding that students used so many of the same scientific concepts to justify their opposite responses highlights the powerful epistemic authority of science in validating or refuting sociocultural norms (Kaiser, 2016). It also shows that these biologically mediated differences remain embedded in students' scientific understanding of human sexes, even as other students show evidence of conceptual change that emphasizes the similarities between forms and functions. Still, essentialist conceptions of sex/gender are problematic since they are strongly correlated with negative attitudes toward the LGBTQIA+ community (Elischberger, Glazier, Hill, \& Verduzco-Baker, 2018; Makwana et al., 2018; Norton \& Herek, 2013). Thus, it is vital that health science educators leverage science authority and the changing nature of science knowledge to refute these problematic (and inaccurate) ideologies in our curricula and classrooms.

Although characterizing misconceptions about the science of sex/gender and sexuality was outside the scope of this study, I noticed misconceptions in the open responses. In the future, I would like to evaluate the most common mischaracterizations, so that I can try to deliberately address these misunderstandings about human anatomy/physiology (de Bruin, 2020; Versteeg et al., 2020). Of particular interest are areas like hormones or the function of organs, since I know that these are commonly cited as 'biological differences' which justify the exclusion of transgender and intersex athletes from participating in sporting events (K. Karkazis \& Jordan-Young, 2018). 


\section{Limitations}

This was a single study, rather than a two-part process. I did not survey phobias, attitudes, or cultural competence prior to the case study intervention; therefore, I could not compare the effect of treatment on beliefs prior to reading the case study. Additionally, because of the two-part nature of the study, it was longer than optimal for student attention span (which likely influenced my relatively low response rate). In the future, I want to divide the survey into two parts given at different points during the semester. This should also help increase my sample size, which will better enable us to evaluate interactions between demographic factors like academic major and LGBTQIA+ identity.

Lastly, if I include introductory students in future studies, I need to be aware of the language level of the anatomy/physiology questions, not just the cultural competence and attitude/phobia ones. After consulting with a BIOL 102 instructor it was recommended in particular that the question about the corpora cavernosa should be generalized to say "erectile tissue" to better align with the material presented in introductory biology courses.

\section{Conclusions}

Paradigm shifts are hard, even in spaces where change in response to evidence is a foundational facet of inquiry. This dissertation showcases the complicated, complex, and messy nature of science knowledge; knowledge that cannot be separated from the culture that created it. Science knowledge is not created in a sociocultural vacuum. As I found across these three chapters, no matter how it strives for objectivity, science is a social endeavor. Cultural forces direct the type of research done, so it is no surprise that 
they also manifest in the way textbooks (fail to) represent the diversity of sex, gender, and sexuality. When science succumbs to social pressures, people die. From Ignaz Semmelweis' unsuccessful efforts to champion handwashing to the United States government's handling of the novel coronavirus pandemic, lives are lost when social considerations limit the production and sharing of science knowledge.

To co-opt a well-known phrase, we need to "teach the controversy". In alignment with the epistemic virtues of science, the body of evidence contradicting the 'two sex' model should be included in our classrooms. Additionally, areas like these are prime opportunities to integrate LGBTQIA+ topics into curricula without fetishizing them or casting their identities as disease risks, instead emphasizing the diversity and uniqueness of human bodies and experiences. However, it is vital that LGBTQIA+ people are involved in this process, so that they (finally) have control over how they are embodied in science. Only when the body of knowledge encompasses all people, will we be able to create science spaces that welcome everyone.

Informed consent: Informed consent was obtained from all individual participants included in the study.

Ethical approval: All procedures performed in studies involving human participants were in accordance with the ethical standards of the institutional and/or national research committee (IRB Number: 18.0939) and with the 1964 Helsinki declaration and its later amendments or comparable ethical standards. 


\section{REFERENCES}

AACN, A. A. o. C. o. N. (Producer). (2008, 08/27/2020). Essentials of baccalaureate education for professional nursing practice. Retrieved from https://www.aacnnursing.org/Education$\underline{\text { Resources/AACN-Essentials }}$

Ah-King, M. (2013a). Challenging popular myths of sex, gender and biology. In Crossroads of knowledge. doi:10.1007/978-3-319-01979-6

Ah-King, M. (2013b). Queering animal sexual behavior in biology textbooks. Confero Essays on Education Philosophy and Politics, 1(2), 46-89.

Ahmadi, F., Moinian, D., Pooransari, P., Rashidi, Z., \& Haghighi, H. (2013). Ectopic pregnancy within a cesarean scar resulting in live birth: a case report. Archives of Iranian medicine, 16(11), 0-0.

Akhtar-Danesh, N., Baumann, A., \& Cordingley, L. (2008). Q-methodology in nursing research: a promising method for the study of subjectivity. Western journal of nursing research, 30(6), 759773.

Alexanderson, K., Wingren, G., \& Rosdahl, I. (1998). Gender analyses of medical textbooks on dermatology, epidemiology, occupational medicine and public health. 11,151-163.

Allen, M. (2017). The SAGE encyclopedia of communication research methods: Sage Publications.

APA, A. P. A. (2009). The principles of medical ethics: With annotations especially applicable to psychiatry, 2009 edition revised. Arlington, VA: APA.

Barker, J. H. (2008). Q-methodology: an alternative approach to research in nurse education. Nurse Education Today, 28(8), 917-925.

Bashamboo, A., Eozenou, C., Rojo, S., \& McElreavey, K. (2017). Anomalies in human sex determination provide unique insights into the complex genetic interactions of early gonad development. Clinical Genetics, 91(2), 143-156. doi:10.1111/cge.12932

Bates, D., Mächler, M., Bolker, B., \& Walker, S. (2015). Fitting linear mixed-effects models using lme4. 67(1), 1-48. doi:doi:10.18637/jss.v067.i01

Bazzul, J., \& Sykes, H. (2011). The Secret Identity of a Biology Textbook: Straight and Naturally Sexed. Cultural Studies of Science Education, 6(2), 265-286.

Bell, L. (2015). Code of ethics for nurses with interpretive statements. Critical Care Nurse, 35(4), 84-84.

Bendixen, L. D., \& Feucht, F. C. (2010). Personal epistemology in the classroom : theory, research, and implications for practice. Cambridge, UK ; New York: Cambridge University Press. 
Bidell, M. P., \& Stepleman, L. M. (2017). An interdisciplinary approach to lesbian, gay, bisexual, and transgender clinical competence, professional training, and ethical care: introduction to the special issue. Journal of Homosexuality, 64(10), 1305-1329.

Birke, L. I. A. (2000). Feminism and the biological body. New Brunswich, NJ: Rutgers University Press.

Bohan, J. S. (1993). Regarding Gender: Essentialism, Constructionism, and Feminist Psychology. Psychology of Women Quarterly, 17(1), 5-21. doi:10.1111/j.1471-6402.1993.tb00673.x

Braasch, J. L. G., Goldman, S. R., \& Wiley, J. (2013). The influences of text and reader characteristics on learning from refutations in science texts. Journal of Educational Psychology, 105(3), 561-578. doi: $10.1037 / \mathrm{a} 0032627$

Brennan, A. M. W., Barnsteiner, J., de Leon Siantz, M. L., Cotter, V. T., \& Everett, J. (2012). Lesbian, gay, bisexual, transgendered, or intersexed content for nursing curricula. Journal of Professional Nursing, 28(2), 96-104.

Broussard, K. A., \& Warner, R. H. (2019). Gender Nonconformity Is Perceived Differently for Cisgender and Transgender Targets. Sex Roles : A Journal of Research, 80(7-8), 409-428. doi:10.1007/s11199-018-0947-z

Burke, S. E., Dovidio, J. F., Przedworski, J. M., Hardeman, R. R., Perry, S. P., Phelan, S. M., . . van Ryn, M. (2015). Do Contact and Empathy Mitigate Bias Against Gay and Lesbian People Among Heterosexual First-Year Medical Students? A Report From the Medical Student CHANGE Study. Academic Medicine, 90(5).

Burton, C. W., Nolasco, K., \& Holmes, D. (2020). Queering nursing curricula: Understanding and increasing attention to LGBTQIA+ health needs. Journal of Professional Nursing.

Butler, J. (1990). Gender trouble : feminism and the subversion of identity. New York: Routledge.

Campo-Engelstein, L., \& Johnson, N. L. (2014). Revisiting “The fertilization fairytale:” an analysis of gendered language used to describe fertilization in science textbooks from middle school to medical school. Cultural Studies of Science Education, 9(1), 201-220. doi:10.1007/s11422-0139494-7

Carabez, R., Pellegrini, M., Mankovitz, A., Eliason, M., Ciano, M., \& Scott, M. (2015). "Never in All My Years...": Nurses' Education About LGBT Health. Journal of Professional Nursing, 31(4), 323329. doi:https://doi.org/10.1016/j.profnurs.2015.01.003

Carlson, E. A. (2013). The 7 sexes : biology of sex determination. Bloomington: Indiana University Press.

CDC, C. f. D. C. a. P. (2019, 03/28/2019). Rubella (German Measles) Vaccination. Retrieved from https://www.cdc.gov/vaccines/vpd/rubella/index.html

Chien, S. C., Li, Y. C., Ho, M., Hsu, P. C., Teng, R. H., Lin, W. D., . . Lin, C. C. (2009). Rare rearrangements: a "jumping satellite" in one family and autosomal location of the SRY gene in an XX male. Am J Med Genet A, 149a(12), 2775-2781. doi:10.1002/ajmg.a.32958

Chinn, P. L. (2013). Commentary: Lesbian, Gay, Bisexual, and Transgender Health Disparities We Can Change. Nurse Educator, 38(3), 94-95.

Choleris, E., Galea, L. A. M., Sohrabji, F., \& Frick, K. M. (2018). Sex differences in the brain: Implications for behavioral and biomedical research. Neuroscience and biobehavioral reviews, 85, 126-145. doi:10.1016/j.neubiorev.2017.07.005 
Coleman, J. M., \& Hong, Y.-Y. (2008). Beyond nature and nurture: The influence of lay gender theories on self-stereotyping. Self and Identity, 7(1), 34-53. doi:10.1080/15298860600980185

Cooper, K. M., \& Brownell, S. E. (2016). Coming Out in Class: Challenges and Benefits of Active Learning in a Biology Classroom for LGBTQIA Students. CBE-Life Sciences Education, 15(3), ar37. doi:10.1187/cbe.16-01-0074

Council, F. E. (2019). LGBTQ Family Building Survey. Retrieved from https://www.familyequality.org/fbs

Council, N. R. (1996). National science education standards: National Academies Press.

Council, N. R. (1999). How people learn: Bridging research and practice: National Academies Press.

Cuellar, N. G., Brennan, A. M. W., Vito, K., \& de Leon Siantz, M. L. (2008). Cultural Competence in the Undergraduate Nursing Curriculum. Journal of Professional Nursing, 24(3), 143-149. doi:10.1016/j.profnurs.2008.01.004

de Bruin, A. B. H. (2020). Debunking myths in medical education: The science of refutation. Medical education, 54(1), 6-8. doi:10.1111/medu.14028

De Guzman, F. L. M., Moukoulou, L. N. N., Scott, L. D., \& Zerwic, J. J. (2018). LGBT inclusivity in health assessment textbooks. Journal of Professional Nursing, 34(6), 483-487.

de Vries, E., Kathard, H., \& Müller, A. (2020). Debate: Why should gender-affirming health care be included in health science curricula? BMC Medical Education, 20(1), 51. doi:10.1186/s12909020-1963-6

Dean, M. A., Victor, E., \& Guidry-Grimes, L. (2016). Inhospitable healthcare spaces: why diversity training on LGBTQIA issues is not enough. Journal of bioethical inquiry, 13(4), 557-570.

Dennis, K. E. (1986). Q methodology: relevance and application to nursing research. Advances in nursing science.

Donovan, B. M., Stuhlsatz, M. A. M., Edelson, D. C., \& Buck Bracey, Z. E. (2019). Gendered genetics: How reading about the genetic basis of sex differences in biology textbooks could affect beliefs associated with science gender disparities. Science Education, 103(4), 719-749. doi:10.1002/sce.21502

Dubin, S. N., Nolan, I. T., Streed, C. G., Jr., Greene, R. E., Radix, A. E., \& Morrison, S. D. (2018). Transgender health care: improving medical students' and residents' training and awareness. Advances in medical education and practice, 9, 377-391. doi:10.2147/AMEP.S147183

Dumic, M., Lin-Su, K., Leibel, N. I., Ciglar, S., Vinci, G., Lasan, R., . . New, M. I. (2008). Report of fertility in a woman with a predominantly 46,XY karyotype in a family with multiple disorders of sexual development. The Journal of clinical endocrinology and metabolism, 93(1), 182-189. doi:10.1210/jc.2007-2155

Dunk, R. D. P., Petto, A. J., Wiles, J. R., \& Campbell, B. C. (2017). A multifactorial analysis of acceptance of evolution. Evolution: Education and Outreach, 10(1), 4. doi:10.1186/s12052-017-0068-0

Eliason, M. J. (1998). Correlates of prejudice in nursing students. Journal of Nursing Education, 37(1), 2729. 
Elischberger, H. B., Glazier, J. J., Hill, E. D., \& Verduzco-Baker, L. (2018). Attitudes Toward and Beliefs about Transgender Youth: A Cross-Cultural Comparison Between the United States and India. Sex Roles, 78(1-2), 142-160. doi:10.1007/s11199-017-0778-3

Erduran, S., \& Dagher, Z. R. (2014). Reconceptualizing the Nature of Science for Science Education : Scientific Knowledge, Practices and Other Family Categories. Dordrecht, NETHERLANDS, THE: Springer Netherlands.

European Commission. Directorate-General for, R. (2013). Gendered innovations : how gender analysis contributes to research : report of the Expert group "Innovation through Gender". Luxembourg: Publications Office of the European Union.

Fausto-Sterling, A. (2000). Sexing the body: Gender politics and the construction of sexuality: Basic Books.

Fausto-Sterling, A. (2005). The bare bones of sex: Part 1 - Sex and gender. Signs, 30(2), 1491-1527. doi:Doi 10.1086/424932

Fausto-Sterling, A. (2012). Sex/gender : biology in a social world. New York: Routledge.

Fausto-Sterling, A. (2018). Why sex is not binary. The New York Times, 25.

Ferguson, R. A. (2018). One-dimensional queer: John Wiley \& Sons.

Fifield, S., \& Letts, W. J. (2019). Prolegomenon: queer theories and stem education. Leiden ; Boston: Brill Sense.

Firman, R. e. C. (2018). Postmating sexual conflict and female control over fertilization during gamete interaction. Annals of the New York Academy of Sciences, 1422(1), 48-64. doi:10.1111/nyas.13635

Fitzpatrick, J. L., Willis, C., Devigili, A., Young, A., Carroll, M., Hunter, H. R., \& Brison, D. R. (2020). Chemical signals from eggs facilitate cryptic female choice in humans. Proceedings of the Royal Society B: Biological Sciences, 287(1928), 20200805. doi:10.1098/rspb.2020.0805

Foucault, M. (1978). The history of sexuality: volume I-An introduction: Pantheon Books.

Frohard-Dourlent, H., Dobson, S., Clark, B. A., Doull, M., \& Saewyc, E. M. (2017). "I would have preferred more options": accounting for non-binary youth in health research. Nursing Inquiry, 24(1), e12150.

Fuller, K. (2002). Eradicating Essentialism from Cultural Competency Education. Academic Medicine, $77(3)$.

Fuselier, L., McFadden, J., \& Ray King, K. (2019). Do Biologists' Conceptions of Science as a Social Epistemology Align with Critical Contextual Empiricism? Science \& Education, 28(9-10), 10011025.

Garelick, A. S., Filip-Crawford, G., Varley, A. H., Nagoshi, C. T., Nagoshi, J. L., \& Evans, R. (2017). Beyond the Binary: Exploring the Role of Ambiguity in Biphobia and Transphobia. Journal of Bisexuality, 17(2), 172-189. doi:10.1080/15299716.2017.1319890

Gilbert, J. (2001). Science and Its "Other": Looking underneath "Woman" and "Science" for New Directions in Research on Gender and Science Education. Gender and Education, 13(3), 291-305. 
Glaser, B. G., Strauss, A. L., \& Strutzel, E. (1968). The discovery of grounded theory; strategies for qualitative research. Nursing research, 17(4), 364.

Glaser, R., \& Dimitrakakis, C. (2013). Testosterone therapy in women: Myths and misconceptions. Maturitas, 74(3), 230-234. doi:https://doi.org/10.1016/j.maturitas.2013.01.003

Gliem, J. A., \& Gliem, R. R. (2003). Calculating, interpreting, and reporting Cronbach's alpha reliability coefficient for Likert-type scales.

Granger, D. A., Shirtcliff, E. A., Booth, A., Kivlighan, K. T., \& Schwartz, E. B. (2004). The "trouble" with salivary testosterone. Psychoneuroendocrinology, 29(10), 1229-1240. doi:https://doi.org/10.1016/j.psyneuen.2004.02.005

Greene, M. Z., France, K., Kreider, E. F., Wolfe-Roubatis, E., Chen, K. D., Wu, A., \& Yehia, B. R. (2018). Comparing medical, dental, and nursing students' preparedness to address lesbian, gay, bisexual, transgender, and queer health. Plos One, 13(9), e0204104. doi:10.1371/journal.pone.0204104

Gunckel, K. L. (2019). What does queer theory have to do with teaching science in elementary schools? In W. J. Letts \& S. Fifield (Eds.), STEM of desire : queer theories and science education. Leiden ; Boston: Brill Sense.

Hammarstrom, A., \& Annandale, E. (2012). A Conceptual Muddle: An Empirical Analysis of the Use of 'Sex' and 'Gender' in 'Gender-Specific Medicine' Journals. Plos One, 7(4). doi:ARTN e34193 10.1371/journal.pone.0034193

Harrison, C., \& Tanner, K. D. (2018). Language Matters: Considering Microaggressions in Science. CBELife Sciences Education, 17(1), fe4. doi:10.1187/cbe.18-01-0011

Health, N. I. o. (2011). In The Health of Lesbian, Gay, Bisexual, and Transgender People: Building a Foundation for Better Understanding. Washington (DC).

Heath, H., \& Cowley, S. (2004). Developing a grounded theory approach: a comparison of Glaser and Strauss. International journal of nursing studies, 41(2), 141-150.

Herreid, C. F. (2005). Using Case Studies to Teach Science. Education: Classroom Methodology. American Institute of Biological Sciences.

Heyman, G. D., \& Giles, J. W. (2006). Gender and Psychological Essentialism. 293-310. doi:10.3917/enf.583.0293

Hill, D. B., \& Willoughby, B. L. B. (2005). The Development and Validation of the Genderism and Transphobia Scale. Sex Roles, 53(7), 531-544. doi:10.1007/s11199-005-7140-x

Hill, M. J. (2013). Is the Black Community More Homophobic?: Reflections on the Intersectionality of Race, Class, Gender, Culture and Religiosity of the Perception of Homophobia in the Black Community. Journal of Gay \& Lesbian Mental Health, 17(2), 208-214. doi:10.1080/19359705.2013.768089

Hyde, J. S. (2016). Sex and cognition: gender and cognitive functions. Current Opinion in Neurobiology, 38, 53-56. doi:https://doi.org/10.1016/j.conb.2016.02.007

Hyde, J. S., Bigler, R. S., Joel, D., Tate, C. C., \& van Anders, S. M. (2018). The future of sex and gender in psychology: Five challenges to the gender binary. Am Psychol. doi:10.1037/amp0000307 
Index, C. P. (2020). University of Louisville Campus Pride Index. Retrieved from https://www.campusprideindex.org/campuses/details/492?campus=university-of-louisville $\% 5 \mathrm{~d}$

James, S., Herman, J., Rankin, S., Keisling, M., Mottet, L., \& Anafi, M. a. (2016). The report of the 2015 US transgender survey.

Jamieson, S. (2004). Likert scales: How to (ab) use them? Medical education, 38(12), 1217-1218.

Johnson, J. L., Greaves, L., \& Repta, R. (2009). Better science with sex and gender: Facilitating the use of a sex and gender-based analysis in health research. International Journal for Equity in Health, 8, 111. doi:10.1186/1475-9276-8-14

Kaiser, A. (2016). Sex/Gender Matters and Sex/Gender Materialities in the Brain. Mattering: Feminism, Science, and Materialism, 1, 122.

Kang, S. H. K. (2016). Spaced Repetition Promotes Efficient and Effective Learning : Policy Implications for Instruction. Policy Insights from the Behavioral and Brain Sciences, 3(1), 12-19. doi: $10.1177 / 2372732215624708$

Karkazis, K., \& Jordan-Young, R. M. (2018). The powers of testosterone: Obscuring race and regional bias in the regulation of women athletes. Feminist Formations, 30(2), 1-39.

Karkazis, K. A. (2008). Fixing sex : intersex, medical authority, and lived experience. Durham: Duke University Press.

Kato, K., Abe, H., Hanawa, N., Fukuzawa, J., Matsuo, R., Yonezawa, T., .. . Tsubota, A. (2018). Hepatocellular adenoma in a woman who was undergoing testosterone treatment for gender identity disorder. Clinical Journal of Gastroenterology, 11(5), 401-410. doi:10.1007/s12328-018$0854-4$

Keller, J. (2005). In genes we trust: the biological component of psychological essentialism and its relationship to mechanisms of motivated social cognition. J Pers Soc Psychol, 88(4), 686-702. doi:10.1037/0022-3514.88.4.686

Kellett, P., \& Fitton, C. (2017). Supporting transvisibility and gender diversity in nursing practice and education: embracing cultural safety. Nursing Inquiry, 24(1), e12146. doi:10.1111/nin.12146

Kemp, T. (2013). Three siblings with complete androgen insensitivity syndrome. Journal of Endocrinology, Metabolism and Diabetes of South Africa, 18(3), 159-163.

Kentucky Academic Standards: Science. (2020). https://education.ky.gov/curriculum/conpro/science/Pages/default.aspx Retrieved from https://education.ky.gov/curriculum/standards/kyacadstand/Documents/Kentucky_Academic Stan dards Science.pdf.

Kessler, S. J. (1990). The medical construction of gender: Case management of intersexed infants. Signs: Journal of Women in Culture and Society, 16(1), 3-26.

Kitzinger, C. (1986). Introducing and developing Q as a feminist methodology: A study of accounts of lesbianism. Feminist social psychology: Developing theory and practice, 151-172.

Knaier, M. L. (2019). What makes girls and boys so desirable? : STEM education -- Beyond gender binaries. In W. J. Letts \& S. Fifield (Eds.), STEM of desire : queer theories and science education. Leiden ; Boston: Brill Sense. 
Knight, K. (2017). "I Want to Be Like Nature Made Me" Medically Unnecessary Surgeries on Intersex Children in the US.

Lavrakas, P. J. (2008). Encyclopedia of survey research methods. In SAGE research methods online. doi:https://dx.doi.org/10.4135/9781412963947.n228

Lawrence, S. C., \& Bendixen, K. (1992). His and hers: Male and female anatomy in anatomy texts for U.S. medical students, 1890-1989. Social Science \& Medicine, 35(7), 925-934. doi:https://doi.org/10.1016/0277-9536(92)90107-2

Lee, K. F., Chan, A. O., Fok, J. M., Mak, M. W., Yu, K. C., Lee, K. M., \& Shek, C. C. (2013). Late presentation of simple virilising 21-hydroxylase deficiency in a Chinese woman with Turner's syndrome. Hong Kong Med J, 19(3), 268-271. doi:10.12809/hkmj133717

Lemke, J. (2011). The secret identity of science education: Masculine and politically conservative? Cultural Studies of Science Education, 6, 287-292. doi:10.1007/s11422-011-9326-6

Letts, W. J. (1999). How to make "boys" and "girls" in the classroom: The heteronormative nature of elementary-school science. Queering elementary education: Advancing the dialogue about sexualities and schooling, 97-110.

Letts, W. J. (2002). Revisioning multiculturalism in teacher education: Isn't it queer. Getting ready for Benjamin: Preparing teachers for sexual diversity in the classroom, 119-131.

Liening, S. H., Stanton, S. J., Saini, E. K., \& Schultheiss, O. C. (2010). Salivary testosterone, cortisol, and progesterone: Two-week stability, interhormone correlations, and effects of time of day, menstrual cycle, and oral contraceptive use on steroid hormone levels. Physiology \& Behavior, 99(1), 8-16. doi:https://doi.org/10.1016/j.physbeh.2009.10.001

Lim, F., Johnson, M., \& Eliason, M. (2015). A national survey of faculty knowledge, experience, and readiness for teaching lesbian, gay, bisexual, and transgender health in baccalaureate nursing programs. Nursing Education Perspectives, 36(3), 144-152.

Logie, C., Bridge, T. J., \& Bridge, P. D. (2007). Evaluating the phobias, attitudes, and cultural competence of Master of Social Work students toward the LGBT populations. Journal of Homosexuality, 53(4), 201-221. doi:10.1080/00918360802103472

Longino, H. E. (1990). Science as social knowledge : values and objectivity in scientific inquiry. Princeton, N.J.: Princeton University Press.

Longino, H. E. (2002). The fate of knowledge. Princeton, N.J.: Princeton University Press.

Longino, H. E., Alcoff, L., \& Potter, E. (2002). Subjects, power, and knowledge: Description and prescription in feminist philosophies of science. Knowledge and inquiry: Readings and epistemology, 385-404.

Lubke, G. H., \& Muthén, B. O. (2004). Applying multigroup confirmatory factor models for continuous outcomes to Likert scale data complicates meaningful group comparisons. Structural equation modeling, 11(4), 514-534.

Makadon, H. J., Mayer, K. H., Potter, J., Goldhammer, H., \& American College of Physicians. (2015). The Fenway guide to lesbian, gay, bisexual, and transgender health (Second edition. ed.). Philadelphia: American College of Physicians. 
Makwana, A. P., Dhont, K., De keersmaecker, J., Akhlaghi-Ghaffarokh, P., Masure, M., \& Roets, A. (2018). The Motivated Cognitive Basis of Transphobia: The Roles of Right-Wing Ideologies and Gender Role Beliefs. Sex Roles, 79(3), 206-217. doi:10.1007/s11199-017-0860-x

Mangiafico, S. S. (2020). rcompanion: Functions to Support Extension Education Program Evaluation (Version R package version 2.3.25). Retrieved from https://CRAN.Rproject.org/package $=$ rcompanion

Manzouri, A., \& Savic, I. (2018). Multimodal MRI suggests that male homosexuality may be linked to cerebral midline structures. Plos One, 13(10), e0203189. doi:10.1371/journal.pone.0203189

Marieb, E. N., \& Hoehn, K. (2018). Human anatomy \& physiology (Eleventh edition. ed.). Hoboken, New Jersey: Pearson Education, Inc.

Mayer, L. (2016). Special Report: Sexuality and Gender - Findings from the Biological, Psychological, and Social Sciences. The New Atlantis, 50(Fall 2016).

Mayfield, J., De May, H., Tillery, K., Winer, J., Ball, E., Rogers, J., . . Crandall, C. (2016). Lesbian, Gay, Bisexual, Transgender, and Queer (LGBTQ) Healthcare in Undergraduate Medical Education: Assessment and Focused Intervention for Medical Students Transitioning to the Wards.

Mayo, J. B., Jr. (2016). Adults' Complicity in Limiting Students' Understanding of Sex, Gender and Sexuality at School. Sex Education: Sexuality, Society and Learning, 16(1), 105-110.

McCredie, J. (2011). Making girls and boys : inside the science of sex. Sydney: University of New South Wales Press.

McKeown, B. F., \& Thomas, D. B. (1988). Q methodology (Quantitative applications in the social sciences series, vol. 66). In: Thousand Oaks, CA: Sage.

McNiel, P. L., \& Elertson, K. M. (2018). Advocacy and awareness: Integrating LGBTQ health education into the prelicensure curriculum. Journal of Nursing Education, 57(5), 312-314.

Mendelsohn, K. D., Nieman, L. Z., Isaacs, K., Lee, S., \& Levison, S. P. (1994). Sex and Gender Bias in Anatomy and Physical Diagnosis Text Illustrations. JAMA, 272(16), 1267-1270. doi:10.1001/jama.1994.03520160051042

Minkina, A., Matson, C. K., Lindeman, R. E., Ghyselinck, N. B., Bardwell, V. J., \& Zarkower, D. (2014). DMRT1 protects male gonadal cells from retinoid-dependent sexual transdifferentiation. Developmental cell, 29(5), 511-520.

Mircioiu, C., \& Atkinson, J. (2017). A Comparison of Parametric and Non-Parametric Methods Applied to a Likert Scale. Pharmacy, 5(2), 26.

Motulsky, H. J. (2020). GraphPad Statistics Guide. Retrieved from http://www.graphpad.com/guides/prism/7/statistics/index.htm

Nadal, K. L., Whitman, C. N., Davis, L. S., Erazo, T., \& Davidoff, K. C. (2016). Microaggressions Toward Lesbian, Gay, Bisexual, Transgender, Queer, and Genderqueer People: A Review of the Literature. The Journal of Sex Research, 53(4-5), 488-508. doi:10.1080/00224499.2016.1142495

Nagoshi, J. L., Adams, K. A., Terrell, H. K., Hill, E. D., Brzuzy, S., \& Nagoshi, C. T. (2008). Gender Differences in Correlates of Homophobia and Transphobia. Sex Roles, 59(7), 521. doi:10.1007/s11199-008-9458-7 
Neuendorf, K. A. (2011). Content analysis-A methodological primer for gender research. Sex Roles, 64(34), 276-289.

Nguyen, H. B., Loughead, J., Lipner, E., Hantsoo, L., Kornfield, S. L., \& Epperson, C. N. (2019). What has sex got to do with it? The role of hormones in the transgender brain. Neuropsychopharmacology, 44(1), 22-37. doi:10.1038/s41386-018-0140-7

Nicholson, L. (1994). Interpreting Gender. Signs, 20(1), 79-105.

Norton, A. T., \& Herek, G. M. (2013). Heterosexuals' Attitudes Toward Transgender People: Findings from a National Probability Sample of U.S. Adults. Sex Roles, 68(11), 738-753. doi:10.1007/s11199-011-0110-6

Nulty, D. D. (2008). The Adequacy of Response Rates to Online and Paper Surveys: What Can Be Done? Assessment \& Evaluation in Higher Education, 33(3), 301-314.

Overall, J. E. (1980). Continuity Correction for Fisher's Exact Probability Test. Journal of Educational Statistics, 5(2), 177-190. doi:10.3102/10769986005002177

Papadopoulos, I., \& Lees, S. (2002). Developing culturally competent researchers. Journal of Advanced Nursing, 37(3), 258-264. doi:10.1046/j.1365-2648.2002.02092.x

Parker, R., Larkin, T., \& Cockburn, J. (2017). A visual analysis of gender bias in contemporary anatomy textbooks. Social Science \& Medicine, 180, 106-113. doi:10.1016/j.socscimed.2017.03.032

Phelan, S. M., Burke, S. E., Hardeman, R. R., White, R. O., Przedworski, J., Dovidio, J. F., . . van Ryn, M. (2017). Medical School Factors Associated with Changes in Implicit and Explicit Bias Against Gay and Lesbian People among 3492 Graduating Medical Students. Journal of General Internal Medicine, 32(11), 1193-1201. doi:10.1007/s11606-017-4127-6

Pitts-Taylor, V. (2016). Mattering : feminism, science, and materialism. New York: New York University Press.

Prakash, N., Khurana, A., \& Narula, B. (2009). Persistent müllerian duct syndrome. Indian Journal of Pathology and Microbiology, 52(4), 546-548. doi:10.4103/0377-4929.56160

Reilly, R. R. (2016). Pope Francis vs. gender ideology. Retrieved from https://www.catholicworldreport.com/2016/08/13/pope-francis-vs-gender-ideology/

Reiner, W. G. (1996). Case study: sex reassignment in a teenage girl. Journal of the American Academy of Child \& Adolescent Psychiatry, 35(6), 799-803.

Reiss, M. J. (2019). Thinking like a fox : queering the science classroom when teaching about sex and sexuality. In W. J. Letts \& S. Fifield (Eds.), STEM of desire : queer theories and science education. Leiden ; Boston: Brill Sense.

Richardson, S. S. (2013). Sex itself: the search for male and female in the human genome. Chicago ; London: The University of Chicago Press.

Ringdahl, E. N., \& Teague, L. (2006). Testicular torsion. American family physician, 74(10), 1739-1743.

Rippon, G. (2019). Gender and our brains : how new neuroscience explodes the myths of the male and female minds (First United States edition. ed.). New York: Pantheon Books. 
Risberg, G., Johansson Eva, E., \& Hamberg, K. (2009). A theoretical model for analysing gender bias in medicine. International Journal for Equity in Health, 8(1), 28. Retrieved from

Röndahl, G., Innala, S., \& Carlsson, M. (2004). Nursing staff and nursing students 'emotions towards homosexual patients and their wish to refrain from nursing, if the option existed. Scandinavian journal of caring sciences, 18(1), 19-26.

Rosario, M., Schrimshaw, E. W., \& Hunter, J. (2004). Ethnic/racial differences in the coming-out process of lesbian, gay, and bisexual youths: A comparison of sexual identity development over time. Cultural Diversity and Ethnic Minority Psychology, 10(3), 215.

Rossi, A. L., \& Lopez, E. J. (2017). Contextualizing Competence: Language and LGBT-Based Competency in Health Care. Journal of Homosexuality, 64(10), 1330-1349. doi:10.1080/00918369.2017.1321361

Røthing, Å. (2017). Sexual orientation in Norwegian science textbooks: Heteronormativity and selective inclusion in textbooks and teaching. Teaching and Teacher Education, 67, 143-151. doi:10.1016/j.tate.2017.06.005

Roy, D., \& Subramaniam, B. (2016). Matter in the shadows: Feminist new materialism and the practices of colonialism. Mattering: Feminism, science and materialism, 23-42.

Rubin, G. (1975). The Traffic in Women: Notes on the 'Political Economy' of Sex. In R. R. Reiter (Ed.), Toward an anthropology of women (pp. 179). New York: Monthly Review Press.

Saini, A. (2017). Inferior: how science got women wrong and the new research that's rewriting the story. Boston: Beacon Press.

Saladin, K. S., Gan, C. A., \& Cushman, H. N. (2018). Anatomy \& physiology: the unity of form and function (Eighth edition. ed.). New York, NY: McGraw-Hill Education.

Saldaña, J. (2016). The coding manual for qualitative researchers (3E Third edition . ed.). Los Angeles ; London: SAGE.

Santavicca, N., Bazzul, J., \& Witzig, S. (2019). Camping science education: a trip to Camp Wilde and the queer nature of nature. In W. J. Letts \& S. Fifield (Eds.), STEM of desire : queer theories and science education. Leiden; Boston: Brill Sense.

Schaffner, J. H. (1927). Sex-limited characters and allosome-linked heredity.

Schmolck, P. (2014). PQMethod (Version 2.35).

Scholer, A.-M. (2002). Sexuality in the Science Classroom: One teacher's methods in a college biology course. Sex Education, 2(1), 75-86.

Schulster, M., Bernie, A. M., \& Ramasamy, R. (2016). The role of estradiol in male reproductive function. Asian journal of andrology, 18(3), 435-440. doi:10.4103/1008-682X.173932

Sedgwick, E. K. (2008). Epistemology of the closet (Updated with a new preface. ed.). Berkeley, California: University of California Press.

Senn, C. (1996). Q-methodology as feminist methodology: Women's views and experiences of pornography. Feminist social psychologies: International perspectives, 201-217. 
Shetty, N. K. (2018). Inheritance of Chromosomes, Sex Determination, and the Human Genome. Gender and the Genome. Retrieved from doi:10.1177/2470289718787131

Snyder, V. L., \& Broadway, F. S. (2004). Queering high school biology textbooks. Journal of research in science teaching, 41(6), 617-636.

Stefurak, T., Taylor, C., \& Mehta, S. (2010). Gender-specific models of homosexual prejudice: Religiosity, authoritarianism, and gender roles. Psychology of Religion and Spirituality, 2(4), 247-261. doi:10.1037/a0021538

Stévant, I., Papaioannou, M. D., \& Nef, S. (2018). A brief history of sex determination. Molecular and Cellular Endocrinology, 468, 3-10. doi:https://doi.org/10.1016/j.mce.2018.04.004

Strong, K. L., \& Folse, V. N. (2014). Assessing undergraduate nursing students' knowledge, attitudes, and cultural competence in caring for lesbian, gay, bisexual, and transgender patients. Journal of Nursing Education, 54(1), 45-49.

Taylor, A. K., Condry, H., \& Cahill, D. (2018). Implementation of teaching on LGBT health care. The clinical teacher, 15(2), 141-144. doi:10.1111/tct.12647

Tortora, G. J., \& Derrickson, B. (2017). Tortora's principles of anatomy \& physiology (15th edition, Global edition. ed.). Hoboken, NJ: John Wiley \& Sons, Inc.

Traister, T. (2020). Improving LGBTQ Cultural Competence of RNs Through Education. The Journal of Continuing Education in Nursing, 51(8), 359-366.

Tulchinsky, D., Hobel, C. J., Yeager, E., \& Marshall, J. R. (1972). Plasma estrone, estradiol, estriol, progesterone, and 17-hydroxyprogesterone in human pregnancy: I. Normal pregnancy. American Journal of Obstetrics \& Gynecology, 112(8), 1095-1100. doi:10.1016/0002-9378(72)90185-8

Uhlenhaut, N. H., Jakob, S., Anlag, K., Eisenberger, T., Sekido, R., Kress, J., . . Treier, M. (2009). Somatic Sex Reprogramming of Adult Ovaries to Testes by FOXL2 Ablation. Cell, 139(6), 11301142. doi:https://doi.org/10.1016/j.cell.2009.11.021

van Anders, S. M. (2010). Chewing gum has large effects on salivary testosterone, estradiol, and secretory immunoglobulin A assays in women and men. Psychoneuroendocrinology, 35(2), 305-309. doi:https://doi.org/10.1016/j.psyneuen.2009.06.009

van Anders, S. M. (2013). Beyond masculinity: Testosterone, gender/sex, and human social behavior in a comparative context. Frontiers in Neuroendocrinology, 34(3), 198-210. doi:https://doi.org/10.1016/j.yfrne.2013.07.001

VanPutte, C. L., Regan, J. L., Russo, A. F., Seeley, R. R., Stephens, T., \& Tate, P. (2017). Seeley's anatomy and physiology (Eleventh edition. ed.). New York, NY: McGraw-Hill Education.

Versteeg, M., van Loon, M. H., Wijnen-Meijer, M., \& Steendijk, P. (2020). Refuting misconceptions in medical physiology. BMC Medical Education, 20(1), 250. doi:10.1186/s12909-020-02166-6

Warriner, K., Nagoshi, C. T., \& Nagoshi, J. L. (2013). Correlates of homophobia, transphobia, and internalized homophobia in gay or lesbian and heterosexual samples. Journal of Homosexuality, 60(9), 1297-1314. doi:10.1080/00918369.2013.806177

Watts, S., \& Stenner, P. (2012). Doing Q methodological research : theory, method and interpretation. Los Angeles: Sage. 
Weasel, L. H. (2016). Embodying Intersectionality. Mattering: Feminism, Science, and Materialism, 1, 104.

Weiss, J. T. (2003). GL vs. BT. Journal of Bisexuality, 3(3-4), 25-55. doi:10.1300/J159v03n03_02

Whitley, B. E., \& Ægisdóttir, S. (2000). The Gender Belief System, Authoritarianism, Social Dominance Orientation, and Heterosexuals' Attitudes Toward Lesbians and Gay Men. Sex Roles, 42(11), 947967. doi:10.1023/A:1007026016001

Wiley, A., \& Klosterman, M. (2012). More Is Less: Adding Details to Reduce Complexity and Help Prevent Misconceptions. Science and Children, 50(2), 35.

Zucker, I., \& Beery, A. K. (2010). Males still dominate animal studies. Nature, 465(7299), 690-690. 


\begin{abstract}
APPENDIX I
$\underline{\text { Key Terms Supplement }}$

There are some specific terms used in this survey that may be unfamiliar to some. We have defined these Key Terms below:

Bisexual - individuals experiencing sexual attraction to individuals of two different genders
\end{abstract}

Cisgender - individuals whose gender identity agrees with the sex originally assigned to them at birth (i.e., people identified as male at birth who continue to identify as male throughout their lifetime)

Gay - male individuals who experience sexual attraction to other males

Heterosexual - individuals who experience sexual attraction to the opposite sex

Intersex - individuals born with sex characteristics belonging to both male and female (also called 'hermaphrodite' in some non-human animals)

Lesbian - female individuals who experience sexual attraction to other females Non-binary - individuals whose gender identity is neither male nor female

Transgender - individuals whose gender expression varies significantly from what is traditionally associated with or typical for that sex (i.e., people identified as male at birth who subsequently identify as female, and people identified as female at birth who later identify as male) 


\section{Case Study: Sex Reassignment in a Teenage Girl}

WILLIAM GEORGE REINER, M.D.

This article has been edited to meet study inclusion standards. WC: 1031

\section{Case Study}

V.P., an adolescent female Hmong immigrant, was first evaluated at the age of 14 years, after dropping out of school after placement in girls' physical education and chorus classes. When interviewed by the school nurse, V.P. stated simply, "I am not a girl, I am a boy". V.P.'s first statement about gender identity was this testimony to the nurse, who referred the child for evaluation.

V.P. was born in Laos; there were no problems in the pregnancy or delivery. The parents did not have reason to question the baby's health or physical status. Two brothers were born later to the same parents. When V.P. was 5 years old, the family moved to the United States. All of V.P.'s school-age friends were boys. She never engaged in feminine play roles, and preferred male roles in imaginary play but would be willing to take gender-neutral roles. At the age of 8 years, V.P. recognized that "something was wrong," although she could not pinpoint what. V.P. noted that at about age 10 she realized, "I am a boy." She ceased wearing dresses and wore unisex styles until age 11, when she began the exclusive use of boys' clothes. Her haircut also switched to a unisex then a masculine style. By the age of 12 years, V.P. felt increasingly isolated from family and "different" from her few friends who were all Hmong and male. At the time she was evaluated, her parents were supportive.

Physical examination revealed a mid-to-late pubescent child with lean body mass and moderate musculature. There were no dysmorphic features; shoulders were broad, and the pelvis was narrow and short. There were no abdominal masses or inguinal masses although there was clitoral hypertrophy with a stretched midglans-to-pubis phallic length of about $4 \mathrm{~cm}$ (more than two standard deviations below the male mean for age). Labioscrotal folds were separated by smooth, nonrugated tissue with a small urogenital sinus just inferior to the clitoris but no urethral meatus was visible.

Bloodwork identified a peripheral blood cell karyotype of 46, XY and V.P.'s testosterone (T) level was $135 \mathrm{ng} / \mathrm{dL}$ (normal range $=360$ to 990 for adult male, 17 to 50 for adult female). CT scan of the abdomen and pelvis revealed detected a questionable small gonad in the left inguinal ring. Ultrasound showed a probable small vagina and hypoplastic uterus but did not detect gonads. However, surgical exploration revealed a small undescended testis with a detached epididymis but intact vas deferens. Cystoscopy revealed a moderate-sized urogenital sinus and a 
long urethra opening into the bladder with a broad bladder neck. No prostatic tissue or ejaculatory ducts were visible. Inferiorly and internally was a prepuberal vagina culminating at a normal cervical os. Surgically, an immature hemiuterus, cervix, and internal vagina were identified and palpable; there was a fully formed fallopian tube on the right with its fimbriated end sequestering a non-functional gonad. Biopsy of the left gonad revealed immature testis with sparse seminiferous tubules lined by Sertoli cells and sparse Leydig cells.

Surgically, the labioscrotal folds were united, the left testis was placed in the new scrotum, the right non-functional gonad was excised, the phallus was straightened, and a penile urethra was constructed. In response to T replacement therapy over two years V.P.'s voice changed, minimal axillary and linea alba hair developed, and the penis grew rapidly to a stretched phallic length of nearly $7.0 \mathrm{~cm}$, with a $2.5-\mathrm{cm}$ midshaft breadth while erect. Erections were of full turgidity, and masturbatory activity led to orgasm with a dry ejaculation.

\section{Discussion}

The patient in this case presented with a typical mixed gonadal dysgenesis (MGD) phenotype. Prenatal asymmetrical local lateralization of production of $\mathrm{T}$ and of Müllerian inhibiting substance lead to asymmetry of his internal and external gonadal and genital anatomy. V.P.'s laboratory and anatomic profile rule out other diagnoses of intersex. Neonatal genital ambiguity, including severe hypospadias, pseudohermaphroditism, and cloacal exstrophy, is estimated to occur in around 1 out of every 2500 births. But, gender identity has been difficult to predict in these children because in the human it involves complex biological and psychosocial developmental processes, some of which take place during prenatal developmental periods and some postnatally. Far from being a simple question of the assignment of sex-of-rearing at birth, intersex syndromes imply the need for a greater understanding by the treatment team of psychosexual as well as psychosocial implications of decision making in the neonatal period.

As an adolescent V.P. made a firm decision that he was a male and was to be referred to as "he." However, his psychosocial progress and state were unstable for a period: he was frustrated over the need for corrective repairs for postoperative complications, over Medicaid's refusal to pay for portions of the surgery, and unsupportive parents. Although V.P.'s parents were initially supportive they became unsupportive; they felt they had lost their only daughter. V.P. faced his medical plight alone-including transportation, injections, and office visits. Three months after his final surgery, V.P. expressed disappointment that his penis was short; he showed signs and symptoms of a major depression. Attempts at enlisting psychiatric consultation at this time were difficult and were successful only after he expressed some passive suicidal ideation. 
Within 6 weeks of psychiatric consultation his mood had improved, and he began a series of somewhat regular though spontaneous visits for "psychosexual counseling." While his friends remained nearly all males, V.P. expressed an interest (at age 16) in a girl in his high school class and asked for guidance in conversational content and how to ask her for a date. At age 17 he sought counsel in how to kiss and pet, and at age 18 he noted he was quite serious about a girl in his class and asked whether sexual intercourse was feasible. Being counseled not only in techniques and positions for intercourse (in terms of his anatomical differences), V.P. was also counseled about the need for open communication with his partner about intimate matters prior to initiating sexual contact. V.P. was still dating the same girl and was sexually active when seen for a visit at age 19. His mood remained stable, his outlook was expectant, and he had never again raised questions about his gender identity.

\section{Reading Comprehension Question}

V.P.'s functional gonad was identified as:
a) Testis
b) Ovary
c) Neither 


\section{Testicular Torsion}

ERIKA RINGDAHL, M.D., and LYNN TEAGUE, M.D.

University of Missouri-Columbia School of Medicine, Columbia, Missouri

This article has been edited to meet study inclusion criteria. WC: 1027

\section{Case Study}

D.T., a 14-year-old adolescent white male, presented to the emergency department complaining of acute scrotal pain centered on the left side of his body with onset approximately six hours earlier. He reported no trauma or injury to the area prior to the onset of pain. Discoloration of the scrotum was observed, an absence of the cremasteric reflex noted, and the left testis appeared larger than the right one. Based on our initial physical examination we recommended immediate surgery to confirm our diagnosis of testicular torsion and detorse the left testicle. Testicular torsion, rotation of the testes within the scrotal sac, must be diagnosed quickly and accurately. Delay in diagnosis and subsequent delay in surgery risks testicular viability and infertility, although overdiagnosis subjects the patients to unnecessary surgery. Studies have shown that between 16-42 percent of boys with acute scrotal pain have testicular torsion.

Torsion usually occurs in the absence of any precipitating event, as seen in D.T.'s case; only 4 to 8 percent of cases are a result of trauma. Other factors predisposing patients to testicular torsion include an increase in testicular volume (often associated with puberty), testicular tumor, testicles with horizontal lie, and a spermatic cord with a long intrascrotal portion. The key physical finding in the diagnosis of testicular torsion is the absence of the cremasteric reflex. This reflex is elicited by stroking or pinching the medial thigh, causing contraction of the cremaster muscle, which elevates the testis. The cremasteric reflex is considered positive if the testicle moves at least 0.5 $\mathrm{cm}$. Two studies found the loss of the cremasteric reflex to be at least 99 percent sensitive for testicular torsion.

Surgical exploration identified a 540-degree rotation of the left testis with no evidence of appendix testis or epididymitis. D.T. was experiencing testicular ischemia by the time he entered surgery however the affected testicle was detorsed and salvaged and normal blood flow though the spermatic cord was restored. No evidence of torsion was seen on the right testis however it was found to have horizontal lie. D.T. was encouraged to monitor the right testicle for possible torsion over the next decade. He was discharged without incident 24-hours after surgery.

Fortunately, the rapid diagnosis by the emergency physicians and subsequent surgery allowed the surgeons to keep both testes intact. Testicular ischemia, like D.T.'s, occurs when equalization of venous and arterial pressures compromises arterial flow after venous return is obstructed by the 
torsion. The degree of ischemia depends on the duration of torsion and the degree of rotation of the spermatic cord and can occur as soon as four hours after torsion and is almost certain after 24 hours. Rotation can range from 180 degrees to more than 720 degrees. Greater degrees of rotation lead to a more rapid onset of ischemia, but the degree of rotation cannot be determined without surgical intervention.

This case illustrates the ideal outcome for a case of testicular torsion. D.T.'s family brought him to the emergency department within six hours of onset of pain. Based on the physical symptoms, physicians elected to confirm diagnosis surgically, rather than trying manual detorsion or imaging before surgery.

\section{Discussion}

The physical examination helps to differentiate causes of acute scrotal pain. The most common misdiagnosis is epididymitis. In epididymitis, the scrotal skin becomes edematous and its appearance has been likened to an orange peel. When the appendix testis, a Müllerian duct remnant on the superior aspect of the testicle, undergoes torsion, a hard, tender nodule 2 to $3 \mathrm{~mm}$ in diameter may be palpable on the upper pole of the testicle with a blue discoloration may be visible in this area called the "blue dot sign." Scrotal edema develops rapidly, however, and often obscures the physical examination findings. Finally, the epididymis remains posterior when only the appendix testis undergoes torsion and the affected testis is equal in size to the unaffected testis.

In contrast, in patients with testicular torsion, the epididymis may be located medially, laterally, or anteriorly, depending on the degree of torsion. The epididymis may be located posteriorly with 360 degrees of torsion. The spermatic cord shortens as it twists, so the testis may appear higher in the affected scrotum. This is a very specific finding and, when present, is strong evidence of testicular torsion. Because of venous congestion, the affected testis also may appear larger than the unaffected testis.

Imaging should be done only in equivocal cases in which suspicion for torsion is low. Any patient with a history and physical examination suspicious for torsion should have immediate surgery. As is the case in patients with appendicitis, a negative surgical exploration is preferable to a missed diagnosis. The most significant complication of testicular torsion is loss of the testis, which may lead to impaired fertility. Common causes of testicular loss after torsion are delay in seeking medical attention (58 percent), incorrect initial diagnosis (29 percent), and delay in treatment at the referral hospital (13 percent). 
Once the diagnosis of testicular torsion is confirmed, the rapid restoration of blood flow to the testis is critical. Although not recommended over surgery, manual detorsion can provide quick and noninvasive treatment. The physician stands at the supine patient's feet and rotates the affected testicle away from the midline, as though opening a book. The physician places his or her right thumb and index finger on the testicle and rotates the testicle 180 degrees from medial to lateral. If successful, there should be a dramatic decrease in pain. Because torsion of more than 360 degrees is possible, more than one rotation may be needed to fully detorse the testis. The return of blood flow should be documented. Although successful detorsion confirms the diagnosis of testicular torsion and relieves the acute problem, elective orchiopexy is still recommended. A review of nine studies (with 102 total patients) showed only a 26.5 percent success rate with manual detorsion, but other researchers cite success rates of more than 80 percent. Attempts at manual detorsion should not delay surgical consultation. Only surgical exploration can provide a definitive resolution if torsion is present, and, as evidenced by D.T.'s case, any patient with a history and physical examination results suspicious for torsion should have surgery immediately.

\section{Reading Comprehension Question}

Which of the following is the most common misdiagnosis of testicular torsion?
a) Epididymitis
b) Scrotal lesion
c) Manual detorsion 


\section{Case Study: Three siblings with complete androgen insensitivity syndrome}

Tanja Kemp, Department of Internal Medicine, Steve Biko Academic Hospital; University of Pretoria This article has been edited to meet study inclusion criteria. WC: 1033

\section{Case Study}

A 27-year old female patient "S" from a country on the African continent was referred to the Endocrinology Clinic with primary amenorrhea and infertility. She was one of six siblings, with a 26-year old brother and four younger sisters. Of her younger sisters, the youngest, aged 11, was prepubertal and premenarchal, and only the 16-year old sibling had normal menses. Both the 19year old and the 21-year old siblings experienced primary amenorrhea (a lack of menstruation). S reported a female gender role and female gender identity with strong maternal feelings; she had already adopted a child but wanted biological children with her husband.

On physical examination, $\mathrm{S}$ had a typical female phenotype but was relatively tall at 5'7'. She reported that she was much taller than her mother and the same height as her father; her body mass index was 26. S reported having experienced severely painful and difficult sexual intercourse for the first two years after becoming sexually active. She had palpable inguinal gonads that caused some discomfort but normal female external genitalia with no cliteromegaly or ambiguous genitalia present. However, her vagina was short and blind-ending with no palpable cervix. She had good breast development, but an almost complete absence of axillary and pubic hair. A transvaginal sonar confirmed the absence of a uterus and no intraabdominal ovaries.

Chromosomal studies detected a 46,XY karyotype, indicating that S experienced a form of 46,XY disorder of sex development. Her serum testosterone values were in the adult male range (normal range $=360$ to 990 for adult male, 17 to 50 for adult female), with an elevated luteinizing hormone (LH). Although serum FSH levels were normal, S's estrogen production was $70 \%$ higher than that of normal men. Since $\mathrm{S}$ had testes, her testosterone production rate in the testes increased because of an increase in serum LH. The estrogen originates from the excess testosterone which is peripherally converted to estrogen, plus from the testicular secretion of estrogen.

Considering the clinical examination, the lack ambiguous genitalia and secondary sexual hair, her female phenotype and the sonar findings, in combination with testosterone levels in the high normal male range, the diagnosis was that of complete androgen insensitivity syndrome (CAIS). $S$ underwent surgery for the removal of both of her gonads. After surgery the left gonad was confirmed to be testicular tissue that contained a small nodule while the right testis also contained 
two nodules, as well as a cyst. Neither testis demonstrated spermatogenesis, and the nodules were of Sertoli cell origin. Leydig cell hyperplasia was prominent in both testes. No ovarian tissue was present. S's testosterone level dropped postoperatively into the normal female level; her estrogen levels also decreased. She was started on hormone replacement therapy.

S was extensively counselled before surgery regarding her diagnosis and the implications of this condition regarding fertility. She demonstrated very good insight into the condition.

Unfortunately, her husband left her when he found out about her infertility. She did not disclose her karyotype to him. Her two younger sisters with amenorrhea were also evaluated and demonstrated almost identical clinical phenotypes, ultrasonographic findings and findings on special investigations. They are both still awaiting gonad removal.

\section{Discussion}

S's case is unusual because the majority of CAIS patients present during puberty with primary amenorrhea, although occasionally babies are diagnosed with CAIS prenatally or at birth because of a discrepancy between the karyotype determined through amniocentesis and the anatomical gender. Babies with CAIS have phenotypically normal female external genitalia at birth or on prenatal ultrasound. A few patients are also diagnosed at a young age based on of the presence of palpable gonads in the inguinal area or in the labia majora.

Gender assignment is not an issue in CAIS, even if diagnosed early - these patients should be raised as females. In the case of a minor, the parents should be fully informed and counselled, preferably by a psychologist who is familiar with this condition as disclosure of the diagnosis can lead to strong emotional reactions in the parents. The child may receive information based on age and understanding, and full disclosure should occur before adulthood. The damage caused by non-disclosure and finding out the diagnosis inadvertently, much later, can cause more psychological distress. Female family members should also be offered testing because the risk of cancer is increased in patients with cryptorchid testes.

Tumors can occur in the testes and become malignant. A recent review of adults with CAIS estimated the risk of a gonadal malignancy developing of approximately $14 \%$. Because the development of these tumors in the testes before puberty is very rare, it appears to be safe to defer gonad removal until after puberty to optimize normal breast development and reaffirm the patient's gender identity. Surgery may be deemed necessary earlier in the case of an inguinal hernia requiring surgical repair, if the gonads are uncomfortable or painful, or if there is doubt 
about the completeness of the androgen resistance, because incomplete resistance may lead to virilization during puberty.

Patients with CAIS tend to be taller and larger than would be expected following a calculation of mid-parental height. Usually, the growth pattern follows that of girls, but the final achieved height is between that of average males and females. It is postulated that the Y chromosome may have a direct effect on growth and body size which is not mediated through the androgen receptor. This suggests an important role for androgens in bone mineral density that cannot be replaced by estrogen. Lifelong hormone replacement therapy is necessary post-gonad removal in adults, or from the time of puberty if surgery was performed earlier.

Dilator therapy to increase vaginal depth and size can be started after puberty before sexual activity is initiated. This may be sufficient, but occasionally vaginoplasty may be necessary. Long-term sexual problems can occur if the vagina remains small after dilator therapy or vaginoplasty. Whereas biological offspring has been impossible in the past, fertility is potentially becoming more feasible. If the testes can be preserved after gonad removal, it may possible for these patients to have biological children of their own in the future, with injection of germ cells or spermatocytes into a donor ovum, and with the assistance of a surrogate.

\section{Reading Comprehension Question}

The majority of CAIS diagnoses occur during:
a) Toddler-hood
b) Puberty
c) Pregnancy 


\section{Ectopic Pregnancy within a Cesarean Scar Resulting in Live Birth: A Case Report}

Firoozeh Ahmadi MD, Deena Moinian MSc1, Parichehr Pooransari MD, Zohreh Rashidi BSc , Hadieh Haghighi BSc

This article has been edited to meet study inclusion criteria. WC: 1027

\section{Case Study}

A 41-year-old female, "M", with one previous cesarean section was referred to our institute after three years of secondary infertility. During 2010, she entered a micro-injection cycle twice, both ending unsuccessfully. Eventually during 2011, she became pregnant via embryo transfer freezing. Initially, a transvaginal ultrasonography was performed at six weeks' gestation which revealed a gestational sac beneath the uterine cavity, indicating the possibility of an ectopic pregnancy (EP) within the Cesarean scar (CS).

Cesarean scar ectopic pregnancy (CSEP) like M's one of the rarest forms of ectopic pregnancy, occurring when the fertilized ovum is implanted outside the endometrium and inside the myometrium within the fibrous tissue of a previous Cesarean scar. The most plausible theory to explain this phenomenon suggests a microscopic tract may have been created because of a trauma during a previous uterine surgery: a cesarean delivery, curettage, myomectomy, hysteroscopy, or following the manual removal of the placenta and in vitro fertilization (IVF). The blastocyst uses this tract to migrate into the wall of the myometrium and settles itself in the fibrous tissue. There are two types of CSEP. Type 1 CSEP is implantation of the embryo on the previous CS with progression towards the uterine cavity, which may result in a live birth although it has a very high risk of a life-threatening hemorrhage. Type 2 CSEP occurs when the embryo is implanted deep within the cesarean scar and is growing towards the bladder and abdominal cavity. This is very dangerous and needs to be terminated immediately as it will probably result in a rupture which is life-threatening to the mother.

To determine M's type of CSEP, we performed a second ultrasound at eight weeks' gestation. It showed that the embryo had moved further towards the uterine cavity to an extent that part of the sac could be detected within the cavity. During an ultrasonography at 11.5 weeks, the sac was seen behind the bladder and the thickness of the myometrium was $6 \mathrm{~mm}$ which suggested the thinning of the myometrium. We concluded that M's pregnancy was type 1 CSEP, where the sac was growing towards the cavity and advised termination of the pregnancy. However, despite our efforts to explain to the mother the dangers associated with such a pregnancy especially at her age, she insisted on continuing with the pregnancy and we were left with no choice but to assist 
her by closely monitoring the pregnancy and being completely prepared for the birth and the procedures that were required during the labor.

M's condition was monitored through regular ultrasonographies. The third and fourth ultrasonographies were respectively performed at 12 and 16 weeks and showed the sac to be detected within the lower segment of the uterine cavity with the thickness of the myometrium of 6 $\mathrm{mm}$. At this point, based on the ultrasonographic findings of the placental position, the possibility of placenta accreta (where the placenta grows too deeply into the uterine wall) was suggested. Because of the advanced maternal age, an amniocentesis was performed which gave normal results. At 25 weeks, due to the high possibility of placenta accreta, the clinician asked $\mathrm{M}$ for a magnetic resonance imaging (MRI).

The MRI ruled out the possibility of placenta accreta and suggested the occurrence of placenta previa (where the placenta is low in the uterus and may cover the cervix). At 38 weeks, the baby was safely delivered during a three-hour long cesarean section operation. A placenta previa and $30 \%$ placenta accreta was observed. After delivery, the placenta was stuck to the lower segment of the uterus and caused bleeding. Despite the efforts made to control the bleeding, a hysterectomy was performed. The patient had an uneventful postoperative recovery and was discharged from the hospital on postoperative day 3.

\section{Discussion}

A delayed diagnosis and treatment of a CSEP can cause catastrophic complications, leaving the physician with no option but to perform a life-saving hysterectomy that causes maternal infertility. Much emphasis has been placed on early detection and appropriate management of CSEP. Early diagnosis can lead to prompt treatment thus decreasing the likelihood of uterine rupture or hemorrhage allowing the preservation of the uterus and subsequent fertility. There are no universal guidelines for treatment of CSEP due to limited experience of cesarean scar pregnancies in the first trimester.

Ultrasonography is the first line of diagnosis for CSEP. Transvaginal scans have been used together with Doppler flow imaging as a reliable tool for the detection of majority of cases. Color flow Doppler has the advantage of allowing the physician to distinguish between a viable and nonviable pregnancy which in turn allows the most appropriate treatment option to be taken accordingly. 
Patients with a CSEP can be asymptomatic, or they can suffer from mild to moderate abdominal pain solely or together with vaginal bleeding. To accurately detect a CSEP during an ultrasonography, the following criteria have been designed.

1. Empty uterine cavity and cervical canal,

2. The gestational sac must be detected in the anterior part of the uterine wall at the isthmus,

3. An absence of or a reduction in the thickness of the myometrial wall between the bladder and the sac, allowing the differentiation from cervico-isthmic implantation

4. Evidence of functional trophoblastic circulation on Doppler examination

The most suitable management for CSEP is not clear but most literature reviews suggest the termination of such a pregnancy. However, as previously mentioned, there are two types of CSEP. If the CSEP is of type 1 , which is growing towards the uterine cavity, there is a chance that the fetus will grow to term and be delivered healthy. In this case the line of expectant management can be followed. However, in such a situation the mother needs to be made fully aware of the situation and the consequences and risks of such a pregnancy and, ultimately, it will be her decision whether to continue with the pregnancy. If so, the case needs to be under control and followed throughout the pregnancy. However, if type 2 CSEP is detected or if the mother having been made aware of the risks associated with such a pregnancy wishes to terminate, the most suitable termination method needs to be tailored to each case.

\section{Reading Comprehension Question}

Which of these is NOT a risk associated with CSEP?
a) Maternal morbidity
b) Hemorrhage
c) Placental growth 


\section{CURRICULUM VITA}

\section{Katherine Ray King}

Phone: (501) 690 - 3381

Email: contact@ rayking.me

Website: www.rayking.me
Mailing Address: 728 South $36^{\text {th }}$ Street

Louisville, KY 40211

\section{EDUCATION}

PhD University of Louisville, Biology

December 2020

Dissertation: "On the Straight and Narrow: How Cultural Beliefs about Sex/Gender Manifest in College Learning Environments" Committee: Dr. Linda Fuselier (co-chair), Dr. Paul Ewald (cochair), Dr. Jennifer Mansfield-Jones, Dr. Sheron Mark, Dr.

Holly S. Ewald

MS University of Louisville, Biology

May 2018

Non-Thesis Degree

Advisors: Drs. Paul Ewald and Linda Fuselier

BS University of Louisville, Biology

May 2015

Graduated Cum Laude

Minored in Forensic Anthropology

\section{TEACHING EXPERIENCE}

Teaching Philosophy: I believe my role as an instructor is to facilitate student learning of material. Each student enters the classroom with unique experiences and expectations. My task is to reach each student where they are, so that they can grow and thrive in the learning environment.

University of Louisville, Louisville, KY

Graduate Teaching Assistant, Department of Biology

- Unity of Life - Honors Recitation (Biology 240), Fall 2019

○ Supplement to honor's sections of required introductory biology course for science majors

- Part of a pilot program to provide practical examples of introductory concepts to students as part of recitation

- Taught two courses with 20 students each 
- Met weekly with course developers to provide feedback on prior material and review upcoming curricula

- Utilized active learning strategies to guide class discussions

- Conducted lectures that integrated class concepts into tangible contexts

- Contributed questions over recitation materials to lecture exams

- Principles of Biology Laboratory (Biology 244), Fall 2018-Summer 2019, Spring 2020*

○ Comprehensive laboratory component for paired introductory biology courses for science majors

- Required laboratory component to declare biology major

- Taught four courses with 20-25 students each

- Gave weekly in-laboratory lectures providing more in-depth coverage to topics from class

- Mentored undergraduate research assistants

- Wrote, gave, and graded quizzes and exams

- Assisted students in conducting various basic laboratory tests including gel electrophoresis, PCR, spectrophotometry, enzyme kinetics, etc.

○ *COVID-19 Response

- During Spring 2020, converted to online instruction

- Recorded lectures

- Wrote and conducted online exams and quizzes

- Engaged students using message boards

- Human Anatomy and Physiology Laboratory (Biology 262), Fall 2015Summer 2018

○ Introduction to human anatomy/physiology topics for pre-healthcare majors (nursing, exercise science, etc.)

- Taught five-seven courses per year with 20-25 students each

- Gave weekly in-laboratory lectures providing additional material or introducing topics omitted from in-class coverage

- Wrote, gave, and graded quizzes and exams during summer terms (not responsible for writing exams or quizzes during other terms)

- Aided students in conducing physiological experiments including electromyogram and electrocardiograms

$\circ \quad$ Lead teaching assistant for two years

- Trained new teaching assistants assigned to the course

- Responsible for setup and breakdown of weekly lab materials

- Redesigned course lecture format to incorporate active learning components

- Transitioned from physical quizzes and homework to online versions

University of Louisville, Louisville, KY

Undergraduate Teaching Assistant, Department of Biology

August 2014 to May 2015

- Genetics and Molecular Biology Recitation (Biology 330), Spring 2015

- Primary instructor for twice weekly, one-hour recitation section reviewing in-class lecture materials 
- Conducted lectures each class session

- Wrote, gave, and graded quizzes which contributed to overall course grade

- Led in-class exam reviews for 20-30 students per class

- Principles of Biology Laboratory (Biology 244), Fall 2014

- Assisted graduate instructor

- Conducted $1 / 3$ of in-class lectures

$\circ$ Led student lab-group activities for $10+$ students

\section{RESEARCH EXPERIENCE}

Dissertation, University of Louisville, Louisville, KY

Advisor: Dr. Linda Fuselier

- Designed, validated, and implemented study to evaluate student beliefs about sex/gender

- Obtained review board approval for all relevant studies

- Developed and implemented an educational intervention to improve student understanding of human sex/gender

- Mentored two undergraduate research assistants

Graduate Research Assistant, University of Louisville 2017 to 2018

Teaching, Learning, and Instructional Resource Project; Principle Investigator: Dr. Linda Fuselier

- Collected data from individual subjects

- Used Q-methodology to analyze individual subjectivities about the nature of science

- Conducted data analysis using PQ Method software

- Contributed methods, analysis, and results to manuscript draft

- Worked alongside other graduate research assistants

Undergraduate Research Training in Molecular Anthropology

2013 to 2014

Research Trainee, Advisor: Dr. Christopher Tillquist

- Trained on laboratory practices covering a wide range of genetic techniques: DNA extractions, PCR, cloning, Gel electrophoresis, and DNA sequencing

- Gained practical experience in analyzing results and genetic database searching techniques (NCBI-GenBank, BLAST searches, etc).

PUBLICATIONS

Journal Publications

Fuselier, L., McFadden, J. \& Ray King, K., “Do Biologists' Conceptions of Science as a Social Epistemology Align with Critical Contextual Empiricism?". Science \& Education 28, 1001-1025 (2019); https://doi.org/10.1007/s11191-01900084-8

PRESENTATIONS AND INVITED LECTURES 
Poster Presentation, "Sex/Gender Essentialist Beliefs in Pre-Healthcare Students", National Association for Research in Science Teaching (NARST) Annual Conference, March 2020*

Poster Presentation, "Words Matter: A Queer Theory Analysis of Anatomy/Physiology Textbooks" **, NARST Annual Conference, March 2020*

Long Talk, "From Belief to Reality: How Undergraduates Understand Sex/Gender (And Why We Should Care)", Western Washington University Queering Research Series, February 2020

Poster Presentation, "Representation Matters: A Queer Theory Analysis of Anatomy/Physiology Textbooks" *, Early Undergraduate Summer Research Symposium, July 2019

Short Talk, "From Belief to Reality: Characterizing Undergraduate Sex and Gender Beliefs", Society for the Advancement of Biology Education Research (SABER) National Meeting, July 2019

Invited Lecturer, "Is Race Real: Using Evolutionary Ideas to Examine Race", University of Louisville Introduction to Biology Course, March 2018

Poster Presentation, "Scientists' Beliefs About the Nature of Science", Kentucky Graduate Student Regional Research Conference, March 2018

Short Talk, "Characterizing Epistemic Beliefs Among Scientists" Kentucky Academy of Science Annual Meeting, First Prize: Graduate Science Education Talk, November 2017

Poster Presentation, "Characterizing Epistemic Beliefs Among Biologists", SABER National Meeting, July 2017

* canceled due to COVID-19

** second author

PROFESSIONAL TRAINING

NARST Sandra K. Abell Institute for Doctoral Students, July 2019

Course Design Institute, University of Louisville, May 2019

Teaching with Active Learning, University of Louisville, Spring 2018

STEM GTA Academy, University of Louisville, Summer 2016

PROFESSIONAL AFFILIATIONS

American Association for the Advancement of Science (AAAS), 2013-Present 
NARST, 2017-Present

SABER, 2017-Present

PROFESSIONAL SERVICE

Tour Guide for Biology Department Teaching Labs

Student Preview Days, Summer 2019

COMMUNITY SERVICE

Louisville Regional Science and Engineering Fair

Lead Judge, Senior Biology and Health, March 2019

Louisville Regional Science and Engineering Fair

Lead Judge, Junior Biology and Health, March 2017

Louisville Regional Science and Engineering Fair

Lead Judge, Junior Microbiology March 2016

COMPUTER SKILLS

Programming: R, html

Applications: PQMethod, RStudio, GraphPad, Respondus

Platforms: Microsoft/Windows 